\title{
Company Valuation - Value, Structure, Risk
}

Marek Capiński and Wiktor Patena

University of Applied Sciences Hof, Bavaria, Germany 


\section{The Authors}

Marek Capiński is a professor at AGH University of Science and Technology, Kraków, Poland (Faculty of Applied Mathematics).

Wiktor Patena is an associate professor at Wyższa Szkoła Biznesu - NationalLouis University, Nowy Sącz, Poland (College of Management and Business).

\section{Editorial Committee:}

Prof. Dr. Ulrich Enturp

Prof. Dr. Hans-Peter Sonnenborn

Dr. hab. Jacek Leskow

\section{Cover design:}

Janusz Bąk

Copyright (C) 2008

ISBN: 978-3-935565-23-3

University of Applied Sciences

Hof, Bavaria, Germany.

- hochschule

hof

University of Applied Sciences 


\section{Contents}

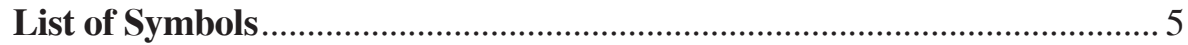

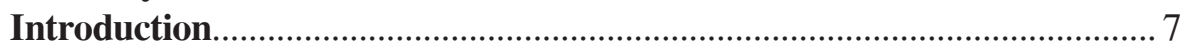

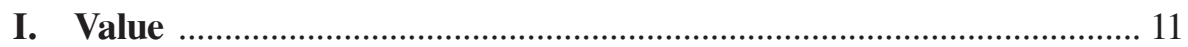

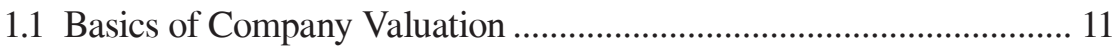

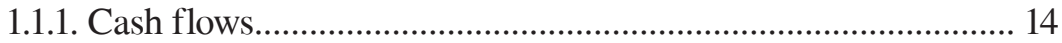

1.1.2. Assets of a company - balance sheet........................................... 15

1.1.3. Summary …….......................................................................... 17

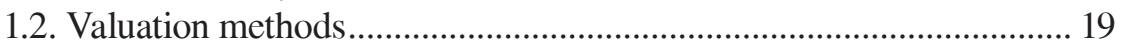

1.2.1. Perpetuity, given capital structure............................................... 22

1.2.2. Perpetuity, given value of debt. ................................................. 26

1.2.3. One period - given capital structure ………….......................... 29

1.2.4. One period - given debt ................................................................ 32

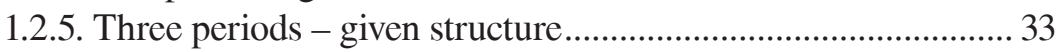

1.2.6. Growing perpetuity - given structure ………............................. 37

1.2.7. Growing perpetuity - given debt .............................................. 39

1.2.8. General case - given structure..................................................... 40

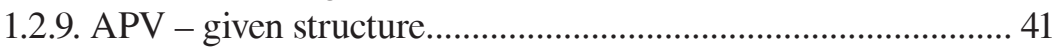

1.2.10. Company valuation via iterations............................................ 44

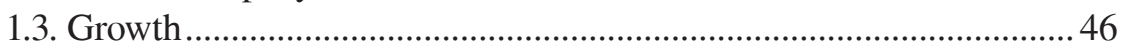

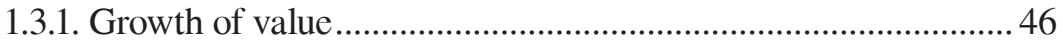

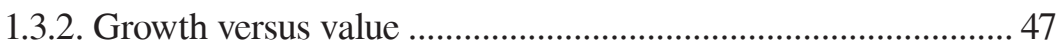

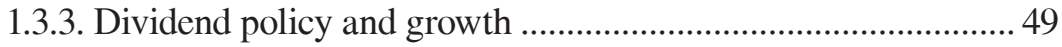

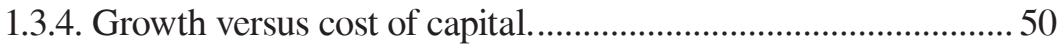

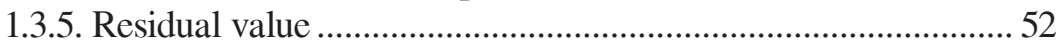

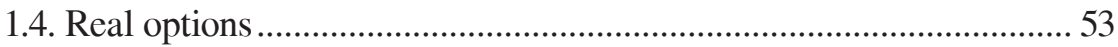

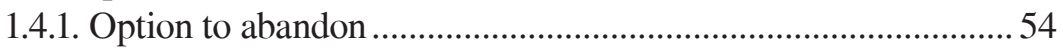

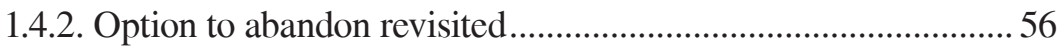

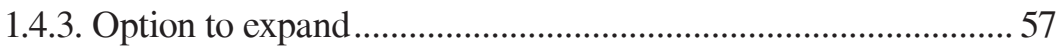

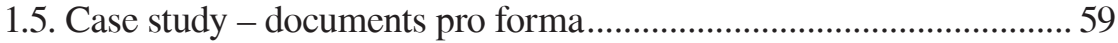

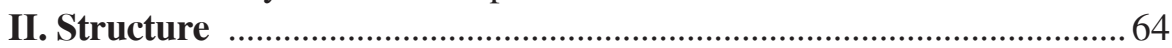

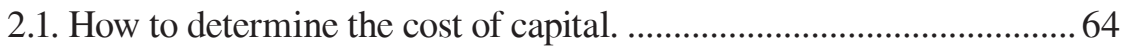

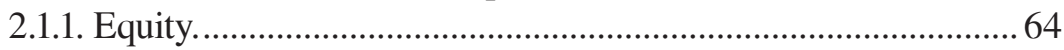




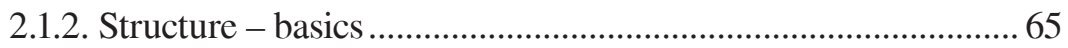

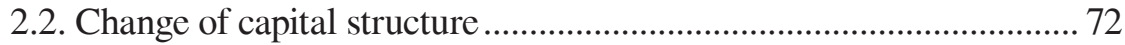

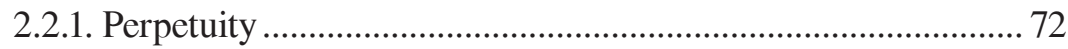

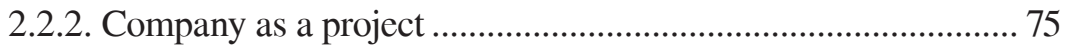

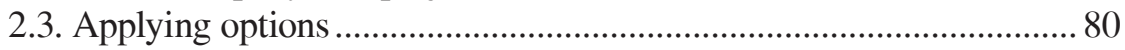

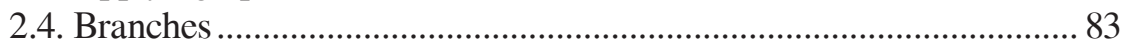

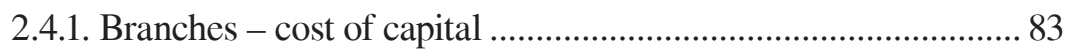

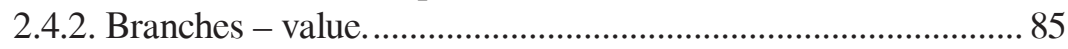

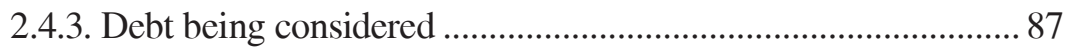

2.4.4. Valuing a branch - structural approach....................................... 89

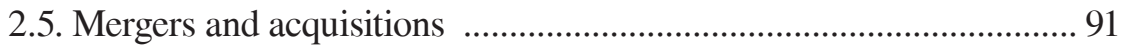

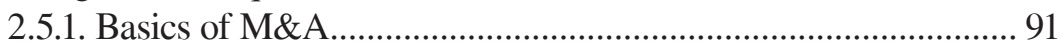

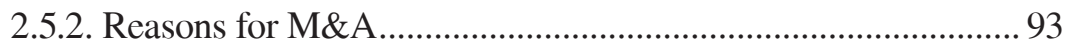

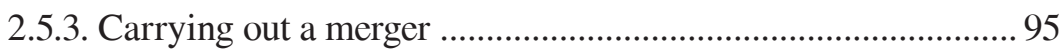

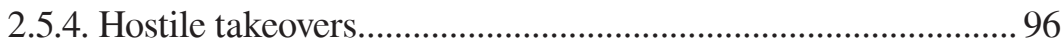

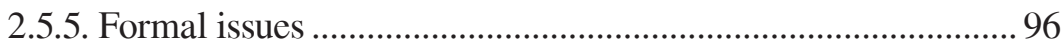

2.6. Case study - valuing a company ........................................................ 99

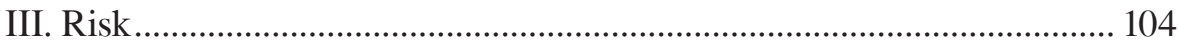

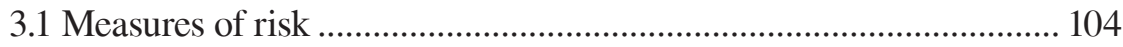

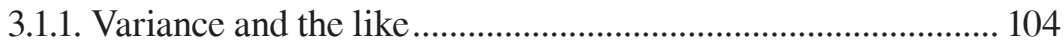

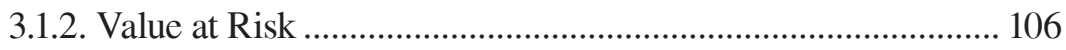

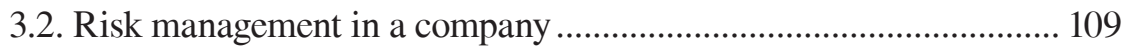

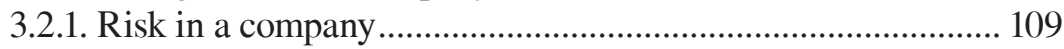

3.2.2. Risk management versus value ...............................................112

3.2.3. Risk managements tools .............................................................113

3.3. Case study - hedging exchange rate risk exposure.............................114

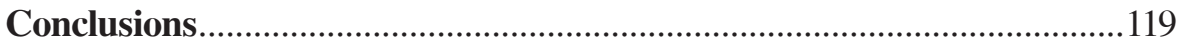

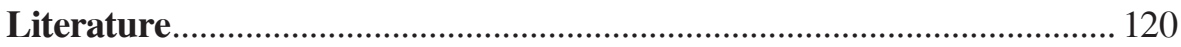




\section{List of Symbols}

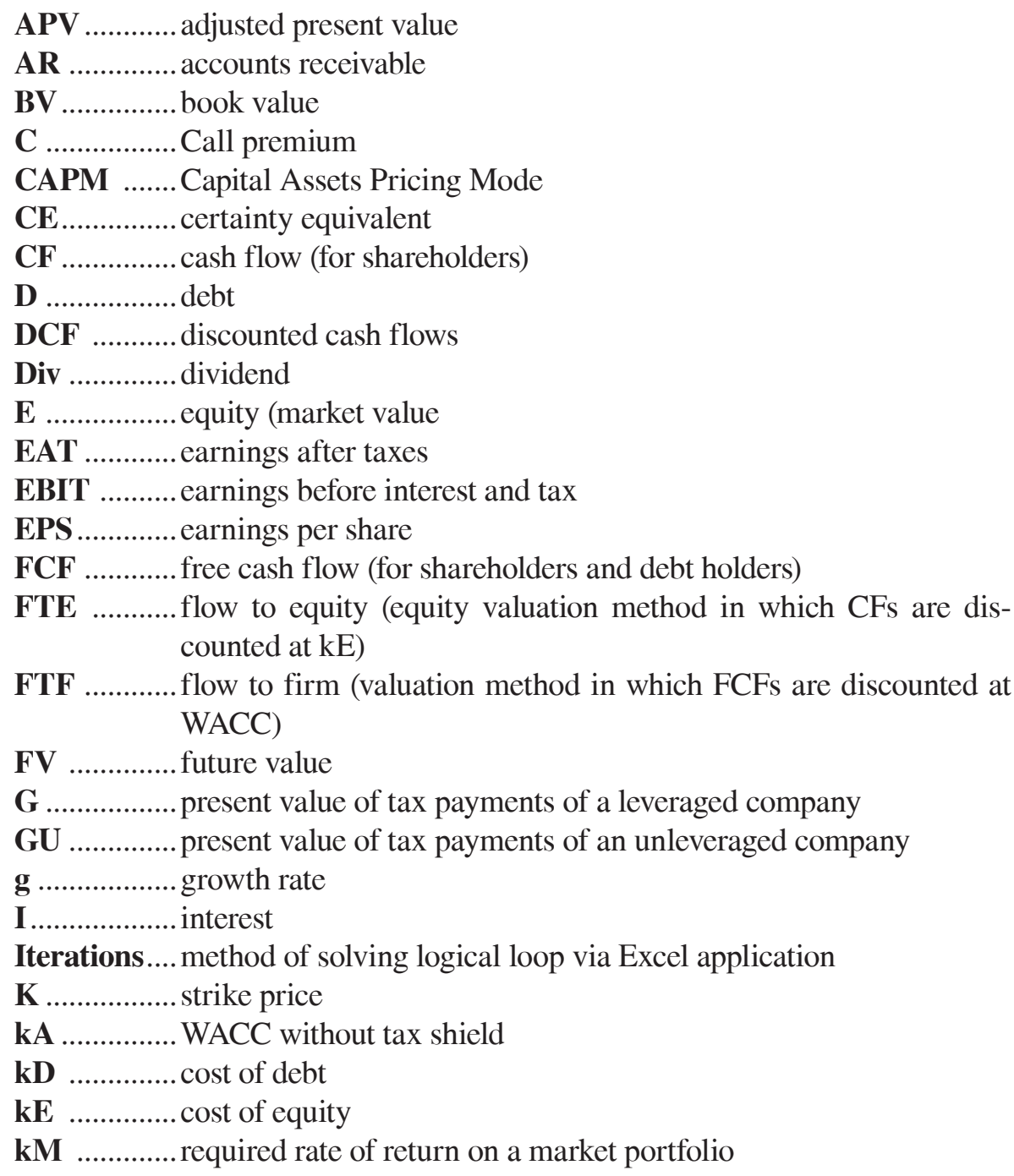


$\mathbf{k U}$ cost of equity of an unleveraged company

MV. market value

NWC net working capital

OP operational profits

P................. put premium

p ................. plowback ratio/investment ratio

P/E ............ price/earnings ratio

PV ............. present value

PVGO ......... present value of growth opportunities

PVTS .......... present value of the tax shield

rRF ............risk free rate of return

ROA............ return on assets

ROE ........... return on equity

SML ........... Security Market Line

S .................. stock price

T ................tax rate

TP ..............tax payments

TS ...............tax shield

V ................value of a company (for shareholders and debt holders)

VU ............. value of an unleveraged company

WACC ....... weighted average cost of capital 


\section{Introduction}

DCF (discounted cash flows) valuation has had a long tradition that dates back to early works of Miller, Modigliani, Gordon and Shapiro. Major contributions in the field of discounted cash flows valuation have been made by Copeland ${ }^{[1]}$, Damodaran ${ }^{[2]}$ and Fernandez ${ }^{[3]}$.

In colloquial terms, DCF valuation, the concept first known for valuing projects, is based on measuring the value of milk given by a cow (the market value depends on future payment surpluses - the stream of cash flow is discounted) instead of focusing on the price of the meat of a cow offered by a butcher (the value of assets).

DCF method (sometimes called "intrinsic value method") is mentioned in the first line of this book not without a reason. This is without a doubt the major valuation method used in most company valuations.

There is also the "peer comparison" ${ }^{[4]}$ method (or multiple approach), where a company is valued by analogy with other assets or companies of the same type. This pragmatic approach assumes that markets are efficient, and the value of one company should be measured by reference to another's value. Speaking of the market and its efficiency, it must be admitted that the market value (and other methods referring to market values, just like the peer comparison method) and present values of cash flows should converge.

In another approach (sum-of-the-parts method, or restated net asset value) a company is valued as the sum of its assets less its net debt. There are numerous variations of the method, starting with a crude one based on book values.

There are attempts to apply options theory - this seems a tempting theoretical concept, which may potentially represent a profound shift in the way equity capital is valued. At present, the structural approach is more often used for credit risk estimation. Real options are more often in use, although after the dot com craze (at the end of XX century) they have fallen out of fashion.

1 T.E. Copeland, Koller T., Murrin J., Valuation, Measuring and Managing the Value of Companies, John Wiley and Sons, New York, 2000.

2 A. Damodaran, Investment Valuation, John Wiley \& Sons, 2002.

3 P. Fernandez, Valuation and Shareholder Value Creation, Academic Press, San Diego 2002.

4 P. Vernimmen, Corporate Finance, John Wiley \& Sons, 2005. 
Mixed methods, which usually boil down to being a weighted average of DCF and restated net asset value, should be treated with caution. Some are tempted to use them as the valuation results can be easily manipulated. Instead, the differences stemming from using various methods should be analyzed, not averaged.

This short review of valuation methods shows that there are three basic approaches: cash flow-based, market-based and asset-based. The methods will be referred to again in Chapter 1.1.

The set of valuation methods that is actually in use in a given country is usually shaped by its history and economic environment ${ }^{[5]}$. Typically, the list may include:

1. replacement method,

2. restated net asset value method,

3. liquidation value method,

4. multiple method,

5. DCF method.

Once the list is created, it often becomes a benchmark for company valuations. The choice (with regard to methods) made by companies performing company valuations depends on a number of factors.

1. If the financial markets are stable, market values may be used and then the multiple method is preferred. However, the multiple method derived value, being greater than DCF derived value, clearly shows that the company should go public.

2. The fact that a company is able to generate positive cash flows is an indication that the DCF method should be used. If this is the case, the DCF derived value is typically higher than the values generated by any other methods.

3. Companies that barely break even, but have a lot of marketable assets are valuated with the use of restated net value method. The restated net value being higher than the DCF value may be an indicator that the company should gradually divest and liquidate its assets to boost profitability.

4. Those already in the red are bound to use the liquidation value method.

5. In most cases, as suggested by the applicable provision, at least two methods are utilized so that the brackets with the lowest and highest values are formed and facilitate negotiations with potentials investors. If the financial market is stable and a company generates positive cash flows,

5 In Poland for example, after the fall of communism in 1989, a lot of previously state-owned property started to be commercialized and then privatized. One of the provisions of the Ministry of Treasury issued at that time (3.06.1997) specified that at least two out of the five valuation methods that were listed there must be used whenever any of the state-owned companies were to be privatized and sold. Since then, the five methods have become a benchmark for company valuations even if they were done for purposes other than commercialization and privatization. 
DCF and comparative methods are used in most cases. Some of the differences in the values generated by the methods stem from the lifecycle theory of company value ${ }^{[6]}$. For example, quite naturally if the company enters a post-maturity phase, its profits decline and the cash flow value slips below the restated net asset value.

The DCF method clearly dominates in most of the valuations of economically sound companies. Besides, other methods are quite straightforward, and do not require sophisticated theories or mathematical models to support. DCF does. The concepts of perfect market, time value of money, cost of capital, portfolio theory and many others laid the foundation for DCF valuation. There are certain standards that apply when DCF is used, some are the part of the common knowledge and are clearly codified, and others have to be presented in detail.

This book is focused on the DCF method, the one that is most complicated - hence needs special explanations, the one that is most sophisticated - hence needs attention. Another reason is that the DCF method captures best the value of profitable, economically sound companies. We believe it works for all firms which have real expertise - this is the core of the economy, its salt of the earth. The main purpose of this book is to explain the inner workings of the DCF method, especially the variant in which capital structure constantly affects cost of equity, as it does in reality.

The basic notion of the DCF method can be introduced with the following valuation formula:

$$
V_{0}=\frac{F C F_{1}}{(1+k)^{1}}+\frac{F C F_{2}}{(1+k)^{2}}+\ldots
$$

where subscripts $1,2, \ldots$ represent the first and further periods ${ }^{[7]}$.

This is how the company's value is determined: certain cash flows are discounted with the cost of capital. There are three components involved: cash flows, cost of capital and the model (or engine, technically speaking) explaining how the first two are related and eventually put together into a coherent system. In other words, one asks three questions.

1. What are cash flows?

2. What is the discount rate?

3. How to discount?

Consequently, the book revolves around these three issues. The three chapters are devoted to the value of cash flows (modules A, B, C, see Figure 1 below), the model focused on capital structure (modules G, H), and the cost of capital

6 P.Vernimmen. Corporate..., op.cit. p. 838.

7 Time dependent $\mathrm{k}$ will be introduced later. 
that expresses risk (modules D, E, F). All of them are intertwined throughout the whole book as they cannot be separated from other problems discussed.

The figure below shows a complete procedure for company valuation. The book will focus on certain issues, and neglect others as in our view, there is enough information on CAPM (Capital Assets Pricing Model) available elsewhere.

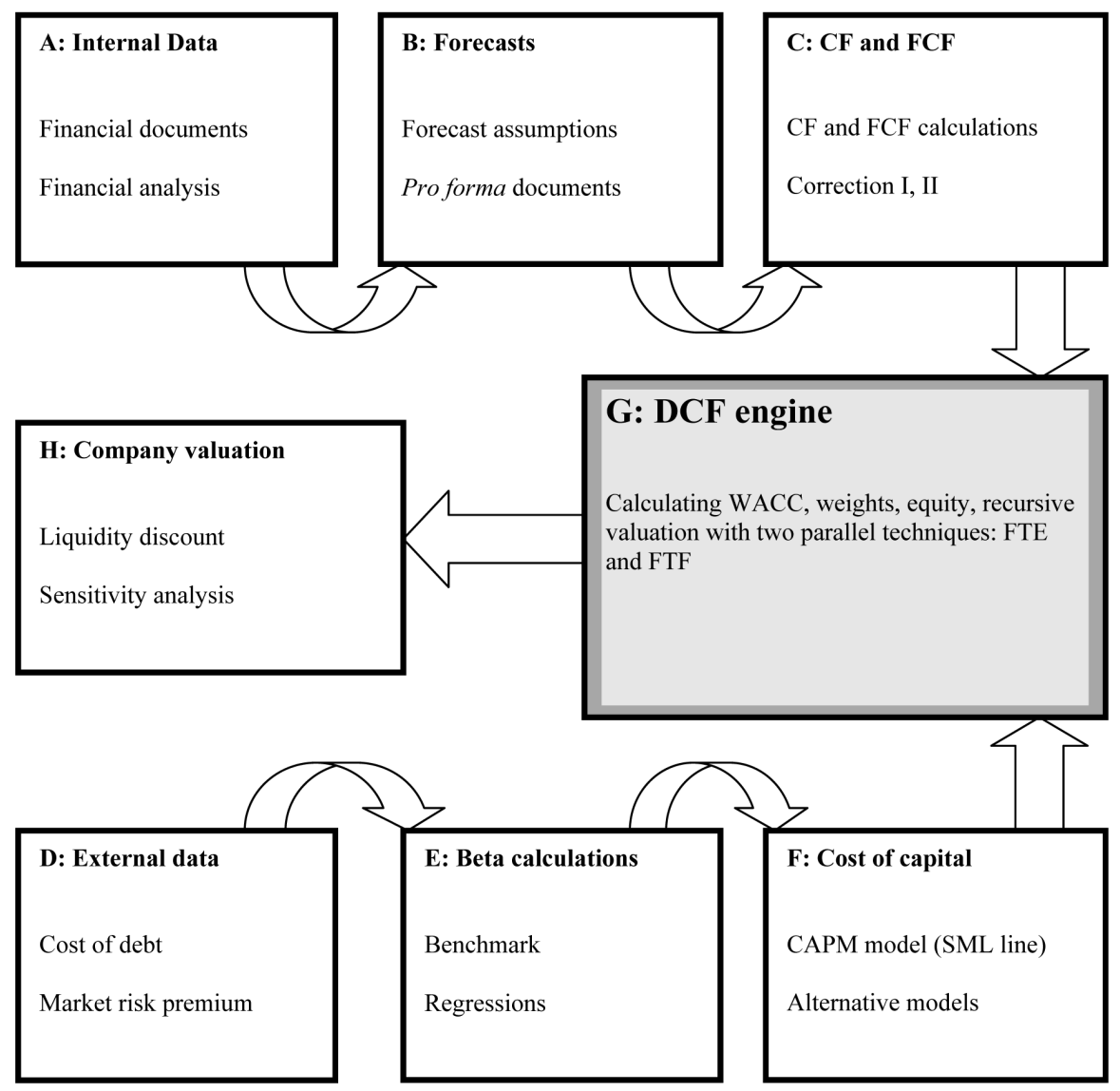




\section{Value}

The main goal of a company is to increase its value for the shareholders. By the value we mean today's value of future cash flows generated by the company and discounted by a proper discount rate. The proper discount rate is meant as a rate that reflects risk, and as suchis the cost of capital.

Let us justify this point of view on a company's value. Obviously, it is not based on book values and to some extent it ignores the company's property, which with DCF is treated as a means of generating cash flows and not an asset per se.

\subsection{Basics of Company Valuation}

In the case of companies listed and traded on a stock exchange, valuation does not seem to be a problem - it is merely a question of multiplying the number of shares in circulation by their price, and the market value (of equity) is instantly obtained. Companies that are not listed may be offered for sale, and the price from tenders can be used to estimate their value. Here we encounter the problem of a slight difference between price and value. The prime difference stems from the fact that buyers and sellers look at the company from two different points of view. For example, for a seller fixed assets may seem to have the most value, whereas a buyer may be anxious to have access to the market only, since he has better production potential himself. Or vice versa, and the buyer is eager to get the assets. Each of the buyers may look at the company from another angle; the same assets in various hands may represent a range of prices understood as potential to generate cash flows. Thus, value is a relative concept and it is not identical to the market price. Whenever dealing with the market price determined by a stock exchange or "peer comparison" methods of valuation (where a company is valued by analogy with other assets or companies of the same type), one must remember that price and value are different notions. 
$\mathrm{P} / \mathrm{E}$ ratio is one of the best known profit-related indicators (often used in a multiple method). As the name suggests (price to earnings ratio), it is the stock price divided by profits generated by a company (attributable to one share, EPS - earnings per share). The ratio would be useful, if it bore decent information. We could value a company that is not listed on a stock exchange by using a P/E ratio of a listed company and multiplying by the profit (E instead of EPS) of the not-listed company. So the value of a not-listed company could be calculated using the following:

$$
V=E A T \times \frac{P}{E} .
$$

The problem however, is that the $\mathrm{P} / \mathrm{E}$ ratio does not include debt, so the assumption that the benchmark company is financed by equity only has to be made. Still, the problem can be solved by making one simplifying assumption. Suppose we know the following: the share price P, P/E ratio of a company that is financed partially by debt whose value D is known (as well as the interest I the company pays), the number of shares in circulation $\mathrm{N}$, and that the company pays tax rate $T$.

\section{Example 1.}

Suppose $P / E=6.1$ and $P=32.50$. Hence, $E P S=32.50 / 6.1=5.3279$.

If the number of shares $N=10000$, EAT $=53.279$. If $D=150000$ and the company pays an $8 \%$ interest rate, the amount of interest paid by the company equals $I=12000$. Should the company have no debt (and the tax rate was $30 \%$ ), the profit would be:

$$
53279+1200(1-30 \%)=61679 .
$$

Having replaced debt by equity, the number of shares is increased by $15000 / 32.5=4615$, and the total number of shares now is 14615 . Hypothetically, we can calculate a new ratio for a company that is financed by equity only; the share price should be divided by EPS $=61679 / 14615=4.22$ :

$\mathrm{P} / \mathrm{E}=32.50 / 4.22=7.7$.

The example shows how misleading the P/E ratio can be. When the company is debt financed, EPS was higher and P/E was lower than when the company was financed by equity only.

The simplifying assumption that was used for the calculations says that the share price will not change after debt is exchanged for equity. However, this as- 
sumption is not met, as we will see later: any change in capital structure will influence its share price. We should and we will try to acquire formulae that take the change into account further on.

Value of a company that is calculated with P/E ratio may be faulty: One problem can be attributed to the difference between price and value. The other is referred to the book value of profit.

A modified ratio that takes cash flows into consideration would be of better use than P/E. Still, mere cash flows do not contain any information about the future or prospects of growth of a company. A part of net profits may be reinvested, the other paid out as dividends. The balance between paid out dividends, growth that has been created, and risk may influence the company's value. The problem will be discussed later.

The menu of multiples is quite wide: P/NOPAT, P/EBIT, and P/EBITDA. The ratios, such as price to sales, and price to EBIT, have the same drawbacks as $\mathrm{P} / \mathrm{E}$. Any attempts to enhance any of these ratios in order to improve their effectiveness are fruitless. One of the few sensible improvements that is often tried is the use of the mean or median of the multiples of the sample of comparable companies. The sample of several companies is better than one, but the medians or means should not be applied mechanically. The multiple method has to be used with extreme caution.

There are many more obstacles in using market prices. The current market price does not reflect the actual value of a company, since any attempt to buy a significant amount of shares may immediately affect the share price. Market prices fluctuate, sometimes violently. The market price cannot be ignored, but one should make an attempt to answer the question of how much the company is really worth. In particular, in case of imperfect markets (low liquidity) the value of a company may be easily over or under estimated. Recognizing this fact is crucial for buyers, sellers, or investors taking any long-term positions. It may also be important for a company when planning a new issue. Finally, when a company is a start-up, or exists but is about to take a strategic decision that may appear to be a big leap, we are devoid of market-based information, when estimating the value of a company is a must.

Setting the proper company value may also facilitate remuneration of managers. Any system that is based on book values may be vulnerable to manipulation. For example, the management may easily increase ROA of a company by taking a decision to cease investing in fixed assets. As an investment in R\&D may mean losses that the company will incur for a few years, the management that is rewarded based on net profit will never take such decisions. They will 
ignore new technologies, avoid entering new markets or developing new products.

The competence in company valuation will provide us with a lot of insight into the role of the components from the formula below:

$$
V_{0}=\frac{F C F_{1}}{(1+k)^{1}}+\frac{F C F_{2}}{(1+k)^{2}}+\ldots .
$$

\subsubsection{Cash flows}

It is clear that cash flows are a better indicator of the value of a company than book profits as book values are often far from reality. Positive book profits do not even exclude bankruptcy, let alone an increase in value. Moreover, (book) profits may be difficult to exercise due to delayed or bad receivables. An extreme case would be fictional profits generated by so-called creative accounting. The simple difference between book profit and cash flow that is a result of depreciation is straightforward and must be taken into account. However, it (depreciation) is not related to our criticism concerning book profit as a company value driver.

Going back to cash flows, they are the true proxy of the value of company. Its value depends very much on how big the future cash flows might be, how soon they will materialize, and how certain they are.

If the cash flows were certain, then valuation would be a piece of cake. The certain cash flows would have to be discounted with the risk-free interest rate, otherwise one would create a money machine (assuming short positions in CF are available). It would also be against the notion of the well known free lunch concept. Let's assume we are considering buying a financial instrument that will generate 105 in one year's time $(t=1)$. If the risk free rate is $5 \%$, then the value of the purchase is 100 (assuming the asset is fully tradable):

$$
V_{0}=\frac{F C F_{1}}{\left(1+k_{R F}\right)}=\frac{105}{(1+5 \%)}=100 .
$$

This, however, is not the case of cash flows generated by a company. A company by definition is a risky asset. How to value under uncertainty? There are a few theoretical concepts that may be applied.

1. Certainty equivalent is, in a nut shell, a payment that would be accepted instead of any risky cash flows. Let's assume we expect a cash flow of 150 (if the market goes up), or 90 (if it goes down). We expect to get 150 or 90 , both with the same probability of $50 \%$. The expected value of 
the cash flow is then 120. The question however is: what cash flow (that would be certain) shall we accept instead? If we are indifferent between the certain payment of 105 and the risk of having either 150 or 90 , then 105 is the certainty equivalent:

$$
V_{0}=\frac{C E_{1}}{\left(1+k_{R F}\right)}=\frac{105}{(1+5 \%)}=100 \text {. }
$$

2. The risk adjusted discount rate method (cost of capital) is much more practical. It assumes making some adjustments to the denominator, such that the discount factor reflects the risk of the uncertain cash flows (where $\mathrm{E}[\mathrm{FCF}]$ representsmathematical expectations). The risk premium kRP captures the risk. The cost of capital method dominates since we find it easier to estimate appropriate discount rates than certainty equivalent cash flows:

$$
V_{0}=\frac{E\left[F C F_{1}\right]}{\left(1+k_{R F}+k_{R P}\right)}=\frac{50 \% \times 150+50 \% \times 90}{(1+5 \%+15 \%)}=100 .
$$

3. In the risk-neutral probabilities approach, the risk free rate is still used for discounting. In the numerator, risk-neutral probabilities are used instead of the subjective ones (the risk is removed). Such expectation is denoted by $\mathrm{E}_{\mathrm{M}}$ (for martingale probabilities) ${ }^{[8]}$. The relevant numbers here have a risk-neutral $(p)$ probability of $25 \%$ (up scenario), and (1- $p$ ) $75 \%$ (down scenario):

$$
V_{0}=\frac{E_{M}\left[F C F_{1}\right]}{\left(1+k_{R F}\right)}=\frac{p \times 150+(1-p) \times 90}{\left(1+k_{R F}\right)}=\frac{25 \% \times 150+75 \% \times 90}{(1+5 \%)}=100,
$$

where:

$$
p=\frac{\left(k_{R F}-d\right)}{(u-d)}
$$

and $u(50 \%)$ and $d(-10 \%)$ are up and down scenario returns respectively.

\subsubsection{Assets of a company - balance sheet}

It is common practice to take the book value of assets as the value of a company. For this purpose, only fixed assets should be considered since in general current assets are financed by current liabilities. Only net working capital

8 For more information about the martingale probabilities go to: M. Capinski, T. Zastawniak, Mathematics for Finance, Springer Verlag, London, 2003 
should be added to the value of fixed assets. However, the book value of assets does not reflect the real value of a company - such an approach ignores a number of critical factors. To name just a few:

- intangible assets,

- the role of environment,

- the role of management,

- the role of human resources.

The comments about the difference between book value and market value of assets are still valid. For example, assets that are fully depreciated and have a book value of zero can still be effectively used in the production process. Hence, numerous attempts to use figures other than the book value of assets are made.

1. Restated net value.

When using the restated net value method, book values (which for many reasons are far from reality) have to be restated and revalued before they are able to represent a true asset's value. Certain components of a balance sheet are adjusted: receivables that are past due are cancelled or their value is reduced relative to the chance of having the invoices paid, inventory value is adjusted by rejecting the items hard to sell and replacing the book value with the market value, and the value of fixed assets is adjusted on the basis of estimates by certified evaluators. In general, each asset has to be valued, some at their market value (the assumption is that we can sell the asset), while others at replacement cost (if the asset is used in the company's operations). The method is easy to use and the result is hardly ever questioned. However, one has to aware of the fact that such a valuation only makes sense if the assets can be used independently of the company's operations. If not, the result obtained through the restated net value method seems meaningless.

2. Liquidation value.

When using the liquidation value method, book values are replaced with market values based on the assumption that the business is to be liquidated and quickly sold off (usually) in pieces.The resulting number will be a lower limit of a price estimate of a company that is close to bankruptcy. In addition to that, costs of the liquidation process (bankruptcy proceedings) must be taken into account, properly estimated and deducted from the previously set value of a company.

3. Replacement value.

When using the replacement value method, we calculate a cost of building a company that has the same operational potential as the company that is being analyzed. Components with no liquidation value should be ignored. In fact (with the last statement) the method becomes a mixture of other methods. 
However, none of the above adjustments are satisfactory, since they do not solve the basic problem of the discrepancy between the value of assets and the value of a business. On one hand, market value may be misleading since, for example, expensive highly specialized machines that are difficult to relocate may have low market value. On the other, replacement value may be too high - buying old equipment may pose a problem, since it is expensive and its efficiency is doubtful. Finally, the liquidation value is typically very low.

What is sometimes discussed is the notion of economic value. The notion is very unclear. The only estimate of such value that makes sense is to calculate cash flows that may be potentially generated, and at the same time taking into account proper costs of production and product quality.

\section{Example 2.}

Let us consider a business: a copying centre. Suppose that instead of buying a copying machine, we buy a scanner, computer and printer. The cost of buying all the equipment is higher that the cost of a copying machine (and the quality is comparable). The real value of the equipment if used for printing is low. We are not going to be competitive, as the costs will be higher and delivery time longer, and the fact that we can easily change the fonts, correct the spelling, or correct red eyes while copying will not be worth much.

There are a few other adjustment methods such as: book value of assets plus certain percentage of revenues or turnover. They go in the right direction as an attempt to recognize the ability of a company to generate cash, but they are arbitrary and extremely subjective. Such valuations depend on the attitude of the person that is doing the valuation and give extremely different results for companies that are similar.

\subsubsection{Summary}

The discussion above on company valuation methods leads to a thought that sometimes assets per se are not important but it is more important how the assets are utilized, and all the organizational environment of a company is often an essential component of the company's value. Let us name a few factors:

- business idea,

- technology,

- licences, 
- staff, management,

- organizational structure,

- brand,

- market share.

Without these factors, equipment and machines themselves are not worth much. They enable the production of high quality, low cost products that are sellable. Estimating their value without looking into the future is impossible.

The value of a company depends on cash flows that the company may generate in the future.

The problem we are facing is to:

- $\quad$ estimate future cash flows

- determine a discount factor- cost of capital.

Let us admit that historical data are of little value. In order to prove the value of this statement it is enough to imagine two companies having very different backgrounds but sharing the same rosy prospects for the future. An argument that the position on the market depends on the historical value can be rejected by proving that expected cash flows should capture that. Risk is a factor of great importance but this is included in the cost of capital.

Future expected cash flows will be calculated on the basis of strategic plans and financial documents pro forma of a company. The starting point for such calculations is sales predictions which are preceded by a macroeconomic analysis. The prospects of economic growth of the economy affect the predicted increase of purchasing power and demand. Such analysis should not ignore the international environment, specifics of the region or a given industry. What follows, is the microeconomic analysis that may help calculate a unit price and the level of sales. In practice, the sales from the previous period of time is accepted as a starting point, then an increase of several basis or percentage points is assumed. Costs can be predicted from analyzing company operations, but let us not forget that they have to be viewed from a larger perspective, taking into account a number of other factors.For example, prices of materials may depend on certain international factors such as exchange rates.

Such predictions are usually made for a period of 5 to 9 years. Further prognosis poses a challenge as predicting sales 10 years from now is not likely to be precise. Here, a simplifying assumption is made, where cash flows are predicted, then discounted to some point in the future and this number is called the residual value. 
In practice, it is often assumed that future cash flows (e.g. after 5 years) become a perpetuity or growing perpetuity. It significantly simplifies calculations of the residual value.

The planned future cash flows are only expected values. In practice, a certain amount risk is involved and there will always be some discrepancies between planned and realized values.

This fact is taken into account in choosing a discount rate (cost of capital) that reflects the level of uncertainty that is risk.

\subsection{Valuation methods}

Once we have financial documents pro forma, we can calculate the cash flows. There are two basic valuation methods, corresponding to two kinds of cash flows.

1. FCF - Free Cash Flow (cash flow available for both shareholders and debt holders)

FCF is cash that is generated by a company's operational activity without taking interest payments into account. We hypothetically assume a situation where a company is equity financed only. The formula below is used in this case:

$$
F C F=E B I T \times(1-T)+\text { correction. }
$$

The correction involves adding back depreciation and the value of actual investments made by a company in working capital and fixed assets. Using the formula means that the tax shield is not taken into account. This however is not true. The tax shield is not ignored but included in the calculations of cost of capital (WACC- weighted average cost of capital). The WACC is defined as:

$$
W A C C=\mathrm{k}_{\mathrm{D}}(1-T) \frac{D}{V}+k_{E} \frac{E}{V} .
$$

Free Cash Flows are discounted and the value of a company is obtained. Then, the market value of debt can be deducted and what is left is the value of equity. The value of each share can be easily found then. In a nutshell: $E=V-D$. 
The method is called Flow to Firm (FTF), or indirect method, since the value of equity is found indirectly - first the value of the whole company is found and then equity.

2. CF - Cash Flow (Cash flow available for shareholders only).

We calculate cash flows $\mathrm{CF}$ available for shareholders:

$$
C F=\left(E B I T-k_{D} \times D\right) \times(1-T)+\text { correction }+\Delta \mathrm{D} .
$$

Cash Flows (CF) are discounted by the cost of equity, which is the rate of return required by shareholders. The value of debt is found independently and the sum of these two gives the value of the whole company: $V=E+D$

The method is called Flow to Equity (FTE) or the direct method.

There is a clearly defined relationship between CF and FCF and the two equalities:

$C F=F C F-k_{D} \times D \times(1-T)+\Delta D$.

It is worth emphasizing that Free Cash Flows are purely hypothetical and (except for a company that is fully equity financed) are not cash flows that are obtained in reality.

It is also worth mentioning that sometimes CCF (Capital Cash Flow) or DCF (Debt Cash Flow) are defined. The latter is easy to calculate - it equals interest plus principal payments or taking additional loans. Then CCF can be defined as a sum of DCF and CF:

$$
C C F=D C F+C F .
$$

The appropriate discount rate for $\mathrm{CCF}$ is (according to the equality above and the properties of the portfolio theory) a weighted average cost of capital (without a tax shield) $k_{A}$ :

$$
k_{A}=\frac{D}{D+E} k_{D}+\frac{E}{D+E} k_{E} .
$$

There is also the APV (Adjusted Present Value) method, where FCF is discounted with the cost of capital $\mathrm{kU}$ (u stands for unleveraged) that does not include a tax shield (assuming that a company is equity financed), and then a correction including the current value of the tax shield, agency costs, etc. is added or subtracted. 


\section{Example 3.}

Here is the data concerning Hip Hop Inc.:

Balance sheet: (in millions)

$\begin{array}{lrrlrr}\text { Assets } & \mathbf{2 0 0 8} & \mathbf{2 0 0 9} & \text { Liabilities } & \mathbf{2 0 0 8} & \mathbf{2 0 0 9} \\ \text { Cash } & 96 & 160 & \text { Account payable } & 232 & 266 \\ \text { Accounts receivable } & 455 & 688 & \text { Tax liabilities } & 196 & 123 \\ \text { Inventory } & 553 & 555 & & & \\ \text { Current assets } & \mathbf{1 1 0 4} & \mathbf{1 4 0 3} & \text { Current liabilities } & \mathbf{4 2 8} & \mathbf{3 8 9} \\ \text { Fixed assets } & 1644 & 1709 & \text { Debt } & 400 & 454 \\ & & & \text { Equity } & 600 & 640 \\ & & & \text { Retained earnings } & 1320 & 1629 \\ \text { Assets } & \mathbf{2 7 4 8} & \mathbf{3 1 1 2} & \text { Liabilities } & \mathbf{2 7 4 8} & \mathbf{3 1 1 2}\end{array}$

Income statement: (in millions) 2009

Sales 1509

Cost of sales $\quad 750$

Depreciation 65

EBIT $\quad 694$

Interest $\quad 70$

EBT 624

Tax (34\%) 212

EAT $\quad 412$

Dividend 103

Retained earnings 309

Here is the way to calculate the company's cash flows:

$$
\begin{aligned}
& F C F=E B I T \times(1-T)+\text { correction. } \\
& F C F=694 \times(1-34 \%)+65-130-338=55 . \\
& C F=\left(E B I T-k_{D} \times D\right) \times(1-T)+\text { correction }+\Delta D . \\
& C F=412+65-(299+39)-130+54=63,
\end{aligned}
$$


Let us check whether the formula that translates CF into FCF applies:

$$
\begin{aligned}
& C F=F C F-k_{D} \times D \times(1-T)+\Delta D, \\
& C F=55-70 \times(1-0.34)+54=63 .
\end{aligned}
$$

There are certain technical problems that are likely to appear in the calculations described so far.

1. One has to know the cost of capital WACC (and both its components: cost of debt and cost of equity) in order to calculate the value of a company.

2. One has to know the capital structure, that is the value of debt and equity, in order to calculate the cost of capital (cost of equity or WACC).

3. One has to know the value of interest payments, which is the value of debt, in order to calculate cash flows.

The problems create a logical loop: step 1 needs step 2, but step 2 requires step 1.In the next subsection we will show how to tackle the problem in a few specific situations. By the way, the problem seems technical, but as a matter of fact it is a profound shift in the way the value can be found.

Another problem with cash flows is that the term is not clearly defined. We cannot rely on IFRS (International Financial Reporting Standards) or USGAAP (Generally Accepted Accounting Standards), or any of the local laws in that respect. By no means are the two definitions of cash flows given above the only ones that can be used. They are specific enough to justify the use of two methods of company valuation, and general enough to allow further differences. For example, cash is often treated as a non-operational asset and removed from cash flow calculations. By the way, our view is that a certain amount of cash is always needed for company operations. There are even models for optimizing the amount of cash a company should hold (Baumol, Stone's models) and therefore any decisions with regards to cash levels should definitely be treated as operational ones. Thus, there a whole gamut of methods used for cash flow calculations - a good review of them is presented in Velez-Pareja's paper ${ }^{[9]}$.

\subsubsection{Perpetuity, given capital structure.}

There is a range of problems in the valuation of companies. We will make some simplifications in order to come up with a result. Here are a few examples of applying both methods of company valuation. First, an infinite investment horizon is assumed (the company will never terminate its operation).

9 I. Velez-Pareja, "Construction of Free Cash Flow", Working Paper 1995/6, www.paper.ssrn.com 


\section{Example 4.}

Suppose, sales of $200^{[10]}$ are generated every year. Costs are always $70 \%$ of sales. The company is financed by debt of $20 \%$, that is $\mathrm{D} / \mathrm{V}=20 \%$. The cost of debt is $16 \%$ and the cost of equity $26 \%$. The company pays $30 \%$ corporate income tax.

\section{FTF method (based on FCF)}

An income statement for the years to come is drawn up. Hypothetically, it assumed that there is no debt (in order to determine free cash flows).

\begin{tabular}{|lr|}
\hline Sales & 200 \\
\hline Operational costs & 140 \\
\hline EBIT & 60 \\
\hline Interest & 0 \\
EBT & 60 \\
Tax & 18 \\
FCF & 42 \\
\hline
\end{tabular}

Now, it is easy to calculate the weighted average cost of capital:

$W A C C=16 \% \times(1-30 \%) \times 20 \%+26 \% \times 80 \%=23.04 \%$.

The value of the whole firm is:

$$
V=\frac{F C F}{W A C C}=\frac{42}{23.04 \%}=182.29 \text {. }
$$

Debt is stipulated at $20 \%$ of the total value of the firm, so $D=36.46$ and $E=145.83$.

The above income statement was calculated with no debt assumption. The genuine profit can now be found, since interest can be found once debt is known.

10 Money amounts in most of the examples and cases are expressed in thousands. 


\begin{tabular}{|lr|}
\hline Sales & 200.00 \\
\hline Operationalcosts & 140.00 \\
EBIT & 60.00 \\
\hline Interest & 5.83 \\
EBT & 54.17 \\
Tax & 16.25 \\
CF & 37.92 \\
\hline
\end{tabular}

We can also calculate the present value of cash flows by discounting them with the cost of equity. The result is the same as before:

$$
\begin{aligned}
& E=\frac{C F}{k_{E}} \\
& \frac{37.92}{26 \%}=145.83 .
\end{aligned}
$$

\section{FTE method (based on CF)}

Had we known both methods would give the same result, we could use the above calculations (both), where the level of debt, interest and cash flows were found. However, we did not know that and thecalculations had to be repeated. It is good practice to use both methods and prove the result by executing the calculations separately, otherwise we are in facing a tautology.

We have another series of relationships leading to a loop:

1. $\mathrm{CF}$ is calculated with the use of interest rates of $16 \%$ of debt - the value of debt is not known yet.

2. The value of debt can be derived from a capital structure $(\mathrm{D} / \mathrm{E}=20 \% /$ $80 \%=25 \%$ ) - but this needs the value of equity as an input.

3. The value of $E$ is equivalent to the value of cash flow discounted at the cost of capital - the loop is complete, $C F$ is not known yet.

The problem can be solved numerically, or by solving the set system of simultaneous equations: 


$$
\begin{aligned}
& C F=\left(E B I T-k_{D} D\right)(1-T), \\
& D=25 \% E, \\
& E=\frac{C F}{k_{E}} .
\end{aligned}
$$

By substituting $C F$ and $D$ from the equations above to the last equation, it is easy to solve and will generate $E$ :

$$
\begin{aligned}
& k_{E} E=\left(E B I T-25 \% k_{D} E\right)(1-T), \\
& E=\frac{E B I T(1-T)}{k_{E}+25 \% k_{D}(1-T)}=\frac{60 \times 70 \%}{26 \%+25 \% \times 16 \% \times 70 \%}=145.83 .
\end{aligned}
$$

( $25 \%$ is the $\mathrm{D} / \mathrm{E}$ ratio that is derived from the implied capital structure.)

Once we know the value of equity, the value of debt can also be found: $\mathrm{D} / \mathrm{E}$ $=20 \% / 80 \%$, so debt is $5 \%$ of equity, hence $D=36.46$ as before.

It has been proven that this method leads to the same result as before. It is not a coincidence. Let us analyze the case again by reformulating the equation for $E$ :

$$
E=\frac{E B I T(1-T)}{k_{E}+\frac{0.2}{0.8} k_{D}(1-T)}=0.8 \frac{E B I T(1-T)}{0.8 \times k_{E}+0.2 \times k_{D}(1-T)}=0.8 \frac{F C F}{W A C C}=0.8 \times V .
$$

It is worth emphasizing an existing flaw in assuming a fixed capital structure. If the value of equity changes, the capital structure changes too. It could happen as a result of a change in risk or a change in expected cash flows. It is worth bearing in mind that changing share prices may affect even the value of companies that are not listed, let alone those that are traded. We should then adjust the level of debt, so the capital structure is always as planned. Obviously, this is difficult as the value of debt is determined at the very beginning, and the changes may take place later. Besides, it is easier to assume that the level of debt at a particular point in time is given. It does not exclude using the policy aimed at obtaining a certain required capital structure.

The assumption that the capital structure is known brings (apart from simplicity of calculations) a significant advantage. In most of the cases analyzed in this chapter, it was assumed that cost of equity is given. However, the cost of equity depends on financial risk, which is also represented by the capital structure. Relying on debt that is given and used to determine the capital structure leads to a logical loop: structure determines cost of equity, cost of equity determines the value of equity, and finally equity defines capital structure. The problem will be taken care of in Chapter 2, which is devoted to capital structure only. Here, 
in this section, it is assumed that the cost of equity is found independent of the structure of financing, e.g. by using CAPM.

\subsubsection{Perpetuity, given value of debt.}

Taking for granted that the value of debt is given is reasonably realistic. The capital structure is temporarily unknown and will be calculated as soon as the value of equity is found.

\section{Example 5.}

Let's assume that sales do not change and are 200 every year. Costs are $70 \%$ of sales. The company is partly financed by debt of 50 . Interest is a perpetuity of 8 , since the cost of debt is $16 \%$. Cost of equity is $26 \%$. The company pays corporate tax of $30 \%$.

\section{Method based on FCF.}

For FCF calculations, the same data as before are used:

\begin{tabular}{|lr|}
\hline Sales & 200 \\
\hline Operational costs & 140 \\
EBIT & 60 \\
\hline Interest & 0 \\
EBT & 60 \\
Tax & 18 \\
FCF & 42 \\
\hline
\end{tabular}

The following problem is encountered:

1. We need to know the weights (share of debt and equity in total financing), in order to calculate weighted average cost of capital.

2. We need to know the value of debt (this is given) and equity in order to find the weights.

3. The sum of debt and equity gives the value of the company that we are looking for. 
An analytical solution to the problem is fairly straightforward: we are facing the following system of equations, where $V$ is the value of a company and $k$ the cost of capital:

$$
\begin{gathered}
\left\{\begin{array}{c}
V=\frac{F C F}{k} \\
k=k_{D} \times(1-T) \times \frac{D}{V}+k_{E} \times \frac{V-D^{\circ}}{V}
\end{array}\right. \\
\qquad \begin{array}{c}
V=\frac{42}{k} \\
k=16 \% \times(1-30 \%) \times \frac{50}{V}+26 \% \times \frac{V-50}{V}
\end{array}
\end{gathered}
$$

The first equation shows the value of the whole company as a perpetuity with an annual payment of 42 and an unknown discount rate $k$. The other shows the formula for WACC, where " $V-50$ " is the value of equity. The system can be easily solved by entering $k=42 / \mathrm{V}$ into the other equation. We get:

$$
42=16 \% \times(1-30 \%) \times 50+26 \% \times(V-50),
$$

and then,

$$
\begin{aligned}
& V=190, \\
& k=22.11 \% .
\end{aligned}
$$

Thus, $E=140$ after deducting the value of debt from the value of the company.

The problem can also be solved numerically. First, let us accept any cost of capital, e.g. $10 \%$. This would provide the value of equity as follows:

\begin{tabular}{|lr|}
\hline FCF & 42 \\
K & $10 \%$ \\
V & 420 \\
D & 50 \\
E & 370 \\
\hline
\end{tabular}

The value is incorrect, since for such values for $D$ and $E$, the resulting value of WACC would be different from $10 \%$.

$$
10 \% \times(1-30 \%) \times \frac{50}{420}+28 \% \times \frac{370}{420}=25.5 \% .
$$


In order to make the necessary corrections, we should enter a formula for WACC in the appropriate cell in Excel, replacing the $k=10 \%$ with the result above. The loop is then complete and the final results, as shown below, are correct.

\begin{tabular}{|lr|}
\hline FCF & 42 \\
\hline K & $22.11 \%$ \\
V & 190 \\
\hline $\mathrm{D}$ & 50 \\
$\mathrm{E}$ & 140 \\
\hline
\end{tabular}

The loop will work on one condition: a feedback loop must be activated in Excel (go to Tools/Options/Calculations, tick Manual Calculation and Iteration boxes) ${ }^{[11]}$. By setting the Maximal Number of Iterations to 1, it can be observed how the computer gets closer and closer to the right answer. The computer will only execute one loop and each following loop can be triggered by pressing the F9 key.

\section{Method based on CF.}

The same result can be obtained by relying on $C F$. The income statement looks as follows:

\begin{tabular}{|lr|}
\hline Sales & 200 \\
\hline Operational costs & 140 \\
EBIT & 60 \\
Interest & 8 \\
EBT & 52 \\
Tax & 15,6 \\
EAT $=$ CF & 36,4 \\
\hline
\end{tabular}

The value of equity can be easily found, once we know the cost of equity. The result is identical to the one found before:

$$
\frac{36.4}{26 \%}=140 .
$$

11 In more recent versions of MS Office, the path is slightly different. 


\subsubsection{One period - given capital structure}

The assumption that operations of a company are represented by a perpetuity is an gross simplification. A one-period case is essential since later on it will become a starting point for developing a multi-period case. It will be based on repeating a single-period case.

\section{Example 6.}

Let us assume an investment horizon of one year. Starting the business involves investing 200 , including working capital (say this is mostly land in order to avoid problems with depreciation). EBIT $=80$ is generated at the end of the year, and the value of assets does not change. The company pays $30 \%$ tax. The shareholders require $28 \%$ return on the money invested into the business. Cost of debt (that provides $40 \%$ of financing) is $10 \%$.

\section{Method based on FCF.}

Let us calculate FCF: profit after taxation is 56 , and so at the end of the year 200 is recovered:

$$
\mathrm{FCF}=256 .
$$

Now, WACC can be found:

$$
W A C C=0.4 \times(1-30 \%) \times 10 \%+0.6 \times 28 \%=19.60 \% .
$$

$F C F$ can be discounted at $W A C C$ :

$$
V=\frac{F C F}{1+W A C C}=214.05 \text {. }
$$

Finally, the values of $E$ and $D$ can be calculated:

$$
\begin{aligned}
& E=0.6 \times 214.05=128.43 \\
& D=214.05-128.43=85.42 .
\end{aligned}
$$

We are able to determine how much has to be borrowed in order to finance the business idea. The missing 114.38 must be invested by the shareholders. Shortly afterwards, the value of the shares (if traded) grows to 128.43 , as a result of the fact that the investment is characterized by a positive NPV of 14.05, as shown below:

$$
200-85.42=114.38
$$




$$
N P V=-200+\frac{256}{1+19.6 \%}=14.05 \text {. }
$$

This is exactly the difference between the principal initially invested and the market value of equity:

$$
114.38+14.05=128.43 .
$$

Let us put the phenomenon into a wider context. The value of the company $V$ is its discounted value of future cash flows, so the relationship $N P V=-I+V$ holds. There are some more relationships that follow:

$$
\begin{aligned}
& V=D+E, \\
& N P V=-I+V=-I+E+D, \\
& E=(I-D)+N P V .
\end{aligned}
$$

where $(I-D)$ is the sum of money supplied by shareholders in order to finance the business. This is an illustration of the general fact that equity is typically increased by the NPV of a project.

\section{Method based on CF.}

Let us first find a solution to the problem by solving a system of equations. In the first equation, the fact that debt has to be paid back and assets can be sold is taken into account. The second one shows the implied capital structure. The last one defines equity as the discounted cash flow available to shareholders:

$$
\begin{aligned}
& C F=\left(E B I T-k_{D} D\right)(1-T)-D+I, \\
& D=\frac{0.4}{0.6} E, \\
& E=\frac{C F}{1+k_{E}} .
\end{aligned}
$$

$E$ may be easily obtained by solving the last equation:

$$
\begin{aligned}
& \left(1+k_{E}\right) E=\left(E B I T-\frac{0.4}{0.6} k_{D} E\right)(1-T)-\frac{0.4}{0.6} E+I, \\
& \left(1+k_{E}\right) E+\frac{0.4}{0.6} E+\frac{0.4}{0.6} k_{D}(1-T) E=E B I T(1-T)+I, \\
& E=\frac{E B I T(1-T)+I}{1+k_{E}+\frac{0.4}{0.6}+\frac{0.4}{0.6} k_{D}(1-T)}=128.43 .
\end{aligned}
$$


$D$ can be determined using the second equation. It also shows that the methods lead to the same result as before. To make sure this is not a single occurrence but a rule, let us reformulate the equation for $E$ to see how both methods $(C F$ and $F C F$-based) are reconciled:

$$
E=0.6 \frac{E B I T(1-T)+I}{1+0.6 k_{E}+0.4 k_{D}(1-T)}=0.6 \frac{F C F}{1+W A C C}=0.6 \times V .
$$

To complete the task, let us solve the problem numerically.

Here is the income statement (suppose $\mathrm{D}=100$ ):

\begin{tabular}{|lr|}
\hline EBIT & 80 \\
D & 100 \\
Interest & 10 \\
EBT & 70 \\
Tax & 21 \\
EAT & 49 \\
CF & 149 \\
\hline
\end{tabular}

Now, let us calculate $E$ by discounting $C F$ at cost of equity:

$$
\begin{aligned}
& E=\frac{C F}{1+k_{E}} \\
& E=\frac{149}{1+28 \%}=116.41 .
\end{aligned}
$$

The loop may now be closed by entering the expression $(0,4 / 0,6) \mathrm{E}$ (implied by the capital structure) instead of 100, and by executing iterations (F9). We eventually get to the same result:

\begin{tabular}{|lr|}
\hline EBIT & 80.00 \\
\hline D & 85.62 \\
Interest & 8.56 \\
\hline EBT & 71.44 \\
Tax & 21.43 \\
EAT & 50.01 \\
CF & 164.39 \\
\hline E & 128.43 \\
\hline
\end{tabular}




\subsubsection{One period - given debt}

The calculations using the direct valuation method are facilitated using the debt assumption,, since interest payments and cash flows (CF) can be easily found. Applying the indirect method to the same set of data is more difficult (compared to the situation with a given capital structure).

\section{Example 7.}

Let us assume that a business is carried out for one year, where the initial investment of 200 is financed $50 \%$ by shareholders and the other $50 \%$ by a loan. At the end of the year EBIT of 80 is generated and the invested funds can be fully recovered. The company pays corporate income tax of $30 \%$, and the cost of equity is $28 \%$.

\section{Method based on FCF}

In the same fashion as before, free cash flows are calculated (taking into account that the assets are sold at the end of the year).

\begin{tabular}{|lr|}
\hline EBIT & 80 \\
\hline Tax & 24 \\
\hline Net profit & 56 \\
\hline FCF & 256 \\
\hline
\end{tabular}

We are dealing with a logical loop once again: WACC is still unknown, the value of the company cannot be calculated without WACC, so we don't know the value of equity either, which means we do not know the capital structure of the company, which we need to find the cost of capital (WACC).

The system of equations that permits to us to find the value of a company is as follows:

$$
\left\{\begin{array}{c}
V=\frac{240}{1+k} . \\
k=10 \% \times(1-30 \%) \times \frac{100}{V}+28 \% \times \frac{V-100}{V}
\end{array} .\right.
$$


The system can be solved (using simple algebra), or the solution can be found with the use of iterations in spreadsheets (the rules of using iterations have already been explained). Here is the solution we obtain:

$$
\left\{\begin{array}{l}
V=216.41 \\
k=18.30 \%
\end{array} .\right.
$$

Since the value of debt (loan) is 100, the value of equity becomes:

$$
E=116.41 \text {. }
$$

Please note, that the financing structure (market-value wise) is different from the initial one (where $50 \%$ of the seed money came from a loan), since debt represents $46.21 \%$ of the company value.

\section{Method based on CF}

Let us calculate cash flow available to the shareholders:

\begin{tabular}{|lr|}
\hline EBIT & 80 \\
Interest & 10 \\
EBT & 70 \\
Tax & 21 \\
EAT & 49 \\
CF & 149 \\
\hline
\end{tabular}

This approach requires paying back the loan at the end of the year. The available cash flow (100) (left after selling the assets) discounted at 28\%, generates the same value of equity $\mathrm{E}$ as before (in the indirect method).

\subsubsection{Three periods - given structure}

The multi-period example will be limited to the method based on given capital structure. An approach which assumes a fixed level of debt, and that has a changing capital structure, will be presented in Chapter 2 together with methods of determining the cost of capital in such a context.

The general case will be illustrated by an example of a company with an investment horizon of three years. The example is general enough, since methods used to cope with problems encountered here are helpful when dealing with a three-period (and more) case as well. 


\section{Example 8.}

The company conducts operations for three years. Initially, 200 is invested in land. At the end of each of the three years, EBIT of 80,90 and 70 respectively is generated.

It is assumed that the value of land will not change and it can be sold as soon as the company terminates its operations. The company is financed $40 \%$ by debt. Other necessary parameters are as follows: $T=30 \%, k_{D}=10 \%, k_{E}=28 \%$.

\section{Method based on FCF}

WACC has already been calculated (Example 6): $\quad$ WACC $=19.60 \%$.

Let us proceed to calculating free cash flow for each of the years and discounting it at WACC.

\begin{tabular}{|lrrr|}
\hline Year & 1 & 2 & 3 \\
\hline EBIT & 80.00 & 90.00 & 70.00 \\
\hline Tax & 24.00 & 27.00 & 21.00 \\
\hline FCF & 56.00 & 63.00 & 249.00 \\
\hline PV & 46.82 & 44.04 & 145.55 \\
\hline
\end{tabular}

The value of the whole company is obtained by summing the present values of free cash flows: $V=236.41$. The values of debt and equity can now easily be found using the following formulae:

$$
\begin{aligned}
& D=40 \% \mathrm{~V}=94.57 \\
& E=\mathrm{V}-\mathrm{D}=141.85 .
\end{aligned}
$$

Now we can take advantage of the values and determine cash flow in the first year. First, however, let us see what the value of company is each year.

The discounted cash flow from the end of year 3 represents the value of the company at the end of year 2, and the discounted cash flows from years 2 and 3 represent the value of the company at the end of year 1 . The same result is obtained if cash flow and the value of company are discounted at the end of year 2:

$$
\frac{63+208.19}{1+19.6 \%}=226.75
$$


There is also another way to show the present value:

$$
\frac{56+226.75}{1+19.6 \%}=236.41 \text {. }
$$

For each of the years, let us split $V$ into debt and equity according to the assumed capital structure:

\begin{tabular}{|lrrrr|}
\hline Year & 0 & 1 & 2 & 3 \\
\hline FCF & & 56.00 & 63.00 & 249.00 \\
V & 236.41 & 226.75 & 208.19 & \\
D & 94.57 & 90.70 & 83.28 & \\
E & 141.85 & 136.05 & 124.92 & \\
\hline
\end{tabular}

Now, cash flows $(C F)$ can be determined for each of the periods. They are going to serve as data for a comparison analysis with the $C F$ method that is to follow. Net profits must be calculated first.

\begin{tabular}{|lrrr|}
\hline Year & \multicolumn{1}{c}{1} & \multicolumn{1}{c}{2} & \multicolumn{1}{c}{3} \\
EBIT & 80.00 & 90.00 & 70.00 \\
Interest & 9.46 & 9.07 & 8.33 \\
EBT & 70.54 & 80.93 & 61.67 \\
Tax & 21.16 & 24.28 & 18.50 \\
EAT & 49.38 & 56.65 & 43.17 \\
\hline
\end{tabular}

Finding the value of cash flow needs a great deal of attention. At the end of year 3, the value of assets (after they are sold) must be added, and the debt (that is paid back) can be deducted:

$$
\mathrm{CF}(3)=43.17+200-83.28=159.89 .
$$

At the end of year 2, another correction has to be made: the value resulting from a changed level of debt must be added. Debt diminishes, so every year cash flow is lower than net profit.

$$
\begin{aligned}
& \mathrm{CF}(2)=56.65+(83.28-90.70)=49.23 . \\
& \mathrm{CF}(1)=49.38+(90.70-94.57)=45.52 .
\end{aligned}
$$


Cash flows discounted at 28\% generate the value of $\mathrm{E}=141.85$. We can also find the value of equity each year (in the same fashion we did for the value of company $V$ ) :

\begin{tabular}{|lrrrc|}
\hline Year & 0 & 1 & 2 & 3 \\
\hline CF & & 45.52 & 49.23 & 159.89 \\
\hline E & 141.85 & 136.05 & 124.92 & \\
\hline
\end{tabular}

For example, 136.05 is calculated by discounting the sum of 45.52 and 124.92 using a $28 \%$ discount rate.

The convergence between the two methods is striking. Still, it does not prove that the CF-based method will give the same result, since $C F$ s were calculated with the use of values obtained via FCF based method. Let us calculate the appropriate values separately.

\section{Method based on CF}

Let us pore over the one-period example and use the experience to deal with an investment horizon of many periods. This time, however, we will limit ourselves to numerical solutions. Solving systems of equations for the multi-period case is viable but it would involve very complicated notation. We will relax these restrictions later and present graphically how such systems of equations might work. For the time being, a numerical solution will do - it is good enough to draw conclusions of a general nature.

Temporarily, debt is assumed to be fixed at 50 every year. The formula for $\mathrm{CF}$ takes into account changes in the level of debt, although now it is irrelevant since debt does not change.

\begin{tabular}{|lrrrr|}
\hline Year & 0 & 1 & \multicolumn{1}{c}{2} & \multicolumn{1}{c}{3} \\
\hline EBIT & & 80.00 & 90.00 & 70.00 \\
D & 50.00 & 50.00 & 50.00 & \\
Interest & & 5.00 & 5.00 & 5.00 \\
EBT & & 75.00 & 85.00 & 65.00 \\
Tax & & 22.50 & 25.50 & 19.50 \\
EAT & & 52.50 & 59.50 & 45.50 \\
CF & & 52.50 & 59.50 & 195.50 \\
E & 170.55 & 165.81 & 152.73 & \\
\hline
\end{tabular}


The value of equity E each year is the discounted value of cash flow from the years to follow, or a discounted sum of one cash flow and the value of equity from the following year. It can be seen that the level of debt must be adjusted, because the capital structure is different from the one that was assumed. The assumed ratio of $\mathrm{D} / \mathrm{E}$ is $2 / 3$ and the adjustment are entered into the appropriate cells:

$$
D=(2 / 3) \times E .
$$

\begin{tabular}{|lrrrr|}
\hline Year & 0 & \multicolumn{1}{c}{1} & \multicolumn{1}{c}{2} & \multicolumn{1}{c}{3} \\
\hline EBIT & & 80.00 & 90.00 & $\mathbf{7 0 . 0 0}$ \\
D & 94.57 & 90.70 & $\mathbf{8 3 . 2 8}$ & \\
Interest & & 9.46 & 9.07 & $\mathbf{8 . 3 3}$ \\
EBT & & 70.54 & 80.93 & $\mathbf{6 1 . 6 7}$ \\
Tax & & 21.16 & 24.28 & $\mathbf{1 8 . 5 0}$ \\
EAT & & 49.38 & 56.65 & $\mathbf{4 3 . 1 7}$ \\
CF & & 45.52 & 49.23 & $\mathbf{1 5 9 . 8 9}$ \\
E & 141.85 & 136.05 & $\mathbf{1 2 4 . 9 2}$ & \\
\hline
\end{tabular}

The order of putting the formulae into the spreadsheet also matters. Let us begin with the debt at the end of year 2. The numbers in bold are safe in that respect as their values are not related to other cells.

In conclusion, for the multi-period case and a fixed capital structure, both methods (CF and FCF-based) give identical results. The case of fixed debt will be considered in Chapter 2.

\subsubsection{Growing perpetuity - given structure}

On one hand, the assumption that a company receives cash flows represented as a growing perpetuity is often criticized as being a gross simplification. On the other hand, in real life a more precise prognosis is not available. Surely, accepting the growing perpetuity is a mistake, as in practice there will never be such a scenario. Still, the assumption is justified by its simplicity, realism and the fact that part of the risk (divergence from the expected values) is reflected in the cost of capital. The growth factor is not likely to be constant, but there is no other reasonable alternative to use instead. Setting the value of the growth factor is a difficult task. 


\section{Example 9.}

Let us assume that the company's operations will never terminate. Initially, 200 is invested in land. At the end of the first year, EBIT of 80 is generated and then it will grow at the pace of $5 \%$ every year. The company is financed $40 \%$ by debt. Other necessary parameters are as follows: $T=30 \%, k_{D}=10 \%, k_{E}=28 \%$.

\section{Method based on FCF}

Free cash flow at the end of the first year has already been calculated, so has WACC $=19.60 \%$. Both EBIT and FCF grow at 5\% every year:

$F C F(2)=(1-30 \%) \times E B I T(2)=(1-30 \%) \times(1+g) \times E B I T(1)=(1+g) \times F C F(1)$.

Let us calculate the present value of a growing perpetuity:

$$
V=\frac{F C F(1)}{W A C C-g} \text {. }
$$

This is also the value of the whole company, which can be split into debt and equity according to the assumed capital structure.

\begin{tabular}{|lr|}
\hline EBIT & 80.00 \\
\hline Tax & 24.00 \\
\hline FCF & 56.00 \\
\hline V & 383.56 \\
D & 153.42 \\
\hline E & 230.14 \\
\hline
\end{tabular}

\section{Method based on CF}

When using this method, we encounter the same logical loop leading to a system of equations as many times before. Please note that because profit grows at the $\mathrm{g}$ rate, equity grows accordingly and debt has to grow at the same rate so the capital structure could be maintained. The initial level of debt $\mathrm{D}$ after one year grows by $\mathrm{gD}$ to $\mathrm{D}(1+\mathrm{g})$. Consequently, $\mathrm{CF}$ (at the end of year 1) is increased by $\mathrm{gD}$. Substituting these values into formulae $\mathrm{x}$ and $\mathrm{y}$, we obtain the following: 


$$
\begin{aligned}
& E=\frac{C F}{k_{E}-g}, \\
& C F=\left(E B I T-k_{d} \times D\right)(1-30 \%)+g D, \\
& D=\frac{2}{3} E .
\end{aligned}
$$

Here is the solution for $E$ :

$$
E=\frac{(1-30 \%) E B I T}{k_{E}-g+\frac{2}{3}(1-30 \%) k_{D}+\frac{2}{3} g}=230.14
$$

The numerical solution involves setting the value of debt at, say, $D=100$, and then calculating cash flow, discounting and finding $D$ based on the assumed capital structure (first column below). Then, the loop has to be closed by referring the 100 cell $(D)$ to the cell in the second column, including a proper formula for debt.

\begin{tabular}{|lrr|}
\hline EBIT & 80.00 & 80.00 \\
D & 100.00 & 153.42 \\
Interest & 10.00 & 15.34 \\
EBT & 70.00 & 64.66 \\
Tax & 21.00 & 19.40 \\
EAT & 49.00 & 45.26 \\
CF & 54.00 & 52.93 \\
E & 234.78 & 230.14 \\
D & 156.52 & 153.42 \\
V & 391.30 & 383.56 \\
\hline
\end{tabular}

To sum up, the method based on FCF seems much simpler; though both give the same results..

\subsubsection{Growing perpetuity - given debt}

To demonstrate this concept, we will assume an initial level of debt and then assume that debt is growing at the same rate as profits. An alternative assumption that debt and profits grow at a different rates leads to many technical problems and is of little practical use.

The case is quite simple to solve. 


\section{Example 10.}

Let us assume that operational profit (EBIT) at the end of the year is 60 (for simplicity depreciation is ignored), $k_{D}=6 \%, k_{E}=14 \%$, and initially the value of debt is 100 . $\mathrm{T}=30 \%$. Profits and debt both grow at $4 \%$ a year.

Net profit can be found by deducting interest payment and tax. Then we have to take into account the fact that growing debt means a positive cash flow for the shareholders. Thus, the cash flow expected at the end of the year must be increased by $g_{D}$, that is, $4 \%$ of debt.

\begin{tabular}{|lr|}
\hline EBIT & 60.00 \\
I & 6.00 \\
EAT & 37.80 \\
CF & 41.80 \\
FCF & 42.00 \\
\hline
\end{tabular}

Now, Gordon's model can be used to calculate the cost of equity (here original $S$ is replaced with $E$ ).

$$
S_{0}=\frac{\operatorname{Div}}{k_{E}-g} \text {. }
$$

The same result is obtained if $F C F$ is discounted at WACC (12.11\%):

$$
\begin{aligned}
& E=418 \\
& V=518 .
\end{aligned}
$$

\subsubsection{General case - given structure}

What is often considered when performing real life company valuations is operations that are not planned to terminate at any point of time, but cash flows for the first, say, five years can be more or less precisely predicted, and then, it is assumed the company will continue operations in a form of a growing perpetuity. Such a situation is easy to analyze: in Example 8 the amount acquired from selling the assets can be replaced by the amount representing continuation. 


\subsubsection{APV - given structure}

A company can be treated as a portfolio of equity and debt. Then, the rate of return for the company can be found, providing costs of debt and equity are available:.

$$
k_{A}=\frac{D}{V} k_{D}+\frac{E}{V} k_{E} .
$$

The APV method involves discounting FCF at this very cost of capital, and then adding some adjustments, such as adding the value of a tax shield. Typically, other adjustments are also included, such as flotation costs, costs of financial distress, etc. The APV method is more flexible than the methods where such costs are only reflected in the discount factor. The tax shield adjustment requires finding the value of the tax shield for each year, and then calculating its present value. The problem that is encountered here relates to establishing the proper value of the discount rate.

\section{Example 11.}

Company $X$ generates EBIT $=200$ (perpetuity), and pays $30 \%$ tax. It is financed $30 \%$ by debt. The cost of debt is $10 \%$ and cost of equity is $16 \%$.

FCF (140) and cost of capital kA can be easily found:

$$
\begin{aligned}
& k_{A}=w_{D} \times k_{D}+w_{E} \times k_{E} \\
& k_{A}=30 \% \times 10 \%+70 \% \times 16 \%=14.2 \% .
\end{aligned}
$$

In the next step, the basis for the further adjustment is calculated - it is the present value of cash flows for a hypothetical situation in which the company is fully financed by equity (then $\mathrm{FCF}=\mathrm{CF}$ )

$$
P V=\frac{F C F}{k_{A}}=\frac{140}{14.2 \%}=985.92 .
$$

The final adjusted value of the company is denoted as APV. Debt is $30 \%$ of the amount, and interest is $10 \%$ of the debt. Tax shield (TS) is $30 \%$ of the latter:

$$
T S=A P V \times w_{D} \times k_{D} \times T .
$$


However, APV is unknown so the calculations cannot be performed. Additionally, there is the question of how to discount the tax shield. The answer depends on how we perceive the risk which is associated with the volatility of the underlying instruments (mostly debt). Here are three different points of view.

1. If the structure is fixed, the value of debt will correspond to the changes in the company value. Thus, we should discount at $\mathrm{kA}$ which reflects the volatility of the value of the company.

2. Initially, the value of debt is known, so the first tax shield is less risky and should be discounted at the cost of debt, and all the others to follow at $\mathrm{kA}$.

3. The cash flows are as risky as debt is (debt is the key component of the tax shield), therefore they should be discounted at the cost of debt.

Some argue that a risk free rate could also be used.Let us present the consequences of supporting the points of view number 1 and 2 above.

\section{Approach 1.}

Let us calculate the present value of a tax shield:

$$
P V(T S)=\frac{T S}{k_{A}}=\frac{A P V \times w_{D} \times k_{D} \times T}{k_{A}} .
$$

Let us correct the present value of cash flows and add the present value of the tax shield:

$$
A P V=\frac{F C F}{k_{A}}+P V(T S)=\frac{F C F+A P V \times w_{D} \times k_{D} \times T}{k_{A}} .
$$

Please note that we are facing a logical loop again: $A P V$ depends on $T S$, and $T S$ cannot be calculated without $A P V$. Still, the system of equations can be solved:

$$
\begin{aligned}
& k_{A} A P V=F C F+A P V \times w_{D} \times k_{D} \times T, \\
& A P V=\frac{F C F}{k_{A}-w_{D} \times k_{D} \times T} .
\end{aligned}
$$

Interestingly enough, if the formula for $\mathrm{kA}$ is entered in the denominator, we obtain a formula that looks familiar:

$$
k_{A}-w_{D} k_{D} T=w_{D} k_{D}+w_{E} k_{E}-w_{D} k_{D} T=w_{D} k_{D}(1-T)+w_{E} k_{E}=W A C C \text {. }
$$


Clearly, the method gives the same result as the ones used so far: the value of the company is obtained by discounting FCF at WACC. Now, we can complete the calculations:

$$
\begin{aligned}
& W A C C=13.30 \% \\
& V=\frac{140}{13.30 \%}=1052.63 .
\end{aligned}
$$

\section{Approach 2 (Miles-Ezzell)}

According to this approach, discounting of the tax shield is done as follows:

$$
\begin{aligned}
P V(T S)= & \frac{T S}{1+k_{D}}+\frac{T S}{\left(1+k_{D}\right)\left(1+k_{A}\right)}+\frac{T S}{\left(1+k_{D}\right)\left(1+k_{A}\right)^{2}}+\ldots \\
& =\frac{1+k_{A}}{1+k_{D}}\left(\frac{T S}{1+k_{A}}+\frac{T S}{\left(1+k_{A}\right)^{2}}+\frac{T S}{\left(1+k_{A}\right)^{3}}+\ldots\right) \\
& =\frac{1+k_{A}}{1+k_{D}} \times \frac{T S}{k_{A}} .
\end{aligned}
$$

Then, we take the same steps as previously in an attempt to find $A P V$ :

$$
A P V=\frac{F C F}{k_{A}}+P V(T S)=\frac{F C F}{k_{A}}+\frac{A P V \times w_{D} \times k_{D} \times T}{k_{A}} \times \frac{1+k_{A}}{1+k_{D}} .
$$

After solving the equation for $A P V$ we get:

$$
A P V=\frac{F C F}{k_{A}-k_{D} w_{D} T \frac{1+k_{A}}{1+k_{D}}} .
$$

The rate in the denominator replaced WACC. It is also a type of a weighted average cost of capital that, in order to distinguish it from regular WACC and appreciate the contribution of its authors, is marked as $W A C C_{M E}$ :

$$
W A C C_{M E}=w_{D} k_{D}\left(1-T \frac{1+k_{A}}{1+k_{D}}\right)+w_{E} k_{E} .
$$

The calculations can now be completed:

$$
\begin{aligned}
& W A C C_{M E}=13.27 \% \\
& A P V=\frac{140}{13.27 \%}=1055.36 .
\end{aligned}
$$


The result is different from that of approach 1, but the difference is not striking. The discounting factor that was used in the first period was lower $\left(k_{D}\right.$ instead $k_{E}$ ), so the resulting number $(A P V)$ is obviously higher.

Admittedly, the formulae are slightly complicated. Let us then present a simple iteration-based method for finding the value of ${ }^{A P V}$. First, the present value of FCF must be found (FCF is discounted at $k_{A}=14.2 \%$ and, for the time being, the value is accepted as $A P V$ ). Then, the tax shield is to be found according to the formula below:

$$
P V(T S)=\frac{T S}{k_{A}} \times \frac{1+k_{A}}{1+k_{D}} .
$$

Here is the result of the attempt:

\begin{tabular}{|lr|}
\hline FCF & 140.00 \\
\hline PV(FCF) & 985.92 \\
\hline APV & 985.92 \\
D & 295.77 \\
TS & 8.87 \\
\hline PV(TS) & 64.87 \\
\hline
\end{tabular}

The loop is completed by replacing APV with $\mathrm{PV}(\mathrm{FCF})+\mathrm{PV}(\mathrm{TS})$. Eventually, we obtain the same results as before:

\begin{tabular}{|lr|}
\hline FCF & 140.00 \\
\hline PV & 985.92 \\
\hline APV & 1055.36 \\
\hline D & 316.61 \\
TS & 9.50 \\
\hline PV(TS) & 69.44 \\
\hline
\end{tabular}

\subsubsection{Company valuation via iterations}

In case of a company represented by a perpetuity (as shown in many cases above) finding the company's value by solving a system of equations is quite viable. In a real life case, however, when one has to deal with numerous parameters and time periods, a numerical solution seems to be the only feasible ap- 
proach. For example, in order to find the value $V$ (for a given year $t$ ), one needs to know the values of $W A C C$, next $E$, and then $k_{E}$. It is impossible to calculate $W A C C$ without $V$ (the one we look for), and $E$ without $k_{E}$. There appears to be many logical loops in the formulae shown below. It is a chain of formulae that becomes so integrated that the information between cash flows and cost of capital moves freely. The cost of capital "tracks" the capital structure and changes accordingly, while $C F$ is a reflection of future profits and also the level of debt in the company. This is the value-add of the iteration-based method.

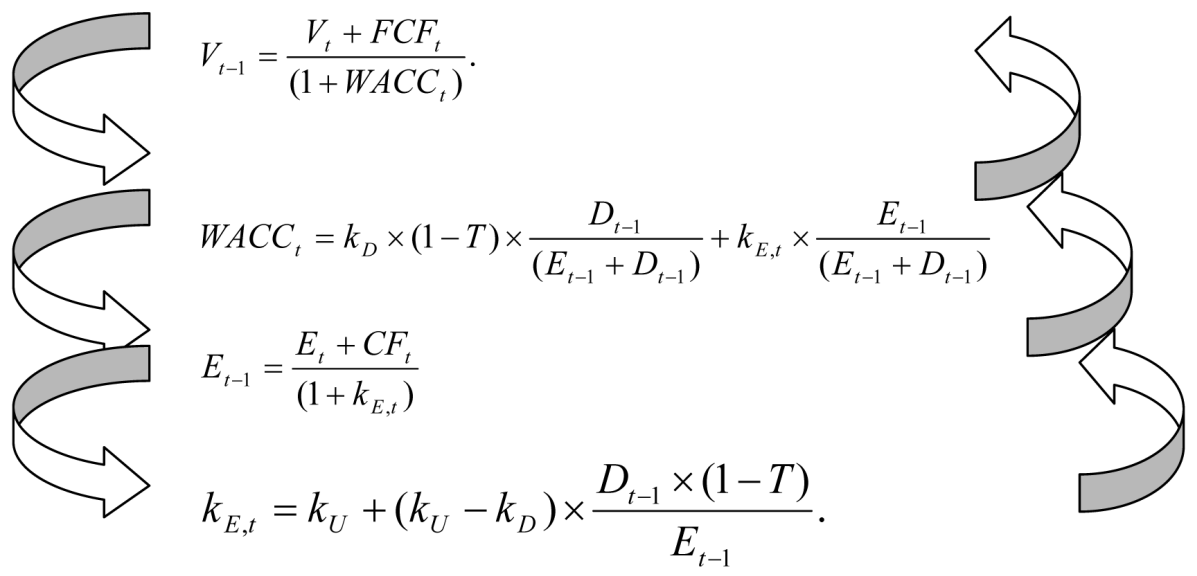

Similar loops will appear if one uses the FTE method (with $C F$ ) instead of $F T F$ ( $F C F$-based). Depending on whether debt or capital structure is given, loops will additionally run along columns (from $V$ to $W A C C$, and from $E$ to $k$ ) and lines (from one year to another). The valuation is recursive, going backwards in time. To conclude, calculating the value of a company without using iterations is tantamount to applying the wrong weights to WACC and leads to an inner contradiction.

In general, the recursive method of company valuation that has been shown through many examples overcomes a fundamental problem that is often ignored by many other methods: the fact that the cost of capital depends on the financial structure. It creates additional technical problems in a form of a logical loop but this was also remedied. Admittedly, there are also many simplifications: one is that we often use perpetuities as the last resort, and second is the assumption that the required rate of return is equal to the expected return (determined by cash flows). However, the latter does not seem far from true; an expected return that is higher than required would lead to a positive NPV, an opportunity which when confronted with competitive markets quickly ceases to exist. 


\subsection{Growth}

\subsubsection{Growth of value}

It goes without saying that growth in value may take place, providing the company carries out projects with a positive NPV. Let us illustrate the issue by showing a company that is financed by equity only, and whose profits it generates are represented by a perpetuity. Let us suppose its cost of capital is $20 \%$, and the company generates cash flows of 300 every year. The value of the company is easy to find:

$$
V=\frac{F C F}{k}=\frac{300}{20 \%}=1500 .
$$

Now suppose the company can invest 150 in a project that additionally generates 50 a year. The value of the project is:

$$
N P V=I+\frac{F C F}{k}=-150+\frac{50}{20 \%}=100 .
$$

Another way to calculate the value of the company is:

$$
V=-150+\frac{350}{20 \%}=1600 \text {. }
$$

The result is in compliance with our prediction and the rule of additivity: the value of two projects is the sum of their values, providing the cash flow of the joined projects is the sum of their individual cash flows. This is not always the case however, since the effect of the growth in units sold may be spoilt by reduction in prices. If the project brings a return that is lower than its cost of capital, the value of the company falls. Let us suppose the project earns only $25 \mathrm{k}$ a year. Then:

$$
\begin{aligned}
& N P V=-150+\frac{25}{20 \%}=-25 \\
& V=-150+\frac{325}{20 \%}=1475 .
\end{aligned}
$$

Generating profits is not enough. Profits have to be above the hurdle set by the cost of capital.

A question arises: how to find projects with a positive NPV. In nine out of ten cases these are a result of a competitive advantage. Here are a few such situations: 
1. Technological advantage,

2. Organizational advantage,

3. Monopolistic position.

None of these advantages last long as the competition is quick to catch up. Case (below) shows technical and numerical aspects of this phenomenon.

\subsubsection{Growth versus value}

Profits generated by a company are the basic source of funds that can be reinvested in order for the company to grow. However, any reinvestment decisions (which may trigger growth) and decisions involving paying out dividends (which may satisfy shareholders) are contradictory. Let us analyze which decision is genuinely rewarding shareholders. It is obvious though that a positive NPV is a sine qua non condition concerning all growth prospects.

We will consider equity financing first, so that we focus on one issue, putting the debt versus value problem aside. The simplest situation imaginable is a company that does not grow: it generates a profit of 25000 every year, all of which is paid out to shareholders (cost of capital is 15\%). Both the value of the company and the share price (assuming that there are 1000 shares in circulation) can be calculated as follows:

$$
\begin{aligned}
& V(0)=\frac{F C F}{k}=166667 \\
& P(0)=\frac{V(0)}{1000}=16.67 .
\end{aligned}
$$

Suppose some investment opportunities appear at the end of year 1 . The whole profit can be reinvested and generate a profit in a form of a perpetuity (for simplicity's sake, in the following years we do not allow any investment).

\section{Case 1}

Suppose the return expected from the investment is the same as the cost of capital $(15 \%)$. This means that the 25000 that is to be invested will bring the profit of 3 750 every year. The expected net present value of the project is no surprise:

$$
N P V(1)=-25000+\frac{3750}{15 \%}=0 .
$$

At the end of year 1, nothing will be paid out to the shareholders, but in the years to come the company will generate profit of:

$$
25000+3750=28750 .
$$


The shareholders miss the dividend in the first year, but then the dividend grows as shown below:

\begin{tabular}{|lrccc|}
\hline Dividend / year & 1 & 2 & 3 & $\ldots$ \\
\hline No reinvestment & 25.00 & 25.00 & 25.00 & $\ldots$ \\
\hline Reinvestment in year 1 & 0 & 28.75 & 28.75 & $\ldots$ \\
\hline
\end{tabular}

The value of the company is the present value of all future cash flows, shown as follows:

$$
V(0)=\frac{28750}{(1+15 \%)^{2}}+\frac{28750}{(1+15 \%)^{3}}+\cdots
$$

To make the calculations easier, let us find the value at year 1, so the perpetuity formula can be used.

$$
V(1)=\frac{28750}{1+15 \%}+\frac{28750}{(1+15 \%)^{2}}+\cdots=\frac{28750}{15 \%}=191667 .
$$

The amount $V(1)$ has to be discounted to year 0 to find $V(0)$. Apparently, the reinvestment decision did not affect the value of the company.

\section{Case 2}

Suppose now the return that is expected from the investment is $20 \%$. It means that the investment will bring an additional 5000 a year, starting year 2 . The value of the project at year 1 is:

$$
N P V(1)=-25000+\frac{5000}{15 \%}=8333.33 .
$$

The table below shows the amount of dividends in both situations:

\begin{tabular}{|lrccc|}
\hline Dividend / year & 1 & 2 & 3 & $\ldots$ \\
\hline No reinvestment & 25.00 & 25.00 & 25.00 & $\ldots$ \\
\hline Reinvestment in year 1 & 0 & 30.00 & 30.00 & $\ldots$ \\
\hline
\end{tabular}

The value of the company is the present value of all future cash flows, so we follow the calculation procedure from the previous case (Case 1):

$$
V(1)=\frac{30000}{1+15 \%}+\frac{30000}{(1+15 \%)^{2}}+\cdots=\frac{30000}{15 \%}=200000 .
$$




$$
V(0)=\frac{200000}{1+15 \%}=173913 .
$$

The reinvestment positively affects the value of the company and share price:

$$
P(0)=173.91 \text {. }
$$

The present value of the company has grown by 7246.38 , (that is 7.25 per share) thanks to some growth opportunities. The amount (7.25) is denoted by $P V G O$ (present value of growth opportunities). The example can be a starting point for analyzing $P V G O$ in a wider context. It is clear that growth higher than zero (investment with the rate of return that is equal to the cost of capital also generates zero growth) increases the share price. This growth potential (denoted by $P V G O$ ) can be defined as:

$$
P V G O=P(0)-\frac{E P S}{k} .
$$

The formula can be rewritten so that it provides a more natural definition of a share price:

$$
P(0)=\frac{E P S}{k}+P V G O .
$$

The share price is broken into two components: value without growth and an additional component derived from the growth potential.

\subsubsection{Dividend policy and growth}

Let us check how dividend policy (or reinvestment policy - both are two sides of the same coin) influences growth and value of a company.

\section{Example 12.}

An evaluator analyses a firm that is fully financed by equity (100 book value), that generates cash flow in a form of perpetuity with ROE $=30 \%$. The cost of capital is $25 \%$. There is an option to reinvest part of the profit ( 30 a year) into a project that may yield $30 \%$ return. 
If the firm does not take the opportunity ${ }^{[12]}, 30$ will be distributed among the shareholders every year, and the value of the firm will reach 120 . If, however, the firm decides to take advantage of the (5\%) growth opportunity, they will have to reinvest $16.67 \%$ of the profit, increase assets to 105 and pay out only 25 to the shareholders. Technically speaking, growth is defined as a product of ROE and plow-back ratio (reinvestment ratio - p).

$$
g=R O E \times p=30 \% \times 16.67 \%=5 \% .
$$

Another year will bring a profit of 31.5, out of which $83.33 \%$ (100\% $16.67 \%$ ) will be paid out to shareholders (5\% more than previously). The growth can be sustained and then the value of the company will reach 125 (using Gordon's model). At $10 \%$ growth, the value of the company will reach 133.3, at $15 \%$ 150. Speaking of PVGO, at different levels of growth (respectively $0 \%$, $5 \%, 10 \%$ and $15 \%$ its value (per share) is:

$$
\begin{aligned}
& \text { PVGO }=0 \\
& \text { PVGO }=5.00 \\
& \text { PVGO }=13.33 \\
& \text { PVGO }=30.00 .
\end{aligned}
$$

Companies with a high PVGO can be defined as growth companies. From the point of view of an investor who is considering buying the shares, profits may be delayed: we swap high dividends now for even higher dividends promised to be paid out in a distant future. The delay involves risk: if the growth is not sustained, the promise may never materialize.

In practice, high growth cannot be sustained in the long run. The market will not be insatiable forever, and so we will eventually have a lower the return from selling our product. The model can be used to simulate moderate growth only (related to GDP, or population growth). Dynamic growth must be analyzed separately.

\subsubsection{Growth versus cost of capital.}

Let us consider the problem of finding the cost of capital for a public company (listed on the stock exchange). In a zero-growth scenario, the cost of capital can be easily found.

$$
g=0 .
$$

and all the dividends are equal to EPS:

$$
\operatorname{Div}(1)=E P S \text {. }
$$

12 cf: A. Damodaran, Damodaran on Valuation, John Wiley \& Sons, New York 1994, p. 86. 
Hence,

$$
k=\frac{E P S}{P(0)} \text {. }
$$

In a scenario with given growth, the formula looks as follows:

$$
k=\frac{\operatorname{Div}(1)}{P(0)}+g \text {. }
$$

However, the growth is usually unstable - it is hardly possible to express it through only one rate. Let us then go back to the PVGO formula:

$$
P(0)=\frac{E P S}{k}+P V G O \text {. }
$$

Let us suppose the share price is $50, \mathrm{PVGO}$ is 50 , and profit per share is 10 :

$$
\begin{aligned}
& P(0)=50, \\
& E S P=10, \\
& P V G O=15 .
\end{aligned}
$$

Now, the cost of capital can be found by solving the equation:

$$
50=\frac{10}{k}+15 \quad k=28,57 \% .
$$

Computing the PVGO remains the main problem, of course.

It is extremely educational to use spreadsheets in order to analyze the relationship.

In practice, $\mathrm{P} / \mathrm{E}$ ratio (price/earnings) is easily available:

$$
P / E=\frac{P(0)}{E P S} \text {. }
$$

In the example, the P/E ratio is 5. The flipped ratio gives the cost of capital for a zero-growth scenario. In other words, in a zero-growth scenario, $\mathrm{P} / \mathrm{E}=$ $1 / \mathrm{k}$.Hence we are able to determine the cost of capital. In this example it equals $20 \%$. Thanks to growth opportunities, the cost of capital grows too. The larger the contribution of the share price that comes from PVGO, the higher the share price is. For example, (ceteris paribus) suppose:

$$
P V G O=20 .
$$

Then,

$$
k=33.33 \% \text {. }
$$


It goes in line with our understanding of the cost of capital as a risk-related required rate of return. For a company, in which a large share of its value is based on growth, the level of risk is understandably higher.

What if a company generates losses? The only justification of a positive market price is faith (of the market) in future profits and PVGO is then higher than share price. The classic example (dated 2000) might be IT companies. Suppose:

$$
\begin{aligned}
& P(0)=50, \\
& E P S=-5, \\
& k=40 \% .
\end{aligned}
$$

Then,

$$
P V G O=62.50 \text {, }
$$

which obviously is more than the share price of 50 .

To conclude, investment pays off (it initiates growth), providing the rate of return on the projects is higher than the cost of capital of the company. Such opportunities are difficult to find and due to competition's activity, hard to sustain.

\subsubsection{Residual value}

Expected cash flows are the foundation of the model of company valuation. Unfortunately, predicting value of cash flows for 7, 9, or 15 years from now is problematic. Working under the assumption that a company has a finite lifespan would mean that beyond a certain point in time, cash flow is no longer generated, and the company would not have any value at that point.This is controversial, since companies are usually set up for the long run. Should we suggest that companies live infinitely. A reasonable approach requires setting a certain finite investment horizon (and then predicting cash flows with a great deal of precision). Beyond that point in time, it should be assumed that the company is still active and has some residual value. The residual value concept typically involves simplifying cash flows generated by a company to a perpetuity. Let us discuss some specific assumptions made for the residual value.

1. Assumption that after some time $T$ a company will generate cash flows in theform of a growing perpetuity.

Once this assumption has been accepted, one has to estimate the growth factor, cost of capital, and first cash flow after time $T$. Next, Gordon's model can be applied. There are pros and cons to this approach. Its simplicity is the biggest 
advantage, with the disadvantage being a high sensitivity of the results with respect to the assumed (estimated) growth factor.

2. Comparison with another company that has reached a phase of development our company is planning to reach at time $T$.

Once we find such a company, some of the ratios that refer to the market value can be used. Suppose the company has $\mathrm{P} / \mathrm{E}$ ratio that equals 8 . The ratio can be applied to our prediction with respect to the level of profits at time $T$. The profit can be multiplied by 8 to obtain the value of the company.

Or suppose that the company's MV/BV is 2 . We should be able to predict the book value of our company at time $T$, and multiply it by 2 to obtain the residual value of the company.

3. Estimating the length of the competitive advantage phase.

Once the competitive advantage phase ends, the growth opportunities will vanish, which, on one hand, is bad news, but on the hand makes valuation much easier (we can completely ignore one of the parameters, namely the growth factor). The residual value can be calculated with the use of a perpetuity only.

\subsection{Real options}

Expected cash flows are the foundation of the model of company valuation. The uncertainty related to future cash flows cannot eliminated, hence we tend to underline the expression "expected". During the life of a project, the cash flows may be lower or higher than the expected ones. When the cash flows are lower e.g. due to diminished demand, we might have a chance to abandon the project. In case of success, we might be able to increase production. This type of flexibility, which is unique to some projects, is not captured by traditional methods of valuation.

Both decisions; to withdraw after failure or expand after success, have some financial consequences and depend on future events that are highly uncertain. The similarity with options theory seems obvious. A buyer of a "put" may exercise the option if the price of underlying asset goes down, likewise buyer of a "call" may benefit from a situation when the price of an underlying instrument goes up. The analogies are actually much deeper than it seems at first glance. Hence, the expression "real options" is often used whenever referring to an option whose underlying assets are not financial instruments.

Hence, here is a brief presentation of the basic ideas demonstrating the concept of a real option. If a company conducts market research, it in fact buys an option: if the research is fruitful the company will launch the product. The expenses incurred during the market research phase represent the option premi- 
um, and the cost of further investment incurred at some future time $T$ is the exercise price. The payoff depends on the success of the new product and it is the difference between the value of the future expected cash flows (discounted to time $T$ ) and the investment. The payoff is then given by the following formula: $\max (0, R(T)-K)$, where $\mathrm{K}$ is the value of the investment and $R(T)$ is the value of the generated cash flows at time $T$ (a situation known in the world of finance under the name "call option"). Obviously, it is zero when the result of the market research is negative and the company does not invest. As another example, consider production facilities allowing for expansion, which will be employed only in case of success. Classical cases here are also concerned with oil-drilling and research and development. On the other hand, "put options" may provide insurance against risk a company may face in case of a failure and a necessity to reduce the production facilities.

Such options as they appear in real business activities are very specific, as the examples above show. They can be rarely written or sold, we cannot hedge, nor can we replicate them using the underlying assets and bonds. These features distinguish them sharply from financial options. This raises the question: how to valuate real options?

If the real option can be related to a financial option, which is the case when there is a financial asset perfectly correlated with the underlying asset of the real option, then applying the valuation tools developed for financial options is justified. However, we face a danger of mispricing if the correlation is not perfect ${ }^{[13]}$.

\subsubsection{Option to abandon}

The first example below deals with the additional value resulting from an option to abandon a project.

\section{Example 13.}

A project requires an investment of 100 . Two future scenarios are conceivable: cash flows of 60 (success), or 10 (flop) for three years. The probability of each scenario materializing is $50 \%$. At any time the operation may be terminated (assets can be sold) for 80 . The cost of capital is $30 \%$.

13 Capiński M., Patena W. "Real Options - Realistic Valuation”, Journal of Business and Society, 2006/3 
0

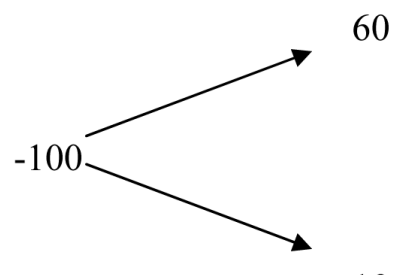

10
2

60

60

80

10

A classic approach suggests finding the expected cash flows. Here, the cash flows are as follows:

$$
\begin{aligned}
& \mathrm{E}(\mathrm{CF} 1)=\mathrm{E}(\mathrm{CF} 2)=35=\left(\frac{1}{2} \times 60+\frac{1}{2} \times 10\right) . \\
& \mathrm{E}(\mathrm{CF} 3)=35+80=115 .
\end{aligned}
$$

NPV of the project is negative (- 0.02). However, we make a mistake by ignoring thepossibility to abandon the project. The previous calculations are correct if the abandonment option is not available. Let us make the calculations again. The operations should be terminated after one year, if the pessimistic scenario materializes (the cash flow is 90 then). NPV of the project now changes significantly and is 7.31 .

Financial options use specific terminology, which we will apply here in order to help us identify crucial components of the real option (option to abandon):

1. Maturity - the end of year 1 .

2. Underlying asset: the value of project. At time 1, it is the value of cash flows as shown below:

$$
\begin{aligned}
& 60+\frac{60}{1+30 \%}+\frac{140}{(1+30 \%)^{2}}=188.99 \\
& 10+\frac{10}{1+30 \%}+\frac{90}{(1+30 \%)^{2}}=70.95
\end{aligned}
$$

It is clear that in the pessimistic scenario we are better off by terminating the project and selling the assets, as the cash flow is 90 then (instead of 70.95).

3. Exercise price - 90 (underlying instrument includes abandoning the project and selling the assets). 
4. Put option payoff $-\max (0, \mathrm{~K}-\mathrm{R}(\mathrm{T})), 0$ in a optimistic scenario and $(90-$ $70.95)=19.05$ in a pessimistic one.

5. Option premium - price of the option (present value of cash flows calculated usingthe cost of capital) is 7.33 .

The project with the option to abandon is worth 7.33 more than the same project without the option. The difference is simply the value of the option (option premium). Please note that the suggested method of valuing the option is based on physical probabilities and as such is not the classic one.Typically, financial options valuation involves the replication method or the use of martingale probabilities. It is important to notice that (because the option is worth 7.33 ) it is worth investing 105 (including 5 for the option), instead of 100 to have the extra opportunity to abandon the project.

\subsubsection{Option to abandon revisited}

\section{Example 14.}

A project requires an investment of 100 and will generate cash flows of 130 (success), or 95 (flop) after one year. The probability of each scenario materializing is $50 \%$. At any time, the operation may be terminated and assets can be sold for 100 provided the infrastructure is up to the buyer's needs. The cost of capital is $30 \%$ and the risk-free rate is $5 \%$. How much to invest in order to have the option?

0

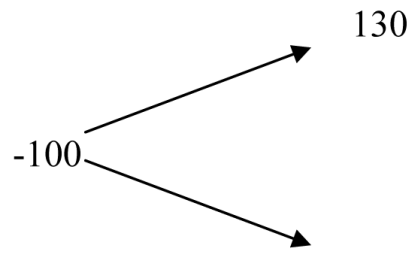

95

The option can be valued with the use of physical probabilities, using the same technique as before. Comparing the values with (4.54) and without (2.27) the option gives an idea of how much the option itself is worth (2.27).

However, it would be tempting to use financial options theory to valuate the real options. The technique relies on replication. One needs to create a portfolio that would generate the same payoffs as the option. The number below (denoted 
as delta) will be helpful (difference in the option payoffs divided by the difference in the project's payoffs):

$$
\Delta=\frac{(0-5)}{(130-95)}=-0.1428 \text {. }
$$

The portfolio composed of the stock (bought in proportion implied by the delta) and bond generates the same payoff as the option $(0,5)$. Delta is the position in the underlying asset which completed in cash position replicates the payoff.

\begin{tabular}{|lrr|}
\hline Scenario & \multicolumn{1}{c}{ up } & \multicolumn{1}{c|}{ down } \\
Stock & -18.57 & -13.57 \\
Bond & 18.57 & 18.57 \\
\hline Total & 0 & 5 \\
\hline
\end{tabular}

The payoffs of the portfolio and option are the same and hence their present values must be equal too.

$$
P V(\text { porfolio })=\text { put premium }=-0.1428 \times 100+\frac{18.57}{(1+5 \%)}=3.40 \text {. }
$$

The option is then worth 3.40. The discrepancy (2.27 versus 3.4$)$ between the values given by the two methods stems from the fact that both approaches have flaws. In the first approach, the physical probabilities have been arbitrarily chosen, while in the second, replication is hardly possible if the real business is at stake (how to short sell the business that is not publicly traded).

\subsubsection{Option to expand}

Another example illustrates the benefits from having an option to expand. When starting a business, we can build a bigger warehouse or buy more efficient (than necessary) machines, which may allow a business to increase production in case of larger demand without having to incur additional investments later on. 


\section{Example 15.}

A project requires an investment of 100 and will bear cash flows of 80 (success), or 20 (flop) for three years. The probability of each scenario materializing is $50 \%$. Sales in years 2 and 3 may be doubled if an investment of 70 is made at the end of year 1 . The cost of capital is $30 \%$.

0

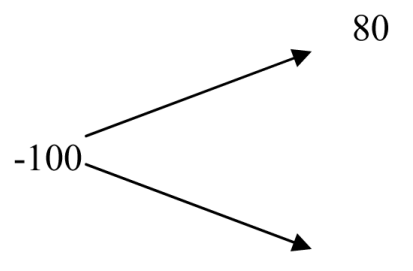

20

$-70$
2

80

20

80
80

3

NPV of the success and flop scenarios (without the option to expand) are 45.29 and -63.68 , respectively. It means that NPV of the project is negative ( -9.19). Exercising the option to expand generates cash flows (in the optimistic scenario) of 10,160, 160 in the three subsequent years. NPV of the project becomes 75.19 and the option is worth 5.76. Here are the components of the option:

1. Maturity $T$ : the end of year 1 .

2. Underlying instrument: value of cash flows, 108.88 or 27.22 that is.

3. Exercise price $K: 70$.

4. Payoff of the call option: $\max (0, R(T)-K) ; 38.88$ in a positive and0 in a negative scenario.

5. Call premium: price of the option (present value of cash flows at the cost of capital) is 14.95 .

Options of that kind are often used in projects concerned with oil-drilling and research and development, where significant amounts of money have to be invested into research and the eventual building of a well depends on the research results. 


\subsection{Case study - documents pro forma}

A firm's value is determined by its ability to generate cash flow, both now and in the future. When approaching a company valuation, a considerable amount of time must be spent on estimating future cash flows.

Let us analyze the case of Tea.dot company - it is a successful but new company which reinvests most of its earnings. The company's performance has to be predicted for, at least, the next five years so the free cash flows and then horizontal value of the company were calculated. However, pro forma financial statements, such as income statements, balance sheets and cash flow statements could not be produced, if we did not make a number of assumptions.

Before doing so, however, let us have a look at the financial situation of the company to see how it is doing. As investment analysts, we are mainly interested in assessing the future performance of the company. The basis of traditional analysis is comparison, as absolute numbers carry little information value. The framework for comparison should be:

1. The company's own performance in other years (trend)

2. An industry average

(benchmarking)

Let us do the benchmarking first and compare the ratios for the relevant industry (Bakery Products) with those of the company:

\begin{tabular}{|lrcc|}
\hline & Industry & Tea.dot (2008) & \\
Quick ratio & 1,0 & 2,39 & OK \\
Current ratio & 1,6 & 2,64 & OK \\
\hline Liabilities/equity & $99,7 \%$ & $358 \%$ & high/risky \\
DSO & 24,1 & 79,56 & poor \\
Total assets turnover & $33,4 \%$ & $93 \%$ & OK \\
ROA & $7,4 \%$ & $11 \%$ & OK \\
ROE & $16,5 \%$ & $48 \%$ & OK \\
\hline
\end{tabular}

The company's liquidity position is very strong. However, it also means that it has a lot of money tied up in nonproductive assets (cash). The company should pay more attention to cash management as well as to inventory control. The average collection period is very long - the company has to wait 80 days after making a sale before receiving cash. This suggests that some steps should be taken to expedite the collection of accounts receivables or at least monitor the receivables position to start with. The turnover of all the firm's assets is high which means that the company is generating a sufficient volume of business given its total assets investment. The analysis raises a few questions about 
the company's gearing and its investment strategy. Tea.dot is highly leveraged. Creditors may be reluctant to lend the firm more money and the management is subjecting the firm to the risk of bankruptcy if it still seeks to increase the debt ratio by borrowing additional funds. Both profitability ratios are fine, although it is obvious that its significantly better result in ROE is due to the company's great use of debt.

Now let us have a look at the trends at Tea.dot over the last 3 years.

\begin{tabular}{|lccc|}
\hline Ratios & -2 & -1 & 0 \\
\hline Liquidity Ratios & & & \\
current ratio & 3.44 & 2.46 & 2.64 \\
quick ratio & 3.26 & 2.24 & 2.39 \\
$\begin{array}{l}\text { cash ratio } \\
\text { Asset Management Ratios }\end{array}$ & 1.69 & 0.76 & 0.94 \\
\hline inventory turnover & 9.32 & 3.47 & 3.76 \\
\hline DSO & 74.16 & 78.84 & 79.56 \\
Evaluating Assets & & & \\
\hline fixed asset turnover & 1.94 & 1.51 & 1.73 \\
\hline total asset turnover & 0.91 & 0.90 & 0.93 \\
\hline Debt Management Ratios & & & \\
\hline debt ratio & 0.26 & 0.71 & 0.78 \\
\hline debt to equity & 0.35 & 2.49 & 3.58 \\
\hline times interest earned & 9.76 & 1.66 & 1.44 \\
\hline Profitability Ratios & & & \\
\hline profit margin on sales & 0.21 & 0.13 & 0.11 \\
\hline basic earning power & 0.26 & 0.19 & 0.20 \\
\hline return on assets & 0.19 & 0.12 & 0.11 \\
\hline return on equity & 0.26 & 0.41 & 0.48 \\
\hline
\end{tabular}

The company has gone through a major expansion over the last 3 years (fixed assets increased by almost $200 \%$ every year) which was financed largely by an increase in debt. This has resulted in increased sales, but at the same time decreased margins on sales. The company was lucky not to have been hit by higher interest costs. The company does not seem to use internal cash flow to finance investment sensibly (fixed assets increase but not as dynamically as the debt). The debt ratio moved from an unremarkable $26 \%$ to a much more danger- 
ous $71 \%$ and then $78 \%$. Overall impressions are that the company set up a very ambitious expansion plan, financed mainly by borrowing. However, it is lucky since demand is not slowing down. It should be able to operate successfully provided bad times do not come soon. They have to generate a lot of profit to reduce gearing. The company's profitability has not improved, even though the sales sky rocketed. ROE is the only ratio that grew significantly, but that was mainly due to more and more debt the company used to finance its operations. Thus, debt was used to increase the rate of return on equity.

Having analyzed the company's financial situation, we can make a set of assumptions for the next few years a savvy manager would make, being in the shoes of Tea.dot. Here is a set of assumptions for the most likely scenario. The country's economy is not booming any more and recession is much more likely, thus we can not expect sales to grow at more than $9 \%$ and then $5 \%, 2 \%$, over the next 3 years, and eventually no growth is expected. The debt has to be handled and the company should not take more long term loans. The quick ratio is definitely too high, as there is no point in having so much cash, although in this kind of business it may be justified to some extent. The company should try to be a bit more efficient and reduce administration costs and overheads to at most $30 \%$ of sales. Interest rates in the country will gradually fall which is in line with the recent tendency and the central bank's policy. The company should have a stable dividend policy.

\begin{tabular}{|c|c|c|c|c|c|c|}
\hline & Balancesheet & 1 & 2 & 3 & 4 & 5 \\
\hline 1 & Cash and cash equivalents & 7605 & 7453 & 6516 & 6516 & 10270 \\
\hline 2 & Accounts receivable & 11154 & 11712 & 11946 & 11946 & 11946 \\
\hline 3 & Inventory & 2028 & 2129 & 2172 & 2172 & 2172 \\
\hline 4 & Prepaid expenses & 2535 & 2662 & 2715 & 2715 & 2715 \\
\hline 5 & Current assets & 23322 & 23956 & 23349 & 23349 & 27103 \\
\hline 6 & Property and equipment & & & & & \\
\hline 7 & Property at cost & 35489 & 36199 & 36923 & 36923 & 36923 \\
\hline 8 & $\begin{array}{l}\text { Less accumulated } \\
\text { depreciation }\end{array}$ & -9065 & -12614 & -16234 & -19926 & -23618 \\
\hline 9 & $\begin{array}{l}\text { Net property } \\
\text { and equipment }\end{array}$ & 26425 & 23586 & 20690 & 16997 & 13305 \\
\hline 10 & Total assets & 49746 & 47541 & 44038 & 40346 & 40408 \\
\hline 11 & Accounts payable & 9126 & 9582 & 9774 & 9774 & 9774 \\
\hline 12 & Income taxes payable & 13 & 35 & 44 & 36 & 36 \\
\hline
\end{tabular}




\begin{tabular}{|c|c|c|c|c|c|c|}
\hline & Balancesheet & 1 & 2 & 3 & 4 & 5 \\
\hline 13 & Other current liabilities & 507 & 532 & 543 & 543 & 543 \\
\hline 14 & Current liabilities & 9646 & 10149 & 10361 & 10353 & 10353 \\
\hline 15 & Long-term debt & 23858 & 18175 & 11448 & 1988 & 0 \\
\hline 16 & Total liabilities & 33503 & 28324 & 21808 & 12341 & 10353 \\
\hline 17 & Common stock & 6243 & 6243 & 6243 & 6243 & 6243 \\
\hline 18 & Retained earnings & 10000 & 12974 & 15987 & 21762 & 23812 \\
\hline 19 & Stockholders' equity & 16243 & 19217 & 22230 & 28005 & 30055 \\
\hline 20 & Total liabilities and equity & 49746 & 47541 & 44038 & 40346 & 40408 \\
\hline
\end{tabular}

A complete set of assumptions now should be incorporated in a balance sheet and income statement and linked sensibly with the most recent financial documents. This is relatively easy.However, the main problem that is faced is that the balance sheet is not in balance automatically. Due to the new assumptions, almost all the components are changed. The common practice then is to use debt (for example short term debt) as a plug. It simply means that the difference between assets and liabilities that stems from the set of assumptions and the internal mechanics of the balance sheet lands in the debt entry. The issue seems technical, but it is crucial in the process of smooth preparation of a pro forma balance sheet. Let us go into the details.

In the simplified balance sheet above, long-term debt is an offset (plug). In the columns 1 to 4 , the assets and liabilities are in equilibrium, because debt (line 15) is given by the formula:

\section{Long - term debt = line 10 - line $14-$ line 19.}

The approach has a handicap - some of the liabilities (retained earnings for example) may grow to the extent that the debt (calculated according to the formula) becomes negative, which (in terms of accounting rules) is absurd.

The formula must be changed into the following:

$$
\text { Long }- \text { term debt }=\max (\text { line } 10-\text { line } 14-\text { line 19,0) . }
$$

Now the debt never becomes negative, but the assets and liabilities are still not in balance. The excess of money (from line 15) must be transferred (for example) to the cash and cash equivalents entry (line 1). The formula there must be altered too (f stands for the cash forecasted):

Cash $_{t}=\max \left(\right.$ line $20-$ line $9-$ line $2-$ line $3-$ line 4, cash $\left._{f}\right)$. 
In real life cases, we follow the same procedure, although the number of entries in the formulae is much larger. Once the pro forma financial documents are ready, the cash flows can be calculated according to the rule presented in Section 1.2. 


\section{Structure}

Structure, as used in this book, is understood as the capital structure which is the proportion in which a company is financed by equity and debt. What is directly related to the issue of structure is mergers and valuation of the company branches. An analysis of a company with respect to the options theory may also be helpful in the process of solving the riddle of company valuation. Before we go any further, let us once again consider the problem of changes in capital structure - the discussion will be complementary with the one from the previous chapter.

\subsection{How to determine the cost of capital.}

\subsubsection{Equity.}

Determining the cost of capital is a difficult task. Two aspects have to be taken into account: risk and a reference point (prospects for the future).

1. Risk has numerous components, the most important ones being:

a) Market risk

b) Operational risk

c) Financial risk

Market risk reflects general prosperity or lack of it. It is extremely difficult to succeed in a crisis while it is reasonably easy to conduct business during a bull market. High tide raises all the boats - as technicians tend to say.There are no good methods that may be used as a hedge against a global change affecting individual companies. This risk is partially captured by CAPM, according to which the required rate of return is given by the formula:

$$
k_{i}=r_{R F}+\beta_{i}\left(k_{M}-r_{R F}\right) \text {. }
$$

where $\mathrm{r}_{\mathrm{RF}}$ is risk-free rate of return, $k_{M}$ is the required rate of return on a market portfolio, and the beta coefficient is the measure of the contribution of a single as- 
set to the risk of portfolio. The idea is that the required rate of return as given by the formula will compensate investors for bearing that risk (as measured by beta).

Operational risk deals with the uncertainty of forecasting. Estimates of future prices of products, materials, levels of sales, or cost structure may be wrong, hence cash flows become random. Expected values of cash flows are used in budgeting, whereas information about the probability distribution (uncertainty) of the cash flows is reflected in the cost of capital.

Debt financing increases riskiness as a company faces fixed interest payments it has to incur, which in an extreme case may lead to bankruptcy. Quantitative relationships between the level of debt and the required rate of return for shareholders will be referred to later in Chapter 2.2.

2. Reference point and prospects for the future.

This reflects a simple observation that the required rate of return depends on the share price. The higher the share price is, the lower is the rate demanded by investors. For example, high profits generated by a company will be sooner or later reflected in its share price, and eventually cashed in by the shareholders, which may partially satisfy the shareholders' demands with regard to their rate of return. If the generated profits are initially low, due to, for example, weak expertise in a new field, or unexpected failures, the shareholders tend to raise their demand through a higher expected rate of return. The problem can be illustrated by the cost of capital formula (derived from Gordon's model):

The lower $S(0)$, the higher $k$ and vice versa. Div(1) represents (together with the growth factor g) prospects of the future profits and, if positive, increases $\mathrm{k}$. To be honest, the cost of capital derived from Gordon's model is usually interpreted as an expected rate of return, but on the other hand both notions: required and expected rates are inseparable. Most of the markets for most of the time are in equilibrium - the high expected rate of return inevitably becomes a high required rate of return too. Otherwise, this would lead to projects with positive NPVs, which is an anomaly in fact. It also coincides with the general idea of risk. High planned inflows are typically riskier than lower ones and a drop in a share price signals higher risk.

\subsubsection{Structure - basics}

Finding factors that are immanently important is the key to a successful analysis of company's value with respect to its capital structure. Cash that is generated by a company finds its way to one of three groups:

- shareholders 
- debt holders

- government

The cash flows can be denoted as:

- dividends

- interest payments

- tax payments

The present value of the cash flows will be denoted as:

- E

- D

- $\mathrm{G}$

The sum of the three gives an amount that is not affected by either the level of tax, or changing proportions between equity and debt. If the tax rates are altered (the government changes its fiscal policy), a different proportion of profits generated by a company goes to the government. If the tax rate is increased, the first two groups will receive less, but the total amount will not change. The change in capital structure will influence the amount of paid tax, because debt is closely related to the tax shield. Tax shield is a result of a law that enables companies to deduct interest before calculating the amount of tax owed. Thus, the higher the debt is, the lower the tax to be paid. The sum of the three streams of cash flows is constant, but the change in one component is likely to affect the other two. Let us denote the sum as $V_{T}$ (total):

$$
V_{t}=D+E+G .
$$

The value of equity is the present value of cash flow for shareholders (CF), and tax payments (TP) are (we temporarily ignore depreciation and assume that the level of debt does not change):

$$
T P=\left(E B I T-k_{D} D\right) \times T .
$$

We already know that:

$$
C F=\left(E B I T-k_{D} D\right)(1-T) .
$$

This implies:

$$
\mathrm{TP}=\frac{T}{1-T} C F \text {. }
$$

The same is true as far as the present values of dividends, $C F$ and tax payments are concerned (assuming perpetuities). $G$ in the formula below is the present value of tax payments and $E$ is the present value of cash flows. 


$$
G=\frac{T}{1-T} E .
$$

The formula for the total value of a company can be rewritten as follows:

$$
V_{t}=D+E\left(1+\frac{T}{1-T}\right)=D+E \frac{1}{1-T} \text {. }
$$

Let us suppose now that we are dealing with an unleveraged (hence subscript $u$ ) company, devoid of the tax shield effect. The value of such a company can be shown as the sum of two components: the value of equity (no debt) and the value of tax payments (no tax shield):

$$
V_{t}=V_{u}+G_{u} .
$$

The values are given by:

$$
\begin{aligned}
& F C F=E B I T(1-T), \\
& \mathrm{TP}_{\mathrm{u}}=E B I T \times T .
\end{aligned}
$$

This implies:

$$
T P_{u}=F C F \frac{T}{1-T} .
$$

The same is true with regard to the present values (assuming perpetuities):

$$
G_{u}=V_{u} \frac{T}{1-T} .
$$

The relationships yield the following:

$$
V_{t}=V_{u}+V_{u} \frac{T}{1-T}=V_{u} \frac{1}{1-T} .
$$

Please note that a change in $\mathrm{T}$ does affect $\mathrm{Vu}$, since it does not affect the total value of a company. A comparison of the two formulae for the total value of a company generates the following:

$$
D+E \frac{1}{1-T}=V_{u} \frac{1}{1-T} .
$$

Hence:

$$
D(1-T)+E=V_{u} .
$$

Let us denote the cost of capital of an unleveraged company (financed by debt only) by ku. From the portfolio theory we get the following important relationship: 


$$
k_{u}=k_{D} \frac{D(1-T)}{V_{u}}+k_{E} \frac{E}{V_{u}} .
$$

The cost of capital does not depend (by definition) on the level of debt, so it is assumed that it is not related to any changes in the capital structure either. Debt, cost of equity, and equity will change in a way that the right side of the formula is unaffected.

Whenever the capital structure changes, the cost of debt, equity, and obviously the value of equity and debt will change too. For simplicity, let us assume that the cost of debt remains the same. The formula may be now rewritten with respect to the cost of equity:

$$
k_{E}=k_{U}+\frac{D(1-T)}{E}\left(k_{U}-k_{D}\right) .
$$

There is a slight problem with applying the formula to real life calculations. It gives us some idea of how $\mathrm{E}$ affects the cost of equity, but on the other hand the very cost of capital is needed to determine the value of equity. However, we went through the chore of solving many such problems (logical loops) in the previous chapter.

It is worth emphasizing that in the case of a company that is partly financed by debt, the value of the company $(\mathrm{D}+\mathrm{E})$ is bigger than the value of the company that is financed by equity only $\left(V_{u}\right)$. The difference can be attributed to the tax shield effect. For a perpetuity, it is $T D$ (a product of tax rate and the value of debt).

The formulae developed so far in this section were obtained for perpetuities. Still, they are precise enough for any other situations and are widely used in literature. Even more precise solutions can be found in M.Capinski, "A New Method of DCF Valuation", Nowy Sacz Academic Review, 2005/2 - they are based on the same idea: cash flows that flow to the government, shareholders and debt holders. Using a spreadsheet and the "goal seek" tool makes it easy to find the final values, whereas an analytic formula, though possible to derive, would be very complicated. Here we only present the solution for a singleperiod case.

The crucial relationship is concerned with two ways of decomposing the total value of the firm (which is the present value of the total generated cash). The company may contribute to debt holders, shareholders and the government and on the other hand to shareholders and the government in a hypothetical situation of an unleveraged firm with the same operations:

$$
V_{\text {total }}=D+E+G=V_{u}+G_{u} .
$$


We then compute the value of all components at time $t$ on the basis of known expected cash flows and the values at the end of year $t+1$. For notational simplicity we set $t=0$ and the general relationship is as before:

$$
V_{t}(0)=D(0)+E(0)+G(0)=V_{u}(0)+G_{u}(0) .
$$

We assume that the cost of debt $k_{D}(0)$ and the cost of an unleveraged company $k_{u}(0)$ are given. The formula for the cost of equity $k_{e}(0)$ will be derived below. We assume that the values $V_{t}(1), D(1), E(1), \mathrm{G}(1), \mathrm{V}_{\mathrm{u}}(1), \mathrm{G}_{\mathrm{u}}(1)$ are known.

We identify some groups of cash flows at the end of year one, including:

1. $\mathrm{C}_{\mathrm{t}}(1)$ - the total cash flow composed of the cash generated by the company together with the terminal value $\mathrm{V}_{\mathrm{t}}(1)$, discounted by $\mathrm{k}_{\mathrm{u}}(0)$ and giving $\mathrm{V}_{\mathrm{t}}(0)$,

2. $C_{D}$ - the cash for debt holders composed of the interest, change of debt, and the value of debt $D(1)$, discounted atk $\mathrm{D}_{\mathrm{D}}(0)$,

3. $\mathrm{C}_{\mathrm{e}}$ - the cash for the shareholders composed of the cash flow at the end of the year and the value $E(1)$, discounted by $\mathrm{k}_{\mathrm{E}}(0)$,

4. $\mathrm{C}_{\mathrm{G}}$ - the cash for the government (taxes) including the value $G(1)$ also discounted by $k_{E}(0)$ (the taxes are proportional to the cash flow to the shareholders so the returns are the same and so is the risk).

The inclusion of the terminal value in the cash available is justified since, for instance, the shareholders can sell the shares and debt holders can sell the bonds, except for the government that is regarded as an investor in an abstract sense.

Application of the basic idea of portfolio theory, regarding the company as a portfolio of debt, equity and government, results in the following relationship:

$$
\frac{C_{D}(1)}{1+k_{D}(0)}+\frac{C_{E}(1)+C_{G}(1)}{1+k_{E}(0)}=\frac{C_{t}(1)}{1+k_{u}(0)} \text {. }
$$

In this formula the only unknown quantity is the cost of equity $\left(\mathrm{k}_{E}\right)$, and so it can be calculated.

To complete the analysis, it is now sufficient to give the formulae for the numerators as:

$$
\begin{aligned}
C_{D}(1)= & k_{D}(0) \times D(0)+D(1)+(D(0)-D(1)) \\
C_{E}(1)= & E(1)+G(1)+\left(E B I T(1)-k_{D}(0) \times D(0)\right) \times(1-T) \\
& +(D(1)-D(0))-\operatorname{Investment}(1)+\text { Depreciation }(1) \\
C_{G}(1)= & G(1)+\left(E B I T(1)-k_{D}(0) \times D(0)\right) \times T \\
C_{t}(1)= & E B I T(1)-\operatorname{Investment}(1)
\end{aligned}
$$

In the example below, we limit ourselves to showing the perpetuity case. 


\section{Example 16.}

A company expects EBIT of 60 every year. The company is financed by debt of 100 , and the cost of debt is $6 \%$ (perpetuity too). The tax rate is $30 \%$. We assume that the depreciation each year is at the same level as the capital investment. We inquire about the cost of equity and capital structure.

Calculating cash flows is quite straightforward:

$$
\begin{aligned}
& F C F=E B I T \times(1-T)+\text { correction. } \\
& C F=\left(E B I T-k_{D} \times D\right) \times(1-T)+\text { correction }+\Delta \mathrm{D} . \\
& F C F=(1-30 \%) \times 60=42 \\
& C F=(60-6 \% \times 100) \times(1-30 \%)=37.8 .
\end{aligned}
$$

\section{Given equity}

The value of equity may be estimated if the company is listed on a stock exchange. Suppose the value of equity is:

$E=300$.

Then, from Gordon's model ( $E$ is equivalent to $S(0)$, zero growth) we get:

$$
\begin{aligned}
& S(0)=\frac{\operatorname{Div}(1)}{k-g} . \\
& k_{E}=12.60 \% .
\end{aligned}
$$

We also receive the financial structure:

$$
\begin{aligned}
& \frac{D}{D+E}=\frac{100}{400}=25 \% \\
& \frac{E}{D+E}=\frac{300}{400}=75 \% .
\end{aligned}
$$

Both, the rate of return and the value of the unleveraged company can be calculated: 


$$
\begin{aligned}
& k_{u}=\frac{k_{D} D(1-T)+k_{E} E}{D(1-T)+E}=11.35 \% . \\
& V_{u}=\frac{F C F}{k_{u}}=E+D(1-T)=370 .
\end{aligned}
$$

We can also compute WACC and then find independently the value of the company:

$$
\begin{aligned}
& W A C C=10.50 \% \\
& D+E=\frac{F C F}{W A C C}=400 .
\end{aligned}
$$

The difference (30) stems from the fact that the company uses financial leverage and hence it is the present value of the tax shield.

\section{Given cost of equity}

Let us suppose the cost of equity (12\%) was found using CAPM. The value of equity (divide CF by $k_{E}$ ) and the financial structure can now be easily determined:

$$
\begin{aligned}
& E=315 \\
& \frac{D}{D+E}=\frac{100}{415}=24,1 \% \\
& \frac{E}{D+E}=\frac{315}{415}=75.9 \% .
\end{aligned}
$$

Next, both the cost of capital and the value of an unleveraged company can be found:

\section{Given the cost of capital of an unleveraged company}

Let us supposeku can be estimated (11\%) for example as a result of a comparison with another company that is equity financed or historical data was used for that purpose. Then:

$$
\begin{aligned}
& V_{u}=\frac{F C F}{k_{u}}=381.82 \\
& E=V_{u}-D(1-T)=311.82 \\
& k_{E}=\frac{C F}{E}=12.12 \% .
\end{aligned}
$$




\subsection{Change of capital structure}

The change of capital structure may be a result of a number of different events such as: issuing new stock, taking or paying off a loan, or stock repurchase. The key problem is to assess how restructuring may affect the costs of capital, the value of the company and equity in particular. The change may also be caused by some alterations in share prices or debt which may result from undertaking certain investment projects.

\subsubsection{Perpetuity}

The usual practice is to begin with analyzing a company, whose profits (EBIT) are in the form of a perpetuity. The question posed here is how changes in capital structure influence the value of a company.

\section{Example 17.}

Company Wardrobe Ltd.: EBIT is 200 every year and we assume that the depreciation each year is at the same level as the capital investment. The company pays $30 \%$ corporate income tax. The initial capital structure is made up of $50 \%$ debt financing, at a cost of $10 \%$. The cost of equity is $16.8 \%$. Raising the debt share to $60 \%$ (or lowering it to $40 \%$ ) is being considered.

We can easily calculate all the elements in the valuation scheme that have been developed so far. Let us find the costs of capital:

$$
\begin{aligned}
& k_{u}=14 \% \\
& W A C C=11.90 \%,
\end{aligned}
$$

and the value of the company, then equity and debt (according to the implied capital structure):

$$
\begin{aligned}
& V=D+E=\frac{140}{11.90 \%}=1176.47 \\
& D=E=588.24 .
\end{aligned}
$$

We know already that using a direct valuation method will generate the same result, as shown below:

$$
E=\frac{\left(E B I T-k_{D} \times D\right)(1-T)}{k_{E}}=\frac{(200-58.82) \times(1-30 \%)}{16.80 \%}=\frac{98.82}{16.80 \%}=588.24 .
$$


The main assumption is:

The cost of capital does not change when the financial structure is altered.

An analogy which justifies this assumption is that the efficiency of the equipment used in the production process is not related to the kind of money (debt or equity) used to buy it. It will affect the cash flows and then indirectly the value of the equipment though.

\section{Increasing debt to $60 \%$}

The assumption that the cost of debt remains at the same level is made, and yet we know that if the increase in the level of debt is dramatic, the assumption may turn out to be false. The increased level of debt is needed for stock repurchase. What follows (according to the formula below) is an increased risk for the rest of the shareholders:

$$
k_{E}=k_{u}+\frac{w_{D}}{w_{E}}(1-T)\left(k_{u}-k_{D}\right) .
$$

The new financial structure changes the weights and gives us the following:

$$
k_{E}=14 \%+\frac{60 \%}{40 \%}(1-30 \%)(14 \%-10 \%)=18.20 \% \text {. }
$$

The new WACC can also be calculated:

$$
W A C C=60 \% \times 10 \% \times(1-30 \%)+40 \% \times 18.20 \%=11.48 \% .
$$

It is lower than the one calculated for the initial (50/50) capital structure (11.90\%), so the value of the company grows:

$$
\begin{aligned}
& V=\frac{140}{11.48 \%}=1219.51 \\
& D=60 \% \times V=731.71 \\
& E=40 \% \times V=487.80 .
\end{aligned}
$$

Once the debt is known, the income statement can be drawn up and CF can be found:

$$
C F=\left(E B I T-k_{D} \times D\right)(1-T)=88.78
$$


If we discount $\mathrm{CF}$, we end up with the same value of equity as above:

$$
E=\frac{C F}{k_{E}=487.80} .
$$

The value of equity has predictably fallen, and so has the share price (assume there are 50 shares in circulation):

$$
\mathrm{P}=588.24 / 50=11.76 .
$$

One may be gullible enough to think that we should purchase 10 shares since the proportion of equity has fallen from $50 \%$ to $40 \%$, but it is misleading. Let us first find out the incremental increase of debt:

$$
731.71-588.24=143.47 \text {. }
$$

It is exactly the amount we have at our disposal in order to buy back the shares (at the current price of 11.76). Thus, we can buy back the following number of shares:

\section{$143.47 / 11.76=12.20$ shares}

It is a fraction, but the problem is negligible - it is good enough to assume that there are actually 50 million shares. The share price after the change in capital structure (we divide the new value of equity by the remaining number of shares) is:

$$
487.80 / 37.80=12.90 .
$$

Surprisingly enough, the share price has grown from 11.76 to 12.90 , the only reason being the change in the financing structure. This case shows the benefits from keeping an optimal capital structure. By the way, companies often have other reasons to buy back their own shares, for example, it is a way to boost the share price after it has been stagnant for some time.

\section{Lowering debt to $40 \%$}

In this case, some new stock is issued in order to pay off a part of the loan and diminish the loan's share in the financial structure to $40 \%$. Since the cost of capital is already known (14\%), all we need is the cost of equity and then the new WACC (in the new capital structure):

$$
\begin{aligned}
& k_{E}=k_{u}+\frac{40 \%}{60 \%}(1-30 \%)\left(k_{u}-k_{D}\right)=15.87 \% \\
& W A C C=12.32 \% .
\end{aligned}
$$


Next, the new value of the company (FCFs are discounted), and the values of debt and equity (compliant with the new 40/60 capital structure) are found:

$$
\begin{aligned}
V & =\frac{F C F}{W A C C}=\frac{140}{12.32 \%}=1136.36 \\
D & =454.55 \\
E & =681.82 .
\end{aligned}
$$

Debt is reduced by 133.69 . Another question that needs urgent answering is the price at which the new stock should be issued. The shareholders will have access to the cash flows after the change, and consequently the share price should change as well. We face another logical loop: the new price is needed to calculate the number of shares to issue, and the number is necessary in order to set the new price. One way to solve the problem is to solve a system of equations, where $\mathrm{C}$ is the new share price and $\mathrm{N}$ is the number of shares after the change:

$$
\begin{aligned}
& C=\frac{681,82}{N} . \\
& \frac{133.69}{C}=N-50 .
\end{aligned}
$$

The solutions are as follows:

$$
\begin{aligned}
& N=62.20 \\
& C=10.96 .
\end{aligned}
$$

A numerical solution using iterations is also a possible approach.

\subsubsection{Company as a project}

This case presents a situation in which a company undertakes an investment project that affects its capital structure, cost of capital and eventually its value. Hypothetically, the company is reduced to the project itself, where it begins to carry out the project and closes after a few years, when the project is complete. The change in capital structure is inevitable when a new project is undertaken. This time the project (to remain realistic) cannot be reduced to a perpetuity - different cash flows have to be allowed in different time periods; what follows is the fluctuation in the value, structure and cost of capital. The assumption that the cost of capital is constant throughout the life of a project is unrealistic too. Debt would have to be constantly adjusted so the capital structure is kept as planned. In practice, there are many technical restrictions concerned with issuing new debt, new stock, huge volatility of the share prices due to changes in interest rates, risk, etc. This makes the process undoable. 
In the example below the level of debt, not the capital structure, will be given every year.

\section{Example 18.}

Beginning an operation requires an investment of 120 . The company takes 60 of debt, and the remaining part is financed by shareholders. The debt (principal) is going to be paid off in equal installments (over the course of three years). A straight depreciation system is used. The company forecasts operational profits (OP) of 60, 80,70 at the end of the three years. Then, the operation is terminated (assets have zero salvage value). The cost of debt $=6 \%$, cost of the company (unleveraged) $=11 \%$, and $\mathrm{T}=30 \%$.

Let us begin with finding the cash flows (FCF) for the three consecutive years. This requires deducting depreciation and tax payments, and then adding back depreciation.

\begin{tabular}{|lrcr|}
\hline & 1 & 2 & 3 \\
\hline OP & 60.00 & 80.00 & 70.00 \\
\hline Depreciation & 40.00 & 40.00 & 40.00 \\
\hline EBIT & 20.00 & 40.00 & 30.00 \\
Tax & 6.00 & 12.00 & 9.00 \\
\hline EAT & 14.00 & 28.00 & 21.00 \\
FCF & 54.00 & 68.00 & 61.00 \\
\hline
\end{tabular}

In order to determine cash flows to the shareholders, we are also required to additionally deduct interest payments and take into account the level of debt. The debt diminishes at the pace of 20 every year, so the correction requires us to add the depreciation of 40 and deduct the change in debt of 20.

\begin{tabular}{|lrrr|}
\hline & 1 & 2 & 3 \\
\hline OP & 60.00 & 80.00 & 70.00 \\
Depreciation & 40.00 & 40.00 & 40.00 \\
EBIT & 20.00 & 40.00 & 30.00 \\
Interest & 3.60 & 2.40 & 1.20 \\
\hline
\end{tabular}




\begin{tabular}{|lrrr|}
\hline & 1 & 2 & 3 \\
\hline EBT & 16.40 & 37.60 & 28.80 \\
Tax & 4.92 & 11.28 & 8.64 \\
\hline EAT & 11.48 & 26.32 & 20.16 \\
CF & 31.48 & 46.32 & 40.16 \\
\hline
\end{tabular}

As suspected, the valuation will be recursive. We will start with finding the value of the company in the final year and then go backwards. The values at the end of year 2 can be found in two ways: either $C F s$ are discounted at the cost of equity, or $F C F$ s are discounted at WACC. The problem lies in a loop: the costs of capital determine the value, the value determines structure, but the structure needs values as inputs. We have already gone through such calculations. For the cost of equity calculations, the following formula is to be used:

$$
k_{E}=k_{u}+\frac{D(1-T)}{E}\left(k_{u}-k_{D}\right) .
$$

Below are the results for the CF-based method and the FCF-based method at the end of year 2 :

\section{CF-based method}

\begin{tabular}{|cc|}
\hline $\mathrm{D}$ & 20.00 \\
$\mathrm{E}$ & 35.55 \\
$\mathrm{~V}$ & 55.55 \\
$\mathrm{k}_{\mathrm{D}}$ & $6.00 \%$ \\
$\mathrm{k}_{\mathrm{E}}$ & $12.97 \%$ \\
$\mathrm{k}_{\mathrm{u}}$ & $11.00 \%$ \\
\hline
\end{tabular}

FCF-based method

\begin{tabular}{|lc|}
\hline $\mathrm{V}$ & 55.55 \\
\hline $\mathrm{D}$ & 20.00 \\
$\mathrm{E}$ & 35.55 \\
\hline $\mathrm{k}_{\mathrm{D}}$ & $6.00 \%$ \\
$\mathrm{k}_{\mathrm{E}}$ & $12.97 \%$ \\
$\mathrm{k}_{\mathrm{u}}$ & $11.00 \%$ \\
\hline WACC & $9.81 \%$ \\
\hline
\end{tabular}


Let us proceed to another year. At the end of year 1, proper CFs (or FCFs) and previously calculated values of equity or company are discounted. For example:

$$
E_{1}=\frac{46.32+35.55}{1+12.93 \%} \text {. }
$$

Below are the results for the CF-based method and the FCF-based method at the end of year 1 :

\section{CF-based method}

\begin{tabular}{|ccc|}
\hline $\mathrm{D}$ & 40.00 & 20.00 \\
$\mathrm{E}$ & 72.50 & 35.55 \\
$\mathrm{~V}$ & 112.50 & 55.55 \\
$\mathrm{k}_{\mathrm{D}}$ & $6.00 \%$ & $6.00 \%$ \\
$\mathrm{k}_{\mathrm{E}}$ & $12.93 \%$ & $12.97 \%$ \\
$\mathrm{~K}_{\mathrm{U}}$ & $11.00 \%$ & $11.00 \%$ \\
\hline
\end{tabular}

\section{FCF-based method}

\begin{tabular}{|lcc|}
\hline $\mathrm{V}$ & 112.50 & 55.55 \\
$\mathrm{D}$ & 40.00 & 20.00 \\
$\mathrm{E}$ & 72.50 & 35.55 \\
\hline $\mathrm{k}_{\mathrm{D}}$ & $6.00 \%$ & $6.00 \%$ \\
$\mathrm{k}_{\mathrm{E}}$ & $12.93 \%$ & $12.97 \%$ \\
$\mathrm{~K}_{\mathrm{U}}$ & $11.00 \%$ & $11.00 \%$ \\
$\mathrm{WACC}$ & $9.83 \%$ & $9.81 \%$ \\
\hline
\end{tabular}

Please note that the values of both costs of capital in use are changed and so is the capital structure. The reference point for the calculations are $\mathrm{ku}, k_{E}$ and the relationship (with the current $D$ and $E$ values) is:

$$
k_{E}=k_{u}+\frac{D(1-T)}{E}\left(k_{u}-k_{D}\right) .
$$

Let us proceed to finding the present value. The procedure as above is repeated. 


\section{CF-based method}

\begin{tabular}{|cccc|}
\hline & 0 & 1 & 2 \\
\hline $\mathrm{D}$ & 60.00 & 40.00 & 20.00 \\
$\mathrm{E}$ & 91.78 & 72.50 & 35.55 \\
$\mathrm{~V}$ & 151.78 & 112.50 & 55.55 \\
\hline $\mathrm{k}_{\mathrm{D}}$ & $6.00 \%$ & $6.00 \%$ & $6.00 \%$ \\
\hline $\mathrm{k}_{\mathrm{E}}$ & $13.29 \%$ & $12.93 \%$ & $12.97 \%$ \\
$\mathrm{k}_{\mathrm{u}}$ & $11.00 \%$ & $11.00 \%$ & $11.00 \%$ \\
\hline
\end{tabular}

\section{FCF-based method}

\begin{tabular}{|lccc|}
\hline & 0 & 1 & 2 \\
\hline $\mathrm{V}$ & 151.78 & 112.50 & 55.55 \\
$\mathrm{D}$ & 60.00 & 40.00 & 20.00 \\
$\mathrm{E}$ & 91.78 & 72.50 & 35.55 \\
$\mathrm{k}_{\mathrm{D}}$ & $6.00 \%$ & $6.00 \%$ & $6.00 \%$ \\
$\mathrm{k}_{\mathrm{E}}$ & $13.29 \%$ & $12.93 \%$ & $12.97 \%$ \\
$\mathrm{~K}_{\mathrm{U}}$ & $11.00 \%$ & $11.00 \%$ & $11.00 \%$ \\
\hline WACC & $9.70 \%$ & $9.83 \%$ & $9.81 \%$ \\
\hline
\end{tabular}

The present value of equity is then obtained by discounting the appropriate cash flows at the different cost of capital for each year.

$E_{0}=\frac{31.48}{1+13.29 \%}+\frac{46.31}{(1+13.29 \%)(1+12.93 \%)}+\frac{40.16}{(1+13.29 \%)(1+12.93 \%)(1+12.97 \%)}=91.78$.

Similar calculations can be performed for the value of the company by discounting FCFs at WACC.

The valuation can be easily applied to a company whose life span is infinite (growing perpetuity after a period of dynamic growth). Then, the residual value (the infinite tail of cash flows that follows the horizon date) must be incorporated at the end of the last finite period.

Finally, it is interesting to see how the $A P V$ method copes with this case. The value of the company (unleveraged) is first calculated (FCFs are discounted at $k_{u}$ ) and then compared with the values obtained so far. 


\begin{tabular}{|lrrr|}
\hline $\mathrm{V}$ & 151.78 & 112.50 & 55.55 \\
$\mathrm{Vu}$ & 148.44 & 110.77 & 54.95 \\
\hline PVTS & 3.34 & 1.72 & 0.59 \\
\hline
\end{tabular}

The present value of the tax shield is the difference between $V_{u}$ and $V$. Interestingly enough, the same amounts can be obtained by discounting $k_{u} x D x T$ at $k_{u}$.

\subsection{Applying options}

There are sophisticated models of a company's financial structure based on derivatives, namely options. Let us consider a company that is financed partly by debt. The debt has a form of a zero-coupon bond with one year maturity $T$. The nominal value of the bond is denoted by $F$. It means that shareholders are obliged to pay $F$ to the debt holders at time $T$, otherwise the company goes under. Let us denote the value of a company at time $T$ by $V(T)$. Once the debt is paid off (on the condition that the value of the company exceeds $F$ ), the shareholders are left with $V(T)-F$. Otherwise, the company goes bankrupt and will be taken over by the debt holders. Here is a set of possible scenarios of what the shareholders get:

$$
\left\{\begin{array}{cc}
V(T)-F & \text { if } V(T)>F \\
0 & \text { if } V(T) \leq F
\end{array} .\right.
$$

It resembles payoffs of a call option. Hence, the present value of equity is the same as a call premium. Shareholders have the right, but not obligation, to buy back the company (from a bank or debt holders) at the nominal price of debt. Another option-related concept that might be useful is a put call parity:

$$
C-P=S(0)-K e^{-r T},
$$

where $\mathrm{S}(0)$ is the present value of the underlying instrument, $C$ and $P$ are call and put premiums respectively, $K$ is the strike price, and $r$ is a risk free rate of return. The value of the underlying instrument is then:

$$
S(0)=C+K e^{-r T}-P .
$$

There are obvious analogies with the value of the company, where the underlying instrument represents the value of company $V(0)$, known as: 
$V(0)=E+D$.

and a call option represents equity:

$$
\begin{aligned}
& V(0)=S(0) \\
& E=C .
\end{aligned}
$$

Both are entered into the put call parity and yield:

$$
V(0)=E+F e^{-r T}-P \text {. }
$$

The present value of debt can be found as:

$$
D=F e^{-r T}-P .
$$

If there is no risk (the value of the company exceeds $F$ at $T$ ), the call option is worthless and the value of debt is represented by $F$. If there is some risk involved, the value of the debt is decreased by the value of the put premium. In a nutshell, it is possible that a bank will never recover the money loaned to the company, and the bank's exposure seems bigger than the value of assets. If the option is deep in-the-money and volatility low, the value of the put is little.

In this context, the validity of Miller-Modigliani proposition (MM argue that in a world without taxes, both the value of a firm and its WACC would be unaffected by its capital structure) is worth emphasizing. It can be easily proved that the right side of the equation below does not depend on $\mathrm{K}$.

$$
S(0)=C+K e^{-r T}-P .
$$

At first sight, it seems ridiculous since $K$ is obviously there. However, there is no contradiction because both put and call premiums change together with the value of $K$ and the changes balance each other out.

Seeing that the values of both options grow with risk, we are able to explain the often observed conflict between shareholders and debt holders. The former can be interested in carrying out risky projects, since it results in increased equity value at the expense of the value of debt ( $P$ grows too). Here is a short illustration of this scenario.

Suppose a company is close to bankruptcy. At a nominal debt of 100, the value of the company is below this number. Still, there is a chance to avoid bankruptcy, since the debt is to be paid off in one year's time. The owners have the following scenarios to choose from:

1. To operate safely. The result of this is that the value of the company at time $\mathrm{T}$ will reach 110 . At maturity the shareholders are left with 10 . If the present value of debt is 100 , then at a $10 \%$ risk free rate of return, the value of debt will reach $100 \mathrm{e}^{-10 \%}=90.48$, and the value of equity is 9.52 . 
2. To take extreme risk. The risky activities are represented by two possibilities: the value of the company may be 50 or 150 at the end of the year, both with a $50 \%$ probability. Then, the company will either go bankrupt (making debt holders very unhappy since then they will receive only half of the money due), or survives and then shareholders get 50. Thanks to the call option, the expected value for the shareholders is significantly higher than in scenario 1.

The risky scenario may mean accepting a negative NPV project, which in turn means a deterioration in the value of the company (high risk is reflected in the high cost of capital, which lowers NPV). And yet, in spite of accepting bad projects, the value of the company may skyrocket. Let us analyze a numerical example.

Let us suppose a company is worth 100 today (out of which 80 can be allocated to a risky project). The expected cash flows at the end of the year are 100. When the cost of capital is higher than $25 \%$, it clearly means a negative NPV. If we let the cost of capital be $30 \%$, then:

$$
N P V=-80+100 e^{-30 \%}=-5.92 \text {. }
$$

(we use continuous compounding to be in line with put call parity) and the value of the company is 94.08 . The value of equity can be represented as the present value of expected cash flows:

$$
25 e^{-30 \%}=18.52 .
$$

Debt holders are left with 71.96. Let us compare the result with the safe scenario: the value of the company has dropped, while at the same time the value of equity has gone up (at the expense of debt holders though).

It is worth mentioning that the above is the structural approach to credit risk estimation in the simplest possible case. It may also be, and often is, the starting point for creating software used by the financial industry to value equity. 


\subsection{Branches}

We will consider a company that has a few branches specializing in very different fields. We will inquire about the cost of capital and related problems: the value of branches and the value of the company.

\subsubsection{Branches - cost of capital}

Suppose that a company conducts operations in two fields (hardware and software). Quite naturally questions appear about the cost of capital for each of the branches and the company. The risk of creating software and the risk of producing hardware are not identical, and hence the costs of capital should differ too. On the other hand all the financing is provided by the company, so the notion of the cost of capital is viewed only with respect to the whole company.

We will restrict ourselves to two branches only for simplicity's sake, but the same method could be used for many more. The method is based on CAPM. Let us start with a general property: if portfolio $P$ is composed of two assets $A$ and $B$ in proportion given by the weights:

$w_{A}, w_{B}, w_{A}+w_{B}=1$,

then, the simple formula for the beta of portfolio can be applied:

$\beta_{P}=w_{A} \beta_{A}+w_{B} \beta_{B}$.

Let us denote the betas of the branches (the ones which we are searching for) by $\beta_{I A}, \beta_{2 A}$. A stands for assets and underlies the fact that the focus is on estimating the risk of the operational activity.

Suppose that market data can be used to determine betas of similar (in terms of size, market position, and market share) companies. If we deal with companies traded on a stock exchange, we have to be aware of the fact that we actually found their equity betas, $\beta_{E}$. Betas of the assets can be found from the relationship below (assume $\beta_{D}=0$ ):

$$
\beta_{A}=\frac{D}{D+E} \beta_{D}+\frac{E}{D+E} \beta_{E} .
$$




\section{Example 19.}

Suppose that (based on data from a stock exchange) the betas of two companies (twins of our two branches) are found (by running linear regressions). They are 1.2 and 0.8 for companies 1 and 2 respectively. The companies are financed by debt at $20 \%$ and $30 \%$ respectively.Their beta of debt is 0.1 .

Betas of assets can be calculated:

$$
\begin{aligned}
& \beta_{1 A}=20 \% \times 0.1+80 \% \times 1.2=0.98 \\
& \beta_{2 A}=30 \% \times 0.1+70 \% \times 0.8=0.59
\end{aligned}
$$

The betas can also be found in a different way: ROA of the branch can be used as a proxy of the branch's returns and regressions can be run between the ROAs and market returns.

Now, CAPM can be followed to find the costs of capital for both branches:

$$
\begin{aligned}
& k_{1 A}=k_{R F}+\beta_{1 A}\left(k_{M}-k_{R F}\right) \\
& k_{2 A}=k_{R F}+\beta_{2 A}\left(k_{M}-k_{R F}\right)
\end{aligned}
$$

Suppose the risk free rate of return is $6 \%$, and market premium is $8 \%$. Then:

$$
\begin{aligned}
& k_{1 A}=13.84 \% \\
& k_{2 A}=10.72 \% .
\end{aligned}
$$

The next step is to find the beta and the cost of capital that reflect operational activity of the company: $\beta_{A}, k_{A}$. The formula for the beta of portfolio can be applied:

$$
\beta_{A}=w_{1} \beta_{1 A}+w_{2} \beta_{2 A},
$$

where the weights correspond to each branch's contribution to the company's financial standing. The weights can be based on book values (sales, operational profit), but comparing present value of expected cash flows seems to be more adequate (at the branch level, without interest and tax payments). 


\subsubsection{Branches - value.}

Valuation of branches does not differ from the company valuation. The task is as difficult as before. First, future cash flows have to be determined, using historical data as the starting point, but then some extraordinary events and projects to be undertaken by the branch have to be considered. Volatility due to the changing market prosperity is already included in the cost of capital.

For example, it is possible to take operational profit from the previous year, separate for each of the branches, as the base for planning profits. The growth rate must be estimated based on either historical data or prospect of the economy growth for the specific industry in particular. Then, the time horizon has to be determined. Dynamic growth (if predicted) cannot last too long; the period of a few years can be split into a fast growth (acquiring new markets) and stable growth phases (natural growth of the market). Generally, an infinite life span for each of the branches is assumed, with the tail of cash flows beyond the horizon date represented by a growing perpetuity. Still, we are not in the position to find out how the capital structure affects the value of each of the branches.

\section{Example 20.}

Operational profits of 400 and 300 are predicted at the end of the year, and growth rate is $3 \%$ for both branches. The cost of capital is $11 \%$ and $15 \%$ respectively. The company pays $30 \%$ tax. Depreciation is ignored.

The value of growing perpetuities is as follows:

$$
\begin{aligned}
& V_{1}=\frac{280}{11 \%-3 \%}=3500 \\
& V_{2}=\frac{210}{15 \%-3 \%}=1750 .
\end{aligned}
$$

These numbers help to determine the value of the company $(V=5250)$ and each branch's share:

$$
\begin{aligned}
& w_{1 A}=\frac{2}{3} \\
& w_{2 A}=\frac{1}{3} .
\end{aligned}
$$

Now, the cost of capital of company can be calculated:

$$
k_{A}=\frac{2}{3} \times 11 \%+\frac{1}{3} \times 15 \%=12.33 \% \text {. }
$$


The value of the company can be calculated again (the 3\% growth rate is the same for each branch, so it applies to the whole company as well):

$$
V=\frac{490}{12,33 \%-3 \%}=5250 \text {. }
$$

Allowing different growth rates for each of the branches makes the situation much more complicated, but more realistic too (different industries may naturally grow at a different rates).

\section{Example 21.}

Suppose that the growth rate of the second branch is $5 \%$ instead of $3 \%$ (as before). The growth of the first branch remains at $3 \%$.

The value of the second branch is found (the branch is still financed by equity only):

$$
V_{2}=\frac{210}{15 \%-5 \%}=2100 .
$$

then the value of the company $\mathrm{V}=5600$, new weights, and the cost of capital become:

$$
\begin{aligned}
& w_{1 A}=62.50 \% \\
& w_{2 A}=37.50 \% \\
& k_{A}=62.50 \% \times 11 \%+37.50 \times 15 \%=12.50 \% .
\end{aligned}
$$

Here is an attempt to set the growth rate for the whole company. The first step is to find the profits in the consecutive years. After the first year we get:

$$
\begin{aligned}
& 400 \times(1+3 \%)+300 \times(1+5 \%)=727 \\
& g=\frac{727}{700}-1=3.8571 \%
\end{aligned}
$$

and after year two:

$$
\begin{aligned}
& 412 \times(1+3 \%)+315 \times(1+5 \%)=755.11 \\
& g=\frac{755.11}{727}-1=3.8666 \% .
\end{aligned}
$$


Clearly the whole company does not grow monotonously, if the branches grow at different speeds. Hence Gordon's model cannot be used to calculate its value. Another problem is that the share of each of the branches will change too, and so will the cost of capital, . Having to analyze each of the branches separately seems inescapable - the financing issue is the exception (this is provided for the company as a whole). The problem resembles the one related to allocating a part of the fixed costs of the company to specific products, commissions, or production units. In the same spirit, financing can be proportionally allocated to different branches. Financing, however, affects the value of the company, which creates a logical loop.

\subsubsection{Debt being considered}

The task of taking debt into account is simple on one condition: the capital structure is fixed. Then, the value of each of the branches can be calculated separately (first the cost of equity, WACC, the total value of the company, and then the values of equity and debt). The branches will grow as planned (with $3 \%$ and 5\% rates), so the debt allocated to each of the branches will grow at the same pace.

Let us consider the situation where debt is given- this will give us an opportunity to analyze the problem of allocating costs to branches.

\section{Example 22.}

Two branches are characterized by the costs of capital (unleveraged) of $11 \%, 15 \%$ and growth rates of $3 \%, 5 \%$ respectively. They generate operational profits of 400 and 300 (zero depreciation is assumed, but if there is a need, it can be easily incorporated). The tax rate is still $30 \%$. The company is financed by 1500 of debt, and pays $7 \%$ APR to service the debt.

The values of the branches have already been calculated (without debt), hence the weights are $62.5 \%, 37.5 \%$. Let us accept them temporarily. It makes it easy to calculate interest, net profits and CF. 


\begin{tabular}{|lrrr|}
\hline Branch & 1 & \multicolumn{1}{c}{2} & Total \\
\hline $\mathrm{ku}$ & $11 \%$ & $15 \%$ & \\
$\mathrm{~g}$ & $3 \%$ & $5 \%$ & \\
$\mathrm{EBIT}$ & 400.00 & 300.00 & \\
$\mathrm{FCF}$ & 280.00 & 210.00 & \\
\hline $\mathrm{V}_{\mathrm{u}}$ & 3500.00 & 2100.00 & 5600.00 \\
\hline Weights & $62.50 \%$ & $37.50 \%$ & \\
\hline
\end{tabular}

The amounts will be corrected as soon as the values of the branches (financed by debt) are found.

First, the changing levels of debt must be taken into consideration when calculating cash flows. In the growing perpetuity model, the debt grows every year by $g$ :

\begin{tabular}{|lrrc|}
\hline Branch & 1 & \multicolumn{1}{c}{2} & Total \\
\hline D & 937.50 & 562.50 & 1500.00 \\
Interest & 65.63 & 39.38 & \\
EAT & 234.06 & 182.44 & \\
CF & 262.19 & 210.56 & \\
\hline
\end{tabular}

$3 \%$ of 937.50 is added to the net profit generated by the first branch. The same procedure is applied to the other branch.

The values can be found by solving (numerically) a loop: $D$ and $E$ determine the capital structure, so they are needed to calculate $k_{E}$, but $k_{E}$ itself requires $E$ as an input. We still use the formula known from precious calculations:

$$
k_{E}=k_{u}+(1-T)(D / E)\left(k_{u}-k_{D}\right) .
$$

\begin{tabular}{|lrrl|}
\hline Branch & 1 & 2 & Total \\
\hline $\mathrm{D}$ & 937.50 & 562.50 & \\
$\mathrm{E}$ & 2949.22 & 1790.63 & \\
$\mathrm{~V}$ & 3886.72 & 2353.13 & 6239.84 \\
$\mathrm{k}_{\mathrm{E}}$ & $11.89 \%$ & $16.76 \%$ & \\
Weights & $62.29 \%$ & $37.71 \%$ & \\
\hline
\end{tabular}

Now, the new weights reflecting the value can be found. The weights are used to split the 1500 debt between the branches. Consequently, all the other values will change. The alterations are not significant, as the initial weights were close to the final ones. 


\begin{tabular}{|lrrr|}
\hline Branch & 1 & \multicolumn{1}{c}{2} & Total \\
\hline $\mathrm{k}_{\mathrm{u}}$ & $11 \%$ & $15 \%$ & \\
$\mathrm{~g}$ & $3 \%$ & $5 \%$ & \\
EBIT & 400.00 & 300.00 & \\
Weights & $62.26 \%$ & $37.74 \%$ & \\
$\mathrm{D}$ & 933.96 & 566.04 & 1500.00 \\
Interest & 65.38 & 39.62 & \\
EAT & 234.24 & 182.26 & \\
$\mathrm{CF}$ & 262.25 & 210.57 & \\
$\mathrm{E}$ & 2951.30 & 1788.68 & \\
$\mathrm{~V}$ & 3885.26 & 2354.72 & 6239.98 \\
\hline $\mathrm{k}_{\mathrm{E}}$ & $11.89 \%$ & $16.77 \%$ & \\
\hline
\end{tabular}

\subsubsection{Valuing a branch - structural approach}

A company starting a new project is similar to adding a branch: what is faced is not only specific operational risk but also common financing. In this context, we have the basket option. Let us consider the following example. It mimics the one from Chapter 2.3 and represents the structural approach to equity valuation.

\section{Example 23.}

Take a company that is financed partly by debt. The debt has the form of a zerocoupon bond with one year maturity $T$. The nominal value of the bond (80) is denoted by $F$ whichmeans that shareholders are obliged to pay $F$ to the debt holders at time $T$, otherwise the company goes under. Let us denote the value of the company at time $T$ by $V(T)$. Currently $V$ is 100 and is expected to be 150 or 60 at the end of the period. In addition to this, there is also a new project (branch) the company is going to implement. The project requires an investment of 50 (denoted as $B(0)$ ), but its value may be 80 or 30 at the end of the period. The project is partly financed by debt with the face value (denoted as $D$ ) of 20 . We are assuming that the project (branch) cannot be a separate company, since the bank would not lend money for such a venture. 
We will compare and contrast two ways of valuing the company: first the company will be treated as the sum of two call options, and then second as the call option on the sum $(V+B)$. In terms of the value for the shareholders, here are two sets of possible scenarios:

$$
\text { 1. }\left\{\begin{array}{cl}
V(T)-F & \text { if } V(T)>F \\
0 & \text { if } V(T) \leq F
\end{array}+\left\{\begin{array}{cl}
B(T)-D & \text { if } B(T)>D \\
0 & \text { if } B(T) \leq D
\end{array}\right. \text {. }\right.
$$

versus:

$$
\text { 2. }\left\{\begin{array}{cl}
V(T)+B(T)-F-D & \text { if }(V(T)+B(T))>(F+D) \\
0 & \text { if }(V(T)+B(T)) \leq(F+D)
\end{array}\right. \text {. }
$$

The hypothesis is that the call option on the sum is worth less than the sum of the two call options.

We have demonstrated in Chapter 2.3 that the value of a company's equity is comparable to the value of a call option on the value of the company. The option's strike price is the amount of debt to be repaid at maturity. This approach, combined with the fundamental equality between put and call (known as put call parity), yields:

$$
S(0)=C+K e^{-r T}-P,
$$

where a call option $(\mathrm{C})$ represents equity.The present value of debt can be found as:

$$
D=F e^{-r T}-P,
$$

and the company value (represented by $S$ ) $=$ the value of the call option + the present value of debt at the risk-free rate - the value of the put option.

The value of equity for the two cases, calculated in accordance with the approach presented at the beginning of the chapter, is as follows: the values of the two calls in scenario 1 are 35.5 and 31.9, whereas the value of the call in scenario 2 is 59.9 (assuming a 10\% risk-free rate and $30 \%$ cost of equity).

Interestingly enough, the call option on the sum is worth less than the sum of the two call options. This means that for specific situations, when a project is implemented within the company structure (i.e. as a branch), it adds less value to a company than if the project was separate from the company structure (carried out as a separate company). It is easier to finance, though. This is caused by the fact that in the second scenario the risk of defaulting (the event when the creditors find themselves the unwilling owners of the company) has been diversified away. 


\subsection{Mergers and acquisitions}

\subsubsection{Basics of $M \& A$}

Before proceeding with a financial analysis of an M\&A example, a crucial difference between merger and acquisition terms need to be underlined. This clarification is not only important to understand the core idea of these complex concepts, but it also has implications for judicial and tax matters.

An acquisition can be compared to a development of an existing product line or starting a completely new venture - it is the purchase of an existing, well-formed company (i.e. the youtube.com purchase by google.com). During this process, assets of an offered company are transferred to the acquirer. The purchasing organization takes actual control over the other company. In M\&A practice two kinds of acquisitions are observed - a friendly takeover when the seller, unforced and actively, participates in the whole process, and a hostile takeover - when the change of ownership takes place against the will of the owners.

A merger is a process of combining two or more entities into one, through a purchase, acquisition or pooling of interests. The merger act is usually undertaken between companies, which perform as partners. The word "partners" should be crucial when discussing this form of business co-operation. As partners, both companies involved in merger share common risk and possible gains.

Fusion and merger are two different categories due to legal provisions. Fusion is a combination of two legal entities, often with similar potential. Companies, which want to fuse, dissolve their legal identities in order to create a new one - in practice, often the economically stronger company sustains its legal body. In case of a merger both companies maintain their separate legal identities.

Mergers and acquisitions are only two types of a wide range of corporate marriages used in the modern business environment. These two forms are the most distinctive and complex operations as the scope of changes in both parties are significant in terms of organizational structures and human resources. Most generally we can classify M\&As as:

1. Strategic - carried out to take advantage of prospective synergy effects and as a part of long-term development strategy.

2. Occasional - used as ad-hoc instrument of raising a company's value by purchasing undervalued companies. 
Another typology includes:

1. Horizontal $M \& A-$ in which companies operating and competing in the same sector (competitors) are combined to create a new entity. The fundamental objective of such integration is to have active influence on price creation.

2. Vertical M\&A - in which suppliers merge with buyers or distributors. The basic reason is to eliminate costs of searching for prices, contracting, payment collection and advertising - in simple terms, broadly understood synergy effects. Unlike horizontal mergers, which have no specific timing, vertical mergers take place when both firms plan to integrate the production process and capitalise on the demand for the product.

3. Conglomerate M\&A - in this type of merger both companies concerned (usually operationally unrelated) usually maintain their autonomy and have a large amount of sovereignty in their decision-making processes.

Vertical Mergers are divided into:

- Upstream - where companies integrate suppliers.

- Downstream - where a company expands its distribution channels with the help of another specialized company.

Conglomerate mergers are divided in the majority of literature into:

- Financial conglomerates - where a stronger company focuses on financial flows within a conglomerate and participates in strategic decisions.

- Managerial conglomerates - where the management of a stronger company not only participates in the strategic decision-making process but also actively controls decisions at the operational level. This is a so-called deep integration.

- Concentric M\&A - companies try to diversify the branch risk and strengthen the internal development through this type of co-operation. There are three basic types of concentric mergers: product-based (merger of companies with substitute products or from similar branches), geographical-based (concentration of companies from one geographic area), and varied concentric merger and acquisition (bargain-based merger of unrelated companies).

Very seldom does only one type of fusion take place. Usually it is matrix of several types, which is usually a function of the market situation and strategic objectives.

The procedures and techniques that are currently known under the term M\&A are as old as the private sector. The first alliances occurred in XV and XVI century but the peak of M\&A activities was observed in XX century. The examination of historical events and literature on the subject empirically proves that, just as we observe waves of growth in the market, we can clearly notice 
ups and downs in integration processes - we refer to these events as mergers waves. Researchers on the subject and practices observed five major waves in last century.

First wave - called the century turn wave rose during 1893 - 1904. The United States of America was a very specific market at this time because, due to large amount of economical liberty, many companies undertook horizontal acquisitions. This resulted in many monopolies (US Steel Corporation (now USX), American Tobacco Company or Standard Oil of New Jersey (now Exxon)).

The second period of dynamic growth of M\&As occurred from 1916 until 1929 and was a direct consequence of economical transformation after World War I. This wave resulted in a new market form - oligopolies. Oligopolies concentrated market leaders' capital in particular branches and sectors, which in fact created impossible to overcome barriers of entry into the particular sector. This second wave was stopped during the Great Depression of 1929.

During the nineteen sixties a new structural form was created in the shape of conglomerates. This corporate identity became popular since it diversified operational risk.

The fourth wave occurred during the early nineties. During this wave a large number of transactions was completed compared to previous periods, but in terms of capital flow it was characterised by small volume. A significant number of acquisitions during this time were attributed to hostile takeovers.

Starting from the mid-nineties the fifth wave was observed. Its rise was stimulated by globalization processes and became the impulse for the creation of Multi National Companies (MNC). 2000 was the year of a historical peak of mergers and acquisitions both in terms of number of transactions and their value. During this boom, the value of all M\&A deals reached four billion dollars. Due to the IT bubble burst in 2001, the volume and the value of transactions drastically plummeted.

\subsubsection{Reasons for $M \& A$}

A major motive for mergers and acquisitions is the realization of the synergy effects in order to raise the efficiency in the company and to lower costs. These synergies can be achieved in many ways. Firstly, production-economical synergies can be achieved by raising the economies of scale, since mass production decreases the unit costs and therefore completes the rationalization gains through staff reductions. Moreover, M\&As give access to other markets and facilitate the creation of market entry barriers. 
Reasons for Mergers or Acquisitions can be so fundamentally different; the literature on the subject divides this rationale into three main groups.

1. Classical motives

A classic motive of M\&A seeks its justification in the power of the market. By merging or acquiring competitors from the same sector the company reduces competitive pressure and wins advantages in a price war. If a company has a monopoly position, the competition completely disappears and the higher prices will be forced onto the market.

2. Neoclassical motives

When a company reaches its development frontier - either in a single market or in a product category - management must decide on the future strategy. M\&As that happen then are described as the neoclassical approach. The main specific reasons are: operational efficiencies arising from the economies of scale, reduction in overall costs from the joint production of complementary products, cost cuts - this motive has become mostly quoted as raison d'ętre, market power effects,development acceleration, and bargain search - a company may seek an acquisition because it believes its target is undervalued, and thus it is a bargain a good investment capable of generating a high return for the acquiring company's shareholders.

3. Managers motives

Mergers and acquisitions are also often triggered by managers' motivations. There are a few types of such transactions: empire building syndrome (strive to grow companies as their salaries, non-wage profits, and both business and social position depend on company size), self-realisation motive (an attempt to fully show one's skills and knowledge), risk diversification (the motive is linked to financial tensions and bankruptcy possibility), and job sustention motive (a threat of evil acquisition by another company).

From a financial point of view M\&A are motivated mostly by:

1. Cost reduction.

2. Better exploitation of the potential of a company.
a) Typically, a company has an excess of cash but suffers from a short- age of interesting projects to carry out.
b) A company cannot use the tax shield.
c) Companies with complementary resources.

3. Diversification. It is doubtful in the case of public companies - investors can do that themselves. In case of small companies the reduction of risk is likely to happen. 
4. Credit rating. Bigger companies may apply for bigger loans and easily serve the existing loans.

5. Better management. Taking over another company is the simplest way to replace an ineffective management team.

6. Increased EPS. It is doubtful whether this should be the main reason for a merger.

\subsubsection{Carrying out a merger}

Mergers and acquisitions should be seen as an ordinary investment and therefore its financing should be structured under the same rules as any other investment. There are three basic forms of financing M\&A transactions - the acquisition by cash i.e. own resources, debt and the acquisition by stock issue. Basically the decision about a stock swap or a cash payment influences the interests of both shareholder groups - groups from the acquiring and the acquired company. The issue of new shares to finance the purchase has usually a negative impact on the stock prices of the company which is buying. This fact is based on the assumption that the board of the acquiring company is willing to pay in shares if they know that these shares are overvalued.

The acquirer may repurchase its own stock or issue new stock. The key question, however, concerns the so-called exchange rate - how many shares of a new company (or the one that it acquires) the shareholders of a company that is being taken over will receive per each of their own current shares. The exchange rate may be determined in many different ways. Let us start with an effective market example.

\section{Example 24.}

There are 3000 shares of company $A$ in trade and they are priced 20 each. There are 500 shares of company $B$, each priced at 40 .

1. One can rely on the market value of companies: $A$ has the value of 60000 , B of 20000. After the acquisition, B shareholders should have $25 \%$ shares of the new company. If A company is to issue new stock, they should issue 1000 shares and offer $2 \mathrm{~A}$ shares per each B share. If the existing shares are to be offered, there should be 750 shares in circulation and 1.5A/B exchange rate should apply. 
2. Relying on share prices leads to the same result. Comparing prices indicates that 2 A shares should be offered per each B share.

3. Relying on EPS or profits level may lead to completely different conclusions.

Typically, the exchange rate that is eventually negotiated is higher than the one resulting from the comparison of the values of the two companies. It is the shareholders of the company that is acquired who often benefit from the transaction. The example above does not take into account the increased post-merger value of companies. It is also important to sieve out the reaction of the market that precedes the planned take-over. The share prices may have discounted the planned post-merger benefits.

\subsubsection{Hostile takeovers}

Hostile takeover transactions are usually finalized through cash payments. LBO (leveraged buyout) is a case when a group of investors acquires a company in a transaction financed largely by debt. Immanent risk of LBOs lies in the fact that such transactions are heavily financially leveraged. What is more, the cash often comes from junk bonds issued to finance the acquisition. This additionally increases risk. Hence, the bonds need to offer an exceptionally high rate of return. Ultimately, the acquired company is usually withdrawn from a stock exchange, and radical cost reduction schemes are implemented. The economizing is enforced by high interest payments on the bonds. All in all, LBOs can be beneficial for the acquirer (they benefit from the cost reduction scheme) and shareholders of the acquired company (the bids are usually higher than the current market price).

Companies (management in particular) that want to avoid being taken over use a range of defensive strategies: restructuring leading to a high tax leverage, or changes in their statute (high majority of votes needed to approve of a merger, "golden votes" - a privileged vote, "poison pills"- provision that allows the stockholders of a firm that is taken over by another firm to buy shares in the second company at a reduced price, or issuing preemptive rights - giving stockholders the right to purchase any new shares sold by the firm).

\subsubsection{Formal issues}

Anti-monopoly regulations that exist in many countries may be an obstacle in the M\&A process. Political interventions or social protest may also take place, if companies that are considered "national assets" are at stake. 
In terms of accounting rules, depending on the type of acquisition, the transaction can be executed through so-called "pooling-of-interests-method" or "purchase method". In the former case, the balance sheets are simply added. In the latter case, there usually appears a difference between the book value of assets and the price. The good will (as it is called) is included in the books and subject to depreciation. The approach thus has tax effects (on net profits only), but does not affect the cash flows.

\section{Example 25.}

The SH company is composed of two operational units: the software unit (SU) and the hardware unit (HU).The company is to operate for three years with sales of 200 , 240, 270 for the SU and 150, 120, 100 for the $\mathrm{HU}$. Variable costs are $50 \%$ of sales. The units require the upfront investment of 120 and 60 respectively. Straight line depreciation is assumed. The cost of capital (unleveraged) for the units is $12 \%$ (SU) and $10 \%(\mathrm{HU})$. The company pays $30 \%$ corporate tax.

The example is to illustrate a problem that is both a benefit and handicap of companies that have just merged: how to exploit the synergy effect, how to share costs, and how to use debt to finance the branches. Here we will limit ourselves to an attempt to allocate fixed costs. The same approach can be used to allocate any costs (debt, retained earnings) that are hard to classify as belonging to one branch only.

\begin{tabular}{|lrrrrrrrrr|}
\hline & \multicolumn{3}{c}{ Hardware } & \multicolumn{3}{c}{ Software } & \multicolumn{3}{c|}{ Total } \\
Year & 1 & 2 & 3 & 1 & 2 & 3 & 1 & 2 & 3 \\
Sales & 200 & 240 & 270 & 150 & 120 & 100 & 350 & 360 & 370 \\
Variable cost & 100 & 120 & 135 & 75 & 60 & 50 & 175 & 180 & 185 \\
Fixed cost & & & & & & & 50 & 50 & 50 \\
Depreciation & 40 & 40 & 40 & 20 & 20 & 20 & 60 & 60 & 60 \\
EBIT & 60 & 80 & 95 & 55 & 40 & 30 & 65 & 70 & 75 \\
Tax & 18 & 24 & 29 & 17 & 12 & 9 & 20 & 21 & 23 \\
EAT & 42 & 56 & 67 & 39 & 28 & 21 & 46 & 49 & 53 \\
\hline
\end{tabular}

Having the initial book values, one can calculate cash flows and the value of equity (which in this case is tantamount to the value of the branch/company, since the company is financed by equity only). 


\begin{tabular}{|lrrrrrrrrr|r|}
\hline & \multicolumn{3}{c}{ Hardware } & \multicolumn{3}{c}{ Software } & \multicolumn{3}{c|}{ Total } \\
Year & 1 & 2 & 3 & 1 & 2 & 3 & 1 & 2 & 3 \\
Sales & 200 & 240 & 270 & 150 & 120 & 100 & 350 & 360 & 370 \\
Variable cost & 100 & 120 & 135 & 75 & 60 & 50 & 175 & 180 & 185 \\
Fixed cost & & & & & & & 50 & 50 & 50 \\
Depreciation & 40 & 40 & 40 & 20 & 20 & 20 & 60 & 60 & 60 \\
EBIT & 60 & 80 & 95 & 55 & 40 & 30 & 65 & 70 & 75 \\
Tax & 18 & 24 & 29 & 17 & 12 & 9 & 20 & 21 & 23 \\
EAT & 42 & 56 & 67 & 39 & 28 & 21 & 14 & 15 & 16 \\
CF & 82 & 96 & 107 & 59 & 48 & 41 & 74 & 75 & 76 \\
$\mathrm{k}_{\mathrm{E}}$ & 0.12 & 0.12 & 0.12 & 0.10 & 0.10 & 0.10 & 0.11 & 0.11 & 0.11 \\
Year & 0 & 1 & 2 & 0 & 1 & 2 & 0 & 1 & 2 \\
E & 226 & 171 & 95 & 124 & 78 & 37 & 349 & 248 & 132 \\
$\mathrm{~W}_{\mathrm{F}}$ & 0.65 & 0.69 & 0.72 & 0.35 & 0.31 & 0.28 & & & \\
\hline
\end{tabular}

$w F$ (the ratio of each branch's (F) value to the value of the whole company) becomes a key component: it is used to find the cost of capital for the company and allocate fixed costs.

The loop is closed when the cells for fixed costs (in bold) are filled (it is wF's proportion of the total fixed costs for a given year). This in turn affects $\mathrm{E}$, and then $w F$. As a result, one can appropriately and fairly allocate fixed costs to the branches. This relatively easy exercise may be followed when trying to allocate to the branches any other resources they share: debt, extra revenues.

\begin{tabular}{|lrrrrrrrrr|}
\hline & \multicolumn{3}{c}{ Hardware } & \multicolumn{3}{c}{ Software } & \multicolumn{3}{c|}{ Total } \\
Year & 1 & 2 & 3 & 1 & 2 & 3 & 1 & 2 & 3 \\
Sales & 200 & 240 & 270 & 150 & 120 & 100 & 350 & 360 & 370 \\
Variable cost & 100 & 120 & 135 & 75 & 60 & 50 & 175 & 180 & 185 \\
Fixed cost & $\mathbf{3 2}$ & $\mathbf{3 4}$ & $\mathbf{3 6}$ & $\mathbf{1 8}$ & $\mathbf{1 6}$ & $\mathbf{1 4}$ & 50 & 50 & 50 \\
Depreciation & 40 & 40 & 40 & 20 & 20 & 20 & 60 & 60 & 60 \\
EBIT & 28 & 46 & 59 & 37 & 24 & 16 & 65 & 70 & 75 \\
Tax & 8 & 14 & 18 & 11 & 7 & 5 & 20 & 21 & 23 \\
EAT & 20 & 32 & 41 & 26 & 17 & 11 & 46 & 49 & 53 \\
CF & 60 & 72 & 81 & 46 & 37 & 31 & 106 & 109 & 113 \\
$\mathrm{k}_{\mathrm{E}}$ & 0.12 & 0.12 & 0.12 & 0.10 & 0.10 & 0.10 & 0.11 & 0.11 & 0.11 \\
Year & 0 & 1 & 2 & 0 & 1 & 2 & 0 & 1 & 2 \\
\hline
\end{tabular}




\begin{tabular}{|lrrrrrrrrr|r|}
\hline & \multicolumn{3}{c}{ Hardware } & \multicolumn{3}{c}{ Software } & \multicolumn{3}{c|}{ Total } \\
\hline $\mathrm{E}$ & 169 & 129 & 73 & 96 & 59 & 28 & 264 & 189 & 101 \\
$\mathrm{wF}$ & 0.64 & 0.69 & 0.72 & 0.36 & 0.31 & 0.28 & & & \\
\hline
\end{tabular}

\subsection{Case study - valuing a company}

L-ectron Ltd. is a start-up that is beginning to produce electronic devices. Sales of 1800 EUR for five years and then 500 EUR for another three, with costs reaching $60 \%$ of sales are predicted. The equipment needed for the start costs 1000 EUR, and it is 50\% financed by a 5-year loan taken at 12\% APR. The costs of equity (which finances the rest) is $34 \%$. Some more equipment will have to be bought during the first three years - each year 100 EUR is planned to be spent. The equipment is subject to straight line depreciation schedule. The company pays $25 \%$ corporate tax. What is the value of the company?

As the above question suggests, the purpose of the case is to valuate the company. We will use techniques described in the two previous chapters. Calculating cash flows is relatively easy.

\begin{tabular}{|lrrrrrrrr|}
\hline \multicolumn{1}{c}{ Year } & 1 & 2 & 3 & 4 & 5 & 6 & 7 & 8 \\
Operational profit & 720 & 720 & 720 & 720 & 720 & 200 & 200 & 200 \\
Depreciation & 200 & 220 & 240 & 260 & 260 & 60 & 40 & 20 \\
EBIT & 520 & 500 & 480 & 460 & 460 & 140 & 160 & 180 \\
Interest & 60 & 48 & 36 & 24 & 12 & & & \\
EBT & 460 & 452 & 444 & 436 & 448 & 140 & 160 & 180 \\
Tax & 115 & 113 & 111 & 109 & 112 & 35 & 40 & 45 \\
EAT & 345 & 339 & 333 & 327 & 336 & 105 & 120 & 135 \\
Investment & 100 & 100 & 100 & & & & & \\
Loan installments & 100 & 100 & 100 & 100 & 100 & & & \\
CF & $\mathbf{3 4 5}$ & $\mathbf{3 5 9}$ & $\mathbf{3 7 3}$ & $\mathbf{4 8 7}$ & $\mathbf{4 9 6}$ & $\mathbf{1 6 5}$ & $\mathbf{1 6 0}$ & $\mathbf{1 5 5}$ \\
Tax on EBIT & 130 & 125 & 120 & 115 & 115 & 35 & 40 & 45 \\
NOPAT & 390 & 375 & 360 & 345 & 345 & 105 & 120 & 135 \\
FCF & $\mathbf{4 9 0}$ & $\mathbf{4 9 5}$ & $\mathbf{5 0 0}$ & $\mathbf{6 0 5}$ & $\mathbf{6 0 5}$ & $\mathbf{1 6 5}$ & $\mathbf{1 6 0}$ & $\mathbf{1 5 5}$ \\
$\begin{array}{l}\text { Debt installment } \\
\text { plus interest }\end{array}$ & 160 & 148 & 136 & 124 & 112 & 0 & 0 & 0 \\
\hline
\end{tabular}


For the time being, the cost of capital of an unleveraged company ku is assumed to be $25 \%$. As a matter of fact the cost of equity $k_{E}$ is known, but the valuation is recursive and is going to start from the year 8 - the cost of equity then is still a mystery.

\begin{tabular}{|c|c|c|c|c|c|c|c|c|c|}
\hline Year & 0 & 1 & 2 & 3 & 4 & 5 & 6 & 7 & 8 \\
\hline Operational profit & & 720 & 720 & 720 & 720 & 720 & 200 & 200 & 200 \\
\hline Depreciation & & 200 & 220 & 240 & 260 & 260 & 60 & 40 & 20 \\
\hline EBIT & & 520 & 500 & 480 & 460 & 460 & 140 & 160 & 180 \\
\hline Interest & & 60 & 48 & 36 & 24 & 12 & & & \\
\hline EBT & & 460 & 452 & 444 & 436 & 448 & 140 & 160 & 180 \\
\hline Tax & & 115 & 113 & 111 & 109 & 112 & 35 & 40 & 45 \\
\hline EAT & & 345 & 339 & 333 & 327 & 336 & 105 & 120 & 135 \\
\hline Investment & & 100 & 100 & 100 & & & & & \\
\hline Loan installments & & 100 & 100 & 100 & 100 & 100 & & & \\
\hline $\mathrm{CF}$ & & 345 & 359 & 373 & 487 & 496 & 165 & 160 & 155 \\
\hline Tax on EBIT & & 130 & 125 & 120 & 115 & 115 & 35 & 40 & 45 \\
\hline NOPAT & & 390 & 375 & 360 & 345 & 345 & 105 & 120 & 135 \\
\hline FCF & & 490 & 495 & 500 & 605 & 605 & 165 & 160 & 155 \\
\hline $\begin{array}{l}\text { Debt installment } \\
\text { plus interest }\end{array}$ & & 160 & 148 & 136 & 124 & 112 & 0 & 0 & 0 \\
\hline D & 500 & 400 & 300 & 200 & 100 & 0 & 0 & 0 & \\
\hline $\mathrm{E}$ & 1071 & 1043 & 984 & 886 & 640 & 314 & 227 & 124 & \\
\hline G & 304 & 278 & 245 & 203 & 149 & 77 & 61 & 36 & \\
\hline $\mathrm{G}_{\mathrm{u}}$ & 355 & 314 & 268 & 215 & 153 & 77 & 61 & 36 & \\
\hline $\mathrm{V}_{\mathrm{u}}$ & 1514 & 1402 & 1258 & 1072 & 735 & 314 & 227 & 124 & \\
\hline Vtotal & 1869 & 1716 & 1525 & 1287 & 888 & 390 & 288 & 160 & \\
\hline $\mathrm{k}_{\mathrm{D}}$ & 0.12 & 0.12 & 0.12 & 0.12 & 0.12 & 0.12 & 0.12 & 0.12 & \\
\hline $\mathrm{k}_{\mathrm{E}}$ & 0.30 & 0.29 & 0.28 & 0.27 & 0.27 & 0.25 & 0.25 & 0.25 & \\
\hline $\mathrm{k}_{\mathrm{u}}$ & 0.25 & 0.25 & 0.25 & 0.25 & 0.25 & 0.25 & 0.25 & 0.25 & \\
\hline WACC & 0.23 & 0.23 & 0.24 & 0.24 & 0.24 & 0.25 & 0.25 & 0.25 & \\
\hline V & 1571 & 1443 & 1284 & 1086 & 740 & 314 & 227 & 124 & \\
\hline Tax & 0.25 & & & & & & & & \\
\hline
\end{tabular}


The formulae in the cells for E, G, V, WACC, $\mathrm{k}_{\mathrm{E}}$ is in accordance with the theory shown in the two previous chapters. The key formulae are presented below again.

$$
\begin{aligned}
& V_{t-1}=\frac{V_{t}+F C F_{t}}{\left(1+W A C C_{t}\right)} \\
& W A C C_{t}=k_{D} \times(1-T) \times \frac{D_{t-1}}{\left(E_{t-1}+D_{t-1}\right)}+k_{E, t} \times \frac{E_{t-1}}{\left(E_{t-1}+D_{t-1}\right)} \\
& E_{t-1}=\frac{E_{t}+C F_{t}}{\left(1+k_{E, t}\right)} \\
& k_{E, t}=k_{U}+\left(k_{U}-k_{D}\right) \times \frac{D_{t-1} \times(1-T)}{E_{t-1}}
\end{aligned}
$$

\begin{tabular}{|c|c|c|}
\hline Year & 0 & 1 \\
\hline Operational profit & & 720 \\
\hline Depreciation & & 200 \\
\hline EBIT & & $=\mathrm{C} 2-\mathrm{C} 3$ \\
\hline Interest & & $=12 \% * 500$ \\
\hline EBT & & $=\mathrm{C} 4-\mathrm{C} 5$ \\
\hline Tax & & $=25 \% * \mathrm{C} 6$ \\
\hline EAT & & $=\mathrm{C} 6-\mathrm{C} 7$ \\
\hline Investment & & 100 \\
\hline Loan installments & & 100 \\
\hline $\mathrm{CF}$ & & $=\mathrm{C} 8+\mathrm{C} 3-\mathrm{C} 9-\mathrm{C} 10$ \\
\hline
\end{tabular}

For example, the unshaded cells for $\mathrm{E}$ and $k_{E}$ include:

$E_{t-1}=\frac{E_{t}+C F_{t}}{\left(1+k_{E, t}\right)}=\frac{(160+124)}{(1+25 \%)}=227$

$$
k_{E, t}=k_{U}+\left(k_{U}-k_{D}\right) \times \frac{D_{t-1} \times(1-T)}{E_{t-1}}=25 \%+(25 \%-12 \%) \times \frac{0 \times(1-25 \%)}{227}=0.25
$$




\begin{tabular}{|c|c|c|}
\hline Year & 0 & 1 \\
\hline Tax on EBIT & & $=25 \% * \mathrm{C} 4$ \\
\hline NOPAT & & $=\mathrm{C} 4-\mathrm{C} 12$ \\
\hline FCF & & $=\mathrm{C} 13+\mathrm{C} 3-\mathrm{C} 9$ \\
\hline Debt service & & $=\mathrm{C} 10+\mathrm{C} 5$ \\
\hline $\mathrm{D}$ & 500 & 400 \\
\hline $\mathrm{E}$ & $=(\mathrm{C} 11+\mathrm{C} 17) /(1+\mathrm{B} 23)$ & $=(\mathrm{D} 11+\mathrm{D} 17) /(1+\mathrm{C} 23)$ \\
\hline G & $=(\mathrm{C} 7+\mathrm{C} 18) /(1+\mathrm{B} 23)$ & $=(\mathrm{D} 7+\mathrm{D} 18) /(1+\mathrm{C} 23)$ \\
\hline $\mathrm{G}_{\mathrm{u}}$ & $=(\mathrm{C} 12+\mathrm{C} 19) /(1+\mathrm{B} 24)$ & $=(\mathrm{D} 12+\mathrm{D} 19) /(1+\mathrm{C} 24)$ \\
\hline $\mathrm{V}_{\mathrm{u}}$ & $=(\mathrm{C} 14+\mathrm{C} 20) /(1+\mathrm{B} 24)$ & $=(\mathrm{D} 14+\mathrm{D} 20) /(1+\mathrm{C} 24)$ \\
\hline $\mathrm{V}_{\text {total }}$ & $=(\mathrm{C} 2-\mathrm{C} 9+\mathrm{C} 21) /(1+\mathrm{B} 24)$ & $=(\mathrm{D} 2-\mathrm{D} 9+\mathrm{D} 21) /(1+\mathrm{C} 24)$ \\
\hline $\mathrm{k}_{\mathrm{D}}$ & 0,12 & 0,12 \\
\hline $\mathrm{k}_{\mathrm{E}}$ & $\begin{array}{l}=\mathrm{B} 24+(\mathrm{B} 16 / \mathrm{B} 17)^{*} \\
(1-\$ \mathrm{~B} \$ 27)^{*}(\mathrm{~B} 24-\mathrm{B} 22)\end{array}$ & $\begin{array}{l}=\mathrm{C} 24+(\mathrm{C} 16 / \mathrm{C} 17)^{*} \\
(1-\$ \mathrm{~B} \$ 27)^{*}(\mathrm{C} 24-\mathrm{C} 22)\end{array}$ \\
\hline $\mathrm{K}_{\mathrm{u}}$ & 0,278988 & $=\mathrm{B} 24$ \\
\hline WACC & $\begin{array}{l}=\mathrm{B} 22 *(1-\$ \mathrm{~B} \$ 27) * \mathrm{~B} 16 / \\
(\mathrm{B} 16+\mathrm{B} 17)+\mathrm{B} 23 * \mathrm{~B} 17 / \\
(\mathrm{B} 16+\mathrm{B} 17)\end{array}$ & $\begin{array}{l}=\mathrm{C} 22 *(1-\$ B \$ 27) * \mathrm{C} 16 / \\
(\mathrm{C} 16+\mathrm{C} 17)+\mathrm{C} 23 * \mathrm{C} 17 / \\
(\mathrm{C} 16+\mathrm{C} 17)\end{array}$ \\
\hline V & $=(\mathrm{C} 26+\mathrm{C} 14) /(1+\mathrm{B} 25)$ & $=(\mathrm{D} 26+\mathrm{D} 14) /(1+\mathrm{C} 25)$ \\
\hline Tax & 0,25 & \\
\hline
\end{tabular}

The table above shows formulae for the cells in columns for year 0 and 1 . The table starts in the top left corner of the spreadsheet. This is cell A1. The unshaded cell in the spreadsheet is represented by B17.

The final maneuver that must be undertaken is to use the GoalSeek tool and change $k_{E}$. The one resulting from our calculation appears to be $30 \%$. We know, however, that it should be $34 \%$ - the number from our initial calculations based on year 0 data. As a matter of fact, it is $k_{U}$ that must be changed in such a way that $k_{E}$ is $34 \%$. After the change, the value of the company is finally known: $\mathrm{E}=977, \mathrm{~V}=1477$. 


\begin{tabular}{|c|c|c|c|c|c|c|c|c|c|}
\hline Year & 0 & 1 & 2 & 3 & 4 & 5 & 6 & 7 & 8 \\
\hline Operational profit & & 720 & 720 & 720 & 720 & 720 & 200 & 200 & 200 \\
\hline Depreciation & & 200 & 220 & 240 & 260 & 260 & 60 & 40 & 20 \\
\hline EBIT & & 520 & 500 & 480 & 460 & 460 & 140 & 160 & 180 \\
\hline Interest & & 60 & 48 & 36 & 24 & 12 & & & \\
\hline EBT & & 460 & 452 & 444 & 436 & 448 & 140 & 160 & 180 \\
\hline Tax & & 115 & 113 & 111 & 109 & 112 & 35 & 40 & 45 \\
\hline EAT & & 345 & 339 & 333 & 327 & 336 & 105 & 120 & 135 \\
\hline Investment & & 100 & 100 & 100 & & & & & \\
\hline Loan installments & & 100 & 100 & 100 & 100 & 100 & & & \\
\hline CF & & 345 & 359 & 373 & 487 & 496 & 165 & 160 & 155 \\
\hline Tax on EBIT & & 130 & 125 & 120 & 115 & 115 & 35 & 40 & 45 \\
\hline NOPAT & & 390 & 375 & 360 & 345 & 345 & 105 & 120 & 135 \\
\hline FCF & & 490 & 495 & 500 & 605 & 605 & 165 & 160 & 155 \\
\hline $\begin{array}{l}\text { Debt installment } \\
\text { plus interest }\end{array}$ & & 160 & 148 & 136 & 124 & 112 & 0 & 0 & 0 \\
\hline D & 500 & 400 & 300 & 200 & 100 & 0 & 0 & 0 & \\
\hline $\mathrm{E}$ & 977 & 964 & 922 & 842 & 614 & 301 & 220 & 121 & \\
\hline $\mathrm{G}$ & 279 & 258 & 230 & 193 & 143 & 73 & 59 & 35 & \\
\hline $\mathrm{G}_{\mathrm{u}}$ & 333 & 296 & 254 & 205 & 147 & 73 & 59 & 35 & \\
\hline $\mathrm{V}_{\mathrm{u}}$ & 1415 & 1320 & 1194 & 1027 & 708 & 301 & 220 & 121 & \\
\hline $\mathrm{V}_{\text {total }}$ & 1749 & 1617 & 1448 & 1232 & 856 & 374 & 279 & 156 & \\
\hline $\mathrm{k}_{\mathrm{D}}$ & 0.12 & 0.12 & 0.12 & 0.12 & 0.12 & 0.12 & 0.12 & 0.12 & \\
\hline $\mathrm{k}_{\mathrm{E}}$ & 0.340 & 0.33 & 0.32 & 0.31 & 0.30 & 0.28 & 0.28 & 0.28 & \\
\hline $\mathrm{k}_{\mathrm{u}}$ & 0.279 & 0.28 & 0.28 & 0.28 & 0.28 & 0.28 & 0.28 & 0.28 & \\
\hline WACC & 0.26 & 0.26 & 0.26 & 0.27 & 0.27 & 0.28 & 0.28 & 0.28 & \\
\hline V & 1477 & 1364 & 1222 & 1042 & 714 & 301 & 220 & 121 & \\
\hline Tax & 0.25 & & & & & & & & \\
\hline
\end{tabular}




\section{Risk}

The risk notion involves uncertainty with regard to future events. We are aware of the fact that future cash flows cannot be precisely predicted. Suppose, we consider cash flows in one year's time - there is a range of numbers that depend on various factors. Thus, we typically use expected values, and risk is seen as the probability distribution of these values. The distribution can be measured and modeled (taking into account the fact that we will be able to take decisions after certain scenarios materialize with the use of decision trees technique).

\subsection{Measures of risk}

\subsubsection{Variance and the like}

Variance is the most commonly used measure of risk (or its square root standard deviation). It measures deviations from the expected value. For an unknown future value denoted by $X$, its expected value is defined as:

$$
E(X)=X_{1} p_{1}+X_{2} p_{2}+\ldots,
$$

where $X_{l}, X_{2}, \ldots$ are the consecutive values of random variable $\mathrm{X}$ (in consecutive scenarios), and $p_{1}, p_{2}, \ldots$ are the corresponding probabilities. Variance (square root of standard deviation) is given by the formula:

\section{Example 26.}

For simplicity, let us consider just two scenarios of future returns. Here are the data:

\begin{tabular}{|ccc|}
\hline Scenarios & Returns & Probabilities \\
1 & $30 \%$ & 0.4 \\
2 & $-15 \%$ & 0.6 \\
\hline
\end{tabular}


Both the expected value (3\%) and standard deviation (22.05\%) can be easily calculated. Suppose that a more precise analysis of the project makes us verify the return in the optimistic scenario, which turns out to be $40 \%$ instead of $30 \%$. The expected value grows to $7 \%$, and standard deviation to $26.94 \%$.

The result contradicts our intuition, since the modified project is not any riskier. The deviations are in fact bigger, but the returns more favorable. We accept that risk is defined as the measure of deviations but the intuitive definition of risk says that it is exposure to loss. To capture the contradiction, a modification of variance notion is introduced and called semi-variance. The formula is similar, but only results represented by the scenarios in which returns are lower than the expected one are calculated:

$$
s_{X}^{2}=\min \left\{0,\left(X_{1}-E(X)\right)\right\}^{2} p_{1}+\min \left\{0,\left(X_{2}-E(X)\right)\right\}^{2} p_{2}+\ldots
$$

\section{Example 27.}

In this example, semi-standard deviation is $13.94 \%$ for returns of $30 \%$ and $-15 \%$, and $17.04 \%$ for the modified returns $(40 \%,-15 \%)$.

The attempt to enhance variance as measure of risk was evidently a failure. In spite of rejecting the positive scenario, the variance grows which still does not agree with our intuition. The reason is simple: after the modification the expected value grows, and then so does the semi-variance.

Another attempt to improve the risk measure is to reject the expected value as a reference point. Let us use another fixed target rate (risk free rate, for example) and calculate semi-variance (below target) again:

$$
b_{X}^{2}=\min \left\{0,\left(X_{1}-k\right)\right\}^{2} p_{1}+\min \left\{0,\left(X_{2}-k\right)\right\}^{2} p_{2}+\ldots
$$

\section{Example 28.}

Take the target rate $\mathrm{k}=10 \%$, then $\mathrm{b}=19.36 \%$, whose value does not change if $30 \%$ return is replaced with $40 \%$. If, however, the unfavorable return changes into even less favorable (for example, it changes from $-15 \%$ to $-20 \%$ ), the semi-variance (below target) falls (to $23.34 \%$ ). Now, the model works as designed.

Another philosophy often adopted to measure risk is based on setting certain limits beyond which returns (or value of investment portfolio, or the level of net profit) become unacceptable. Setting the limit is up to an individual in- 
vestor. Even then, however, there is a hard floor determined by the economic and financial circumstance the investor cannot ignore.

\section{Example 29.}

Suppose a company exports goods worth 100000 EUR. Their costs are 320000 PLN at most, but shareholders demand $16 \%$ return on the equity whose value is 200000 PLN. The company has bought a put option with a 3.8 PLN/EUR strike. If the exchange rate falls below the strike, the company will exercise the option, sell euros at the rate, and receive 380000 PLN, which will cover both the costs and the dividend (there will be 20000 PLN left)

Let us suppose, however, that the options the company has bought have a strike of 3.4. Then the final number becomes negative (-20 000 PLN). The number that distinguishes the unfavorable results (in this case it is simply loss) from the good ones could be a measure of risk. The notion of risk presented here is quite flexible. Value at Risk (VaR) exemplifies the use of the concept in practice.

\subsubsection{Value at Risk}

$\mathrm{VaR}$ is a measure of risk that is becoming more and more popular. Its focus is on risk as a loss, but it also takes into account probabilities with which the event (loss) will occur.

When VaR is defined, first it is usually assumed that future returns are normally distributed. The distribution is determined by a function denoted by $N(x)$ (cumulated normal distribution). In spreadsheets the function is available as:

\section{NORMDIST(x).}

The function yields the probability that a random return is lower than $\mathrm{x}$. The underlying assumption is that the expected value is zero and standard deviation is 1 . 


\section{Example 30.}

Let us suppose that some analysis proves that the expected return is $25 \%$, and standard deviation is $20 \%$.

$$
m=25 \%, \sigma=20 \% \text {. }
$$

We pose the following question: what is the probability that the return we are facing in the nearest period of time will be lower than $30 \%$ ? Let us calculate $\mathrm{x}$ from the formula below:

$$
x=\frac{30 \%-m}{\sigma}=0.25 \text {. }
$$

And then we find:

$$
N(x)=0.5987 \cong 0.6 \text {. }
$$

If the return we mean is based on the share price (today the price is 57), then it can be said that with $60 \%$ probability at the end of the period the price will fall below:

$$
57 \times(1+30 \%)=74.10,
$$

or with $40 \%$ probability will go above 74.10 .

The method applied above can also help answer the important question: what is the limit such that the future return (or asset value) will fall below the limit with a given probability (e.g. $5 \%$ or $1 \%$ )?

The number (limit) sets the loss which is the value at risk.

VaR at the $95 \%$ confidence level is such a number that probability of loss lower than VaR is $95 \%$.

VaR can be easily found with the use of the GoalSeek tool. The demanded probability of $5 \%$ corresponds to the return of $-8 \%$. In this case,the limit price is 52.51. Buying at 57 and selling at 52.51, we incur a loss of 4.49 .

$\mathrm{VaR}_{95 \%}=4.49$.

Should the confidence level be $99 \%$, VaR is:

$\mathrm{VaR}_{99 \%}=57-44.73=12.27$. 
It means that with the probability of $1 \%$ the price of the asset will fall below 44.73, and the loss will be lower than 12.27 (with 99\% chance).

Experiments with the use of spreadsheets are easier if the inversed normal distribution function is used:

\section{$\operatorname{NORMSINV}(\mathrm{p})$}

It calculates the value of $\mathrm{x}$ at a given probability:

$$
k=x \times \sigma+m .
$$

and then the border value of the asset, and finally VaR:

$$
\mathrm{VaR}=V(0)-V(0) \times(1+k),
$$

where $V(0)$ is the initial value of the asset.

The numbers in the formulae below correspond to $95 \%$ and $99 \%$ confidence levels.

$$
\begin{aligned}
& k=m-1.65 \times \sigma \\
& k=m-2.33 \times \sigma .
\end{aligned}
$$

In many cases (such as share prices or exchange rates, where Black-Scholes model can be used) VaR calculations are fairly simple. Suppose the underlying asset is a currency, and a company is worried that the exchange rate may fall below certain level. At the current exchange rate of $S(0)$, the VaR relevant exchange rate at time tis:

$$
S(0) \exp \left(a t-\frac{1}{2} \sigma^{2} t-1.65 \sigma \sqrt{t}\right),
$$

where a is the difference between interest rate for the two involved currencies (PLN and EUR).

$\mathrm{VaR}$, simple as it is, has also its disadvantages. One needs to know and assume a certain distribution function. Another disadvantage is related to portfolios and risk diversification. It turns out that it is possible to find two instruments such that the risk of the portfolio (composed of the two) is higher than the risk of individual instruments. It contradicts the common sense and the idea of diversification. Luckily, such examples are quite rare. 


\subsection{Risk management in a company}

\subsubsection{Risk in a company}

Companies are exposed to a range of risk factors. Let us focus on those whose adverse influence on the value of companies can be prevented with the use of financial instruments.

The factors are as follows:

- interest rate

- exchange rates

- prices of materials

- prices of our products

In certain circumstances, companies may be protected against unfavorable changes in their product prices with the use of futures contracts. It is rare, however - the lack of availability of such futures being the main obstacle. Protection against changes in materials prices (even in the case of crude oil prices) is also difficult due to differences between the size of futures contracts and quantities demanded by most of companies.

Exchange rate risk is faced by both exporters and importers. The importer is worried that the foreign currency may appreciate - the foreign goods get more expensive in the local currency, the exporter, on the contrary, finds depreciation unattractive. As it will be shown, the relationship between net profit and the exchange rate is given by a linear function (assuming flat tax rates).

\section{Example 31.}

A company has sales of 100000 PLN.A part of costs is incurred in dollars (10 000 USD), the rest in PLN (30 000). The company pays $30 \%$ tax. At 4 PLN/USD exchange rate the net profit of the company is 21000 PLN.

\begin{tabular}{|lr|}
\hline Sales & 100000 \\
\hline Exchange rate & 4 \\
Costs-USD & 10000 \\
\hline Costs-PLN & 30000 \\
Total costs & 70000 \\
EBIT & 30000 \\
EAT & 21000 \\
\hline
\end{tabular}


By changing the exchange rate we can easily model the relationship between net profit and the exchange rate.

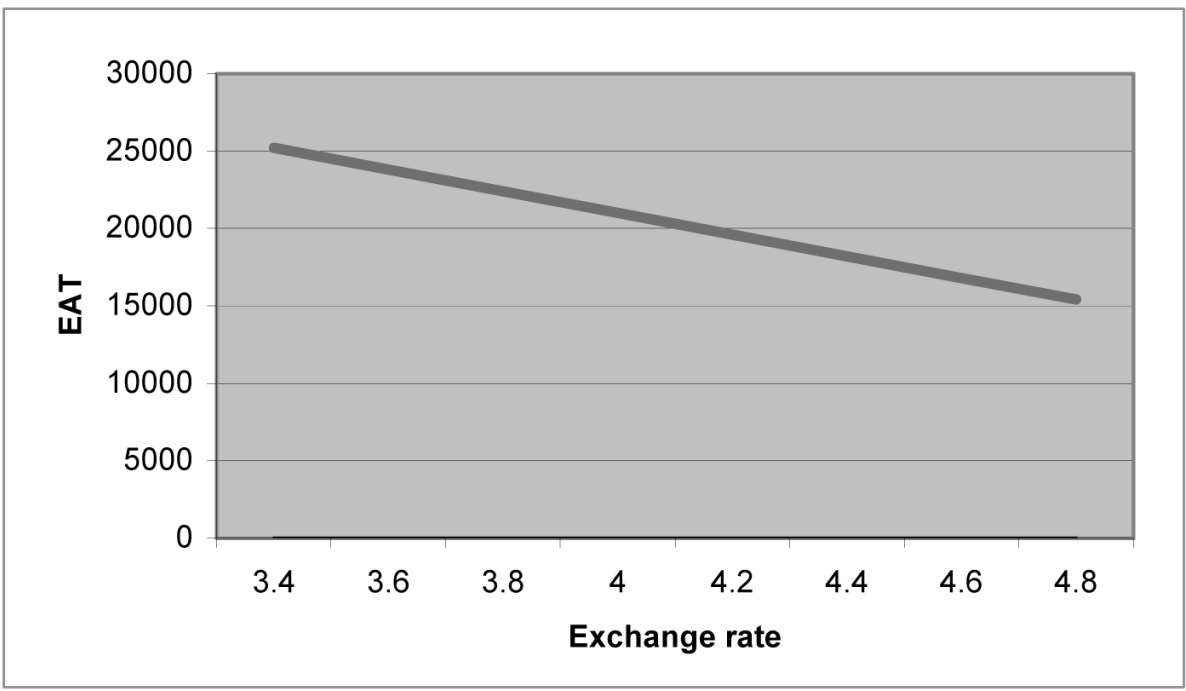

\section{Example 32.}

An exporter's sales are 25000 USD, and costs 70000 PLN. The tax rate is $30 \%$. The net profit at 4 PLN/USD exchange rate is again 21000 PLN.

\begin{tabular}{|lr|}
\hline Sales USD & 25000 \\
\hline Exchange rate & 4 \\
Sales & 100000 \\
Costs & 70000 \\
EBIT & 30000 \\
\hline EAT & 21000 \\
\hline
\end{tabular}

The linear relationship between net profits and exchange rate still can be observed. The line, however, is much steeper, since this time the whole sales amount is exposed to exchange rate risk. 


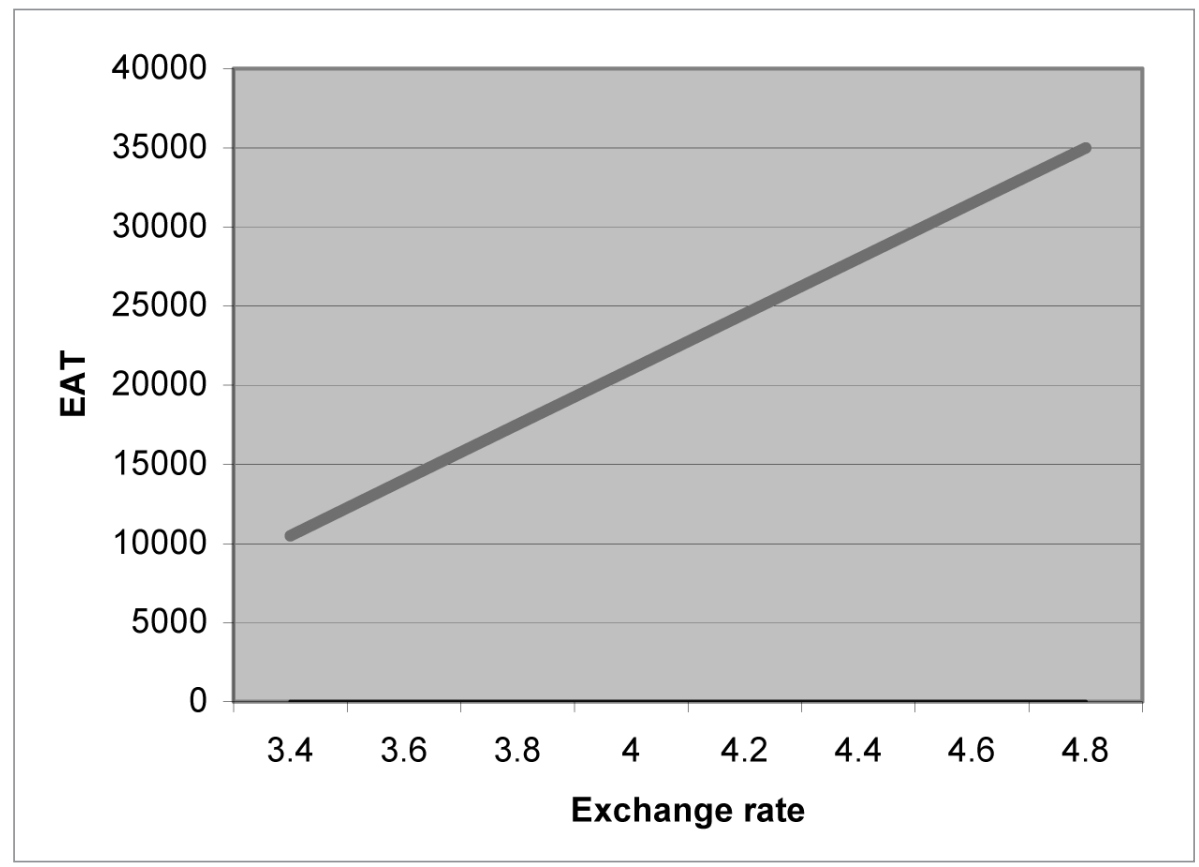

When it comes to the interest rates risk, companies are typically worried about increasing rates which mean higher interest payments. There are cases when companies have an excess of cash that needs to be deposited in banks or invested in bonds. The situation is rare or temporary - in the long run a company should be able to reinvest their profits and finance its own operations, otherwise it contradicts the purpose of setting up the company in the first place.

An increase in interest rates triggered by inflation can affect profits only to some extent as the change concerns both sales and costs.

A special kind of risk (gap risk) concerns mostly banks.

\section{Example 33.}

Imagine a very simple situation of a bank which accepts a deposit (100 deposited for one year) and loans the amount for five years. For simplicity, both deposit and loan are zero-coupon bonds. 


\begin{tabular}{|lrr|}
\hline & Assets & Liabilities \\
\hline & 100 & 100 \\
$\mathrm{r}$ & $10 \%$ & $8 \%$ \\
Time & 5 & 1 \\
FV & 161 & 108 \\
\hline
\end{tabular}

Now suppose the interest rate goes up by 200 basis points. The future values will not change as they are the nominal values of the bonds, but the present values do change.

\begin{tabular}{|lrr|}
\hline & Assets & Liabilities \\
\hline FV & 161 & 108 \\
r & $12 \%$ & $10 \%$ \\
PV & 91.38 & 98.18 \\
\hline
\end{tabular}

The value of the assets falls much lower than the value of the liabilities (market values, not the book ones), which affects the market value of the bank. As it can be noticed, the gap analysis focuses on the value of rate sensitive assets and rate sensitive liabilities with different maturities being the main problem. In practice, the banks positions are much more complicated as they are composed of millions of such transactions. Still, the problem remains the same though it is harder to cope with.

\subsubsection{Risk management versus value}

Does risk management add value?

The simplest answer is: lower risk translates into a lower cost of capital, hence a higher present value of cash flows.

Imagine a company that has been exposed to a given exchange rate risk for years. Its profits naturally fluctuate reflecting the ups and downs of the core operations. The fluctuations may be fortified or weakened by the changes caused by jumps in and cycles of the exchange rate. Imagine the company starts hedging the risk. An effective market should notice that and the stock of the company should be priced higher (due to the lower required rate of return implied 
by lower risk due to hedging). Or at least, it should be easier to issue new stock, since new shareholders may appreciate risk management strategies and accept higher prices. The same applies to an attempt to take new loans - the terms (size, interest rate) should now be more beneficial.

On the other hand, a lack of strategies that provide stability may have disastrous effects for a company. Companies facing bankruptcy quickly lose buyers who are afraid of facing servicing problems. Conflicts between shareholders and debt holders are likely to happen too. Such a conflict may result in rejecting reorganization plans - shareholders may conduct aggressive policies in order to use their position, and increase the value of equity by carrying out risky projects. Due to restrictions imposed by banks, the company may be forced to reject good projects that are recognized as too risky by the bank.

The last argument in favor of risk management concerns tax payments.

\section{Example 34.}

There are two tax brackets: $20 \%$ tax is paid on income up to 30000 , and $30 \%$ tax is paid on income above 30000 . Let us suppose a company expects profits of 25000. If the profits are exposed to fluctuations, they might be 10000 or 40000 (both with $50 \%$ probability) and then the company pays 12000 or 2000 in taxes (on average 7 000). If however the risk is eliminated, the company pays 5000 in taxes. The lesson is that a stable company pays less tax and generates more cash.

\subsubsection{Risk managements tools}

Let us review the instruments that can be used to manage risk - it is mostly derivatives.

Forward contracts are agreements where one party agrees to buy a commodity (also exchange rate, interest rate) at a specific price on a specific future date, and the other party agrees to sell. There are some limitations to the use of forward contracts: first, as a matter of fact it is a credit instrument, second, there is always a need to find the counterparty that would be willing to take a position opposite to ours.

Futures contracts solve the counterparty and credit rating problems, but create others: standardizing. Marking to market is a new feature of such contracts - deposit and then money to be put up to cover losses. 
Options are sophisticated derivatives, whose feature is that call or put premium has to be paid when purchasing options. If the option is unexercised, it is money down the drain, as some managers may say. They ignore the fact that buying an option (especially put) can be compared to buying a car insurance policy - nobody complains if the car is stolen. Still, options are highly leveraged and a small miscalculation may lead to huge losses.

\subsection{Case study - hedging exchange rate risk exposure}

Look at the example below. It deals with the exposure to exchange rate risk. The three questions that will be asked and answered are:

1. What are the sources of risk?

2. How to measure risk?

3. How to hedge the exposure to risk?

HL company exports its products (from England) to the USA. It needs to invest 5 million pounds in order to launch a new line of products. The sales are predicted to generate 8 million USD at the end of the year, the costs being 3 million GBP per year. The interest rates are $8 \%$ and $11 \%$ in the USA and UK respectively (continuous compounding is assumed). The USD/GBP spot is 1.6. Logarithmic returns are normally distributed with $15 \%$ standard deviation. The company pays $20 \%$ effective income tax.

It must be added that the company should be able to achieve a profit of 1.25 million pounds a year to satisfy the expectations of the investors with regard to the required rate of return $(25 \%)$ and pay the dividends. Any lower profit will be regarded as a loss.

We assume that USD/GBP exchange rate is the only source of risk. The risk is going to be measured by VaR. The risk exposure will try to be lowered with the use of OTC (over the counter) forward contracts and options.

Let us consider a few cases.

1. The currency position remains unhedged.

Depending on the exchange rate $\mathrm{S}(1)$, the result (after the dividend) changes drastically (from 350000 to -450 000). Obviously, the exchange rates of 1.8 or 2.0 are hardly acceptable for the company. What is the value of the exchange rate $\mathrm{S}(1)$ at which the company breaks even? 


\begin{tabular}{|lrrr|}
\hline \multicolumn{1}{|c}{ S (1) } & \multicolumn{1}{c}{1.6} & \multicolumn{1}{c}{1.8} & \multicolumn{1}{c|}{2} \\
\hline Sales & 5000000 & 4444444 & 4000000 \\
Cost & 3000000 & 3000000 & 3000000 \\
EBIT & 2000000 & 1444444 & 1000000 \\
Tax & 400000 & 288889 & 200000 \\
EAT & 1600000 & 1155555 & 800000 \\
Dividend & 1250000 & 1250000 & 1250000 \\
Result & 350000 & -94445 & -450000 \\
\hline
\end{tabular}

$$
\begin{gathered}
(1-20 \%) \times\left(\frac{8 \text { million }}{S(1)_{B E}}-3 \text { million }\right)-1.25 \text { million }=0 . \\
S(1)_{B E}=1.7534248
\end{gathered}
$$

Let us explore the issue a bit further. Here is the model of how future values of USD/GBP can be forecasted. The model is based on the uncovered interest rate parity, and it also fulfills the assumptions of Black-Scholes model:

$$
S(1)=S(0) e^{\left(r_{U S D}-r_{G B P}\right) t-\frac{1}{2} \sigma^{2} t+N \sigma \sqrt{t}},
$$

where $\mathrm{N}$ has the standard normal distribution. With probability of $95 \%, \mathrm{~N}$ will not exceed 1.6449, which corresponds to an exchange rate $S(1)=1.9649$.

$$
\begin{aligned}
& \operatorname{NORMSINV}(95 \%)=1.64485 \\
& S(1)=1.6 e^{(8 \%-11 \%)-\frac{1}{2} 15 \%{ }^{2}+1.6449 \times 15 \%}=1.9649
\end{aligned}
$$

This is the VaR exchange rate (at 95\% confidence level). In other words, there is $5 \%$ chance that the USD/GBP exchange rate in one year will be equal to or higher than 1.964979. If this is the spot rate that will materialize in one year, then the income statement for the company looks as follows: 


\begin{tabular}{|lr|}
\hline Sales & 4071290 \\
\hline Cost & 3000000 \\
EBIT & 1071290 \\
\hline Tax & 214258 \\
EAT & 857032 \\
Dividend & 1250000 \\
Result & -392968 \\
\hline
\end{tabular}

$\mathrm{VaR}=392968$ dollars and hedging seems a necessity. The question is how to manage the risk exposure.

2. Forward contract.

We can also try to hedge with forward contracts. The forward exchange rate is 1.5527 (formula below). The assumption is that all the 5 million from sales will be exchanged at the rate:

$$
F=S(0) e^{\left(r_{U S D}-r_{G B P}\right) t}=1.6 e^{(8 \%-11 \%)}=1.5527 .
$$

Seemingly, the income statement now looks good (the gain is 471 818). The problem is however that we are locked into the 1.5527 exchange rate. If the spot rate is more favorable, we are still forced to use the one from the forward contract. Hedging with options leaves much more flexibility.

\begin{tabular}{|lr|}
\hline Sales & 5152273 \\
Cost & 3000000 \\
EBIT & 2152273 \\
Tax & 430455 \\
EAT & 1721818 \\
Dividend & 1250000 \\
Result & 471818 \\
\hline
\end{tabular}

3. Full hedge with Options.

Let us begin with call options so the exchange rate is capped at a certain level. Suppose European call options with the following characteristics are available: strike $=1.6$, call premium $=0.066902$, and a maturity of 1 year. Then the cost of buying options is 334510 dollars (209 069 pounds), plus the interest (16\%) paid on the money that is borrowed, which is 53 
522 dollars (33 451 pounds). The options will be exercised if the spot at the end of the year is higher than 1.6. Let us see what happens if the most pessimistic scenario occurs, and the 1.964979 spot rate materializes. The income statement looks much better (compared to the unhedged version) as VaR was negative (it means the gain of 114 170).

\begin{tabular}{|lr|}
\hline Sales & 5000000 \\
\hline Cost & 3000000 \\
\hline Interest & 33451 \\
EBT & 1966549 \\
Tax & 393310 \\
EAT & 1573239 \\
Loan repaid & 209069 \\
Dividend & 1250000 \\
Result & 114170 \\
\hline
\end{tabular}

If the exchange rate drops to 1.5 , the option will not be exercised. The strategy then leads to a positive result of 380837 pounds.

4. Partial hedge with options

When hedging with options, one incurs a cost of paying the option premium. Let us try to reduce the cost by hedging only a fraction (50\%) of the exposure. Assuming the same characteristics of the option, only 4 million dollars will be exchanged into pounds at the strike price of 1.6, the rest at 1.965 .

\begin{tabular}{|lr|}
\hline Sales & 4535646 \\
\hline Costs & 3000000 \\
EBIT & 1535646 \\
\hline Interest & 16726 \\
EBT & 1518921 \\
Tax & 303784 \\
EAT & 1215136 \\
Loan repaid & 104534 \\
Dividend & 1250000 \\
\hline Result & -139398 \\
\hline
\end{tabular}


5. There are more combinations possible, one of them being for example combining options and forward contracts. The outcome is shown below, where we summarize the resulting VaR for all strategies considered (the results below are equal to minus VaR):

\begin{tabular}{|cccccc|}
\hline Strategy & 1 & 2 & 3 & 4 & 5 \\
Result & -392968 & 471818 & 114170 & -139399 & 292994 \\
\hline
\end{tabular}

The values are computed at a 95\% confidence level, corresponding to the exchange rate of USD/GBP 1.9887.

We hedged with options (line 3), used delta hedging and covered only $50 \%$ of the exposure (line 4), used forward contracts (line 2), combined options and forward (line 5), and last but not least did nothing (line 1). The figure below shows the outcomes as a function of the exchange rate $\mathrm{S}(1)$ for each of the strategies.

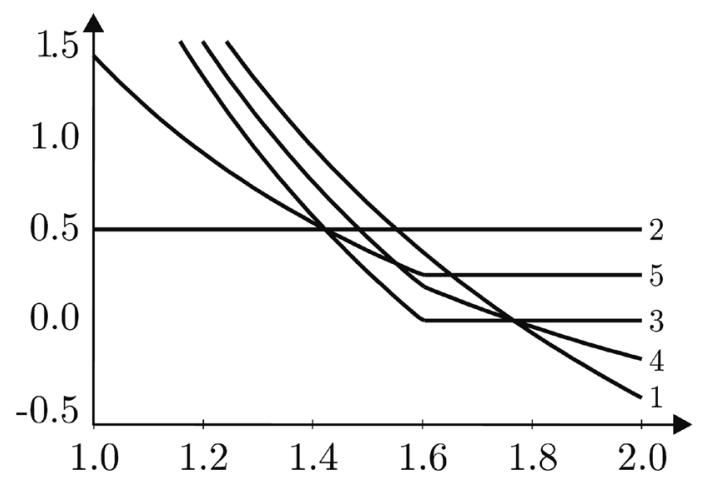

The strategy using a forward contract appears to be the safest one, but leaves no flexibility. Those believing that the pound will weaken may remain unhedged. A variety of middle-of-the road strategies are also available. The final choice should depend on the VaR amount itself. If, say, losing 392968 (strategy 1) puts the whole company in jeopardy, then we definitely should hedge. Basically, derivatives in commercial use should be used with the aim of protecting companies, not for speculation. 


\section{Conclusions}

This book, for a few different reasons, was focused on the DCF method, the main of the reasons being that the DCF method captures best the value of profitable, economically sound companies - it works for all firms which have real expertise. The main purpose of this book was to explain the inner workings of the DCF method, especially the variant in which capital structure constantly affects cost of equity, as it does in reality.

The focus then was on the valuation model which integrates the three components that elsewhere are often treated separately: cash flows, the cost of capital and the discounting process itself. The book revolved around these three issues. For example, it is commonly known that if the value of equity changes, the capital structure changes too. At the same time the change may affect the cost of capital, which in turn will influence the value of equity itself. The recursive approach to company valuation that was presented in the book relied on solving such logical loops that appeared both at each time period and along time periods. Performing the company valuation is such a way is much more complicated than assuming no links between for example the value of equity and the cost of capital, but leads to a much more reliable and methodically flawless valuation. 


\section{Literature}

Benninga S., O. Sarig, Corporate Finance: A valuation Approach, McGrawHill, 1996.

Brealey R.A., S.C. Meyers, Principles of Corporate Finance, McGrow Hill, Boston, 2003

Capiński M., "A New Method of DCF Valuation", Nowy Sacz Academic Review, 2005/2

Capiński M., W. Patena, "Real Options - Realistic Valuation", Journal of Business and Society, 2006/3

Copeland T.E., T. Koller, J. Murrin, Valuation, Measuring and Managing the Value of Companies, John Wiley and Sons, New York, 2000

Damodaran A., Investment Valuation, John Wiley \& Sons, 2002

Damodaran A., The Dark Side of Valuation, New York, John Wiley and Sons, 2001

Fernandez P., Valuation and Shareholder Value Creation, Academic Press, San Diego 2002

Fernandez P., A. Bilan, 110 Common Errors in Company Valuations, 2007, http://ssrn.com

Fernandez P., Financial Literature about Discounted Cash Flow Valuation, IESE Business School Working Paper No.606, 2005, http://ssrn.com

Fama E.F., K.R. French, Common Risk Factors in the Returns on Stocks and Bonds, Journal of Financial Economics, 1993, No 33.

Ibragimov R., Errors in 110 Common Errors in Company Valuation, 2008, http://ssrn.com

Kruschwitz L., A. Loffler, Discounted Cash Flow - A Theory of the Valuation of Firms, Wiley Finance, 2006

Vernimmen P., Corporate Finance, Theory and Practice, John Wiley \& Sons, 2005 